\title{
Dopamine Agonists and Impulse Control Disorders: A Complex Association
}

\author{
Marie Grall-Bronnec $^{1,2}$ (1) Caroline Victorri-Vigneau ${ }^{2,3} \cdot$ Yann Donnio $^{1} \cdot$ \\ Juliette Leboucher $^{1} \cdot$ Morgane Rousselet $^{1,2} \cdot$ Elsa Thiabaud $^{1} \cdot$ Nicolas Zreika $^{1}$. \\ Pascal Derkinderen $^{4,5}$ - Gaëlle Challet-Bouju ${ }^{1,2}$
}

Published online: 31 August 2017

(c) The Author(s) 2017. This article is an open access publication

\begin{abstract}
Impulse control disorders (ICDs) are a wellknown adverse effect of dopamine agonists (DAAs). This critical review aims to summarize data on the prevalence and factors associated with the development of an ICD simultaneous to DAA use. A search of two electronic databases was completed from inception to July 2017. The search terms were medical subject headings (MeSH) terms including "dopamine agonists" AND "disruptive disorders", "impulse control disorders", or "conduct disorders". Articles had to fulfill the following criteria to be included: (i) the target problem was an ICD; (ii) the medication was a dopaminergic drug; and (iii) the article was an original article. Of the potential 584 articles, 90 met the criteria for inclusion. DAAs were used in Parkinson's disease (PD), restless legs syndrome (RLS) or prolactinoma. The prevalence of ICDs ranged from 2.6 to $34.8 \%$ in PD patients, reaching higher rates in specific PD populations; a lower prevalence was found in RLS patients. We found only two studies about prolactinoma. The most robust findings relative to the factors associated with the
\end{abstract}

Marie Grall-Bronnec

marie.bronnec@chu-nantes.fr

1 Clinical Investigation Unit "Behavioral Addictions/Complex Affective Disorders", Addictology and Psychiatry

Department, CHU Nantes, Hospital Saint Jacques, 85, rue Saint Jacques, 44093 Nantes Cedex 1, France

2 Université de Nantes, Université de Tours, Inserm U1246, Nantes, France

3 Department of Pharmacology, CHU Nantes, Center for Evaluation and Information on Pharmacodependence, Nantes, France

4 Department of Neurology, CHU Nantes, Nantes, France

5 Université de Nantes, Inserm U913, Nantes, France development of an ICD included the type of DAA, the dosage, male gender, a younger age, a history of psychiatric symptoms, an earlier onset of disease, a longer disease duration, and motor complications in PD. This review suggests that DAA use is associated with an increased risk in the occurrence of an ICD, under the combined influence of various factors. Guidelines to help prevent and to treat ICDs when required do exist, although further studies are required to better identify patients with a predisposition.

\section{Key Points}

The use of dopamine agonists could contribute to the development of impulse control disorders (ICDs).

We need to consider ICDs as multifactorial disorders, involving drug-, patient-, and diseaserelated factors.

\section{Introduction}

\subsection{Dopamine and Dopaminergic Pathways in the Central Nervous System}

Dopamine is a neurotransmitter that is particularly important as it is involved in both everyday brain functioning (such as the control of motor function, motivation, and reinforcement learning) and in several common disorders of brain functioning, notably Parkinson's disease (PD), drug dependence, and certain endocrine disorders [1]. 
Three main dopaminergic pathways are described in the central nervous system (CNS): (i) the nigrostriatal pathway consisting of cell bodies in the substantia nigra whose axons terminate in the corpus striatum; (ii) the mesocorticolimbic pathway (also known as the reward system), whose cell bodies are situated in the ventral tegmental area and whose axons project to parts of the limbic system, in particular the nucleus accumbens (NAcc) and the amygdaloid nucleus, and to the frontal cortex; and (iii) the tuberoinfundibular pathway, whose cell bodies are found in the ventral hypothalamus and project to the median eminence and pituitary gland [1]. The first pathway is particularly involved in motor function, while the second pathway is especially implicated in reward- and aversionrelated cognition as well as executive functions. The third pathway influences the secretion of certain hormones, including prolactin. The impairment of these different pathways leads to a variety of disorders, ranging from important motor deficits (as is the case in PD) to the compulsive repetition of rewarding behavior (as is the case in addictive disorders and ICDs).

\subsection{Dopamine Agonists}

Dopamine agonists (DAAs) represent a pharmacological class of drugs that act on the nervous system. The following molecules are all DAAs: bromocriptine, pergolide, piribedil, lisuride, cabergoline, pramipexole, ropinirole, rotigotine, and apomorphine. The main indication of this class of drug is PD. Bromocriptine, pergolide, piribedil, and cabergoline exhibit a slight selectivity for dopamine $D_{2 / 3}$ over $D_{1}$ receptors. Lisuride acts specifically on $D_{2}$ receptors. The use of bromocriptine, pergolide, lisuride, and cabergoline, which are all ergot derivatives, is currently limited mainly due to their adverse effects. The aforementioned drugs have in fact been supplanted by pramipexole and ropinirole, which are $\mathrm{D}_{2 / 3}$ selective and thus better tolerated [1]. These two drugs have a highly specific affinity to cerebral $D_{3}$ receptors, which are known to be localized to the mesolimbic system [2]. Rotigotine is a newer DAA, delivered via transdermal patch, which is highly selective to $D_{3}$ receptors as compared to $D_{2}$ receptors. Apomorphine, which has approximately equal affinities for $D_{2}$ and $D_{3}$ [3], is only active when administered via injection and has a short onset time and duration.

\subsection{Parkinson's Disease, But Also Restless Legs Syndrome and Prolactinoma...}

DAAs are mainly indicated to treat PD, although they are also used to relieve symptoms of restless legs syndrome (RLS) and prolactinoma or lactation inhibition. Others diseases may be anecdotally targeted by the prescription of
DAAs, including fibromyalgia [4] and tetrahydrobiopterin deficiency [5], but use for these diseases falls outside of the approved recommendations.

\subsection{Impulse Control Disorders (ICDs) Associated with Dopamine Agonists}

When treating CNS disorders, it is often a desire to target a certain type of receptor; activating or inhibiting it in only a specific neuronal pathway. However, drug action is rarely limited to one region of the brain and a drug tends to impact a given receptor type throughout the brain [1]. The first cases of iatrogenic impulsive behaviors were reported in the early 2000s after DAAs received marketing authorization and began to be widely prescribed for PD [6, 7]. These first cases were considered to be iatrogenic based on chronological and pharmacological arguments: (i) they appeared after the onset of PD and dopamine replacement therapy (DRT) initiation and disappeared after discontinuing DRT; and (ii) DRT acted on dopamine receptors in both the nigrostriatal pathway and the reward pathway, which plays a role in addictive behavior. Several reviews have compiled published case reports or case series $[8,9]$ on this topic. Reported impulsive behaviors were pathological gambling, hypersexuality, compulsive shopping, binge eating, obsessive hobbying, punding, and compulsive medication use. The authors have rigorously examined the link between DRT and iatrogenic impulsive behaviors while considering a large range of disorders under a single umbrella term: impulse control disorders (ICDs) $[10,11]$. ICDs are a heterogeneous group of diseases that are now included in the extended "Disruptive, Impulse Control, and Conduct Disorders" chapter in the Diagnostic and Statistical Manuel of Mental Disorders, Fifth Edition (DSM-5) [12]. ICDs involve dysfunctions in both emotional and behavioral regulation. A shared key symptom of all ICDs is the failure to resist an impulse or temptation to perform an act that is harmful to a person or to others [13]. Individuals experience an increased sense of tension prior to an act and pleasure, gratification, or the release of tension at the time of committing the act. Some disorders that are classified in other nosographic categories (binge eating disorder in "Feeding and Eating Disorders" or gambling disorder in "Substance-Related and Addictive Disorders") are considered in the literature in this field as ICDs due to their clinical proximity or evolutions in classifications. Similar adverse drug reactions have also been reported in RLS [14-23] and prolactinoma patients [24, 25], thus implying that nigrostriatal denervation is not a prerequisite for the development of ICD. However, only a minority of individuals with from PD, RLS, or prolactinoma develop ICDs. This is in contrast to the high frequency of the other adverse effects (i.e., nausea, low blood pressure, or 
nightmares), which are directly linked to the central or peripheral action of DAAs. Concluding that medication is the only factor involved in the onset of ICDs would be simplistic and dangerous. Many other potential risk factors should be considered, including individual predisposition and/or disease-related factors.

\subsection{Lack of Evidence}

A substantial amount of literature is consecrated to the examination of the links between the use of DAAs in PD and the development of ICDs [2, 11, 13, 26-63], and this topic continues to be a very active field of research. In most cases, emphasis is placed on iatrogenic factors. Furthermore, the same association in RLS or prolactinoma is rarely addressed, and, to the best of our knowledge, there is no review available that takes into account the three diseases for which DAAs are prescribed. To fill this void, we undertook a comprehensive review of ICDs simultaneous to DAA use, integrating iatrogenic factors, predisposing factors, and disease-related factors. We decided to focus only on original articles based on a control study design. Finally, recommendations to manage ICDs are briefly provided.

\section{Materials and Methods}

A systematic review of available literature was conducted to identify all relevant publications pertaining to the links between the use of DAAs and ICDs. For this review, we complied with the Preferred Reporting Items for systematic reviews and Meta-Analyses (PRISMA) [64].

\subsection{Search Resources}

A search of two electronic databases was completed from inception to July 2017: PubMed and ScienceDirect. The search terms were medical subject headings (MeSH) terms including "Dopamine Agonists" AND "Disruptive, Impulse Control, and Conduct Disorders" found in the title, abstract, or keywords. Duplicates were eliminated. Additional records were included after manual search. The search strategy is summarized in Fig. 1.

\subsection{Eligibility Criteria}

Articles had to fulfill the following criteria to be included:

- The target problem was an impulse control disorder;

- The medication was a dopaminergic drug; and

- The article was an original article.

\subsection{Article Selection}

Firstly, articles were selected based on their titles and abstracts. Secondly, the full text of all of the included articles was read. Two of the authors (MGB and GCB) performed this work independently using the same bibliographic search. In the event of disagreement, the relevant articles were discussed.

\subsection{Data Extraction}

Clinical and pharmacological data were extracted from the articles (by MGB, YD, JL, MR, ET, NZ, and GCB). Factors taken into account included the sample size of the studies, the type of participants, the characteristics of the disease, the characteristics of the drug, the study design, and the objectives. The main results are presented in tables that summarize the prevalence data, the iatrogenic factors, the patient-related factors and the disease-related factors (Tables 1, 2, 3, 4 in Appendix).

\section{Results}

Ninety articles met the criteria for inclusion. DAAs were used in PD, RLS, or prolactinoma.

\subsection{Prevalence}

The results of the prevalence survey are presented in Table 1 in Appendix.

In PD patients, the prevalence of ICDs in general ranged from $2.6 \%$ [65] to $34.8 \%$ [66], reaching higher rates in specific populations: $39.1 \%$ in patients only treated using DAAs with a predefined minimum exposure to DAAs after study enrollment of at least 50 levodopa (L-dopa) equivalent daily dose (DAA-LEDD, calculated using the standard conversion factors described by Tomlinson and colleagues [67]) of DAA for at least 3 consecutive months [68] or $58.3 \%$ in early-onset PD (EOPD) patients [69]. No ICD stood out more than another, and authors reported discordant results concerning the frequency of each ICD.

In RLS patients, reported prevalences were lower, between $7.1 \%$ [70] and 11.4\% [71]. Surprisingly, Bayard et al. [72] reported rates that were even lower for patients taking DAAs $(2 \%)$ than for drug-free patients $(2.5 \%)$, although DAA doses were three to five times lower in that study's RLS population than in other RLS populations.

We found only two studies about prolactinoma. ICDs were observed in two patients out of 20 in one study [73], and concerned a quarter of the sample in another [74]. 


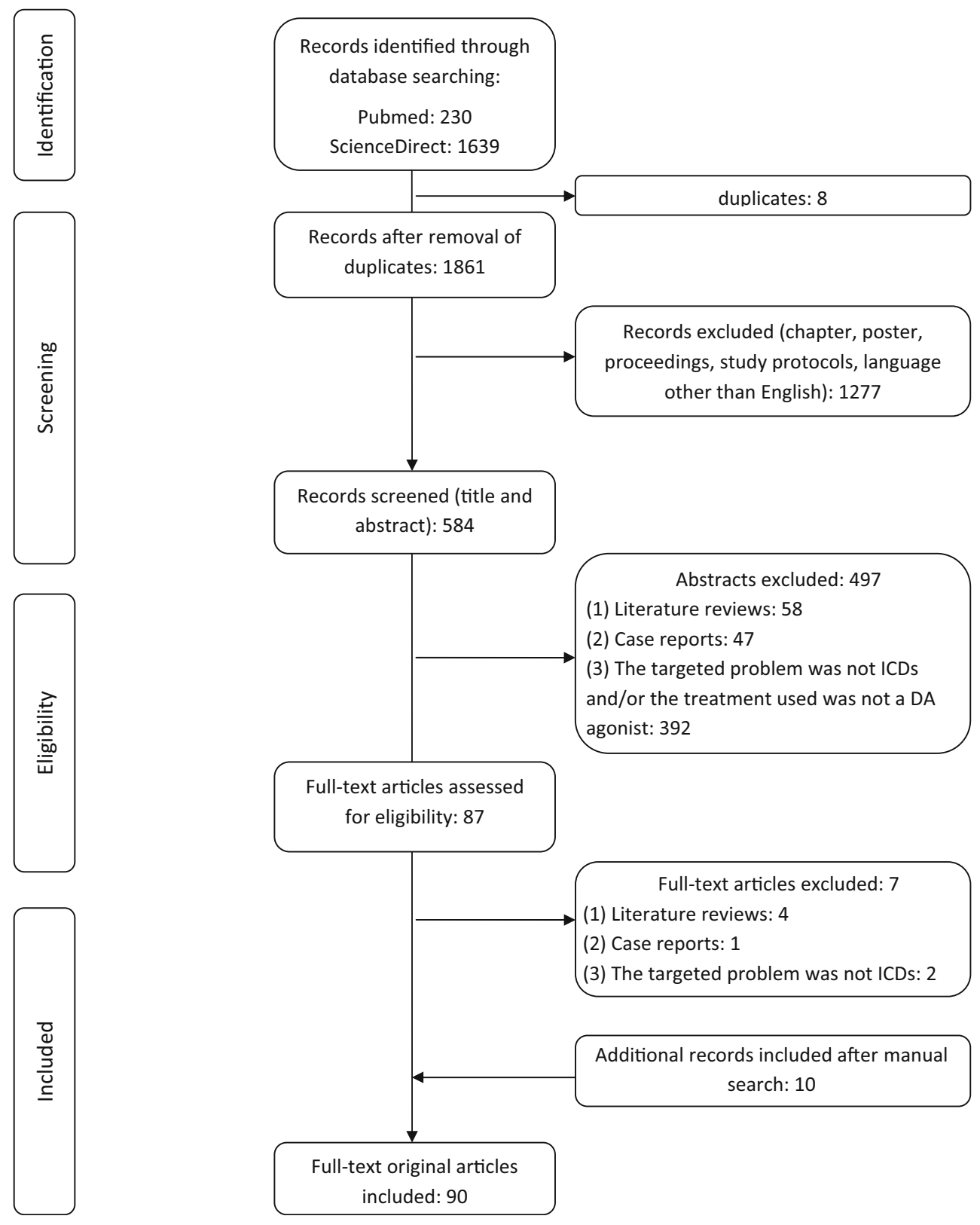

Fig. 1 Flow chart of the search

\subsection{Drug-Related Factors}

The results regarding drug-related factors are presented in Table 2 in Appendix.

Exposure to DRT was found to be a risk factor in the emergence of an adverse drug event such as ICD, and patients with ICDs were shown to take a significantly higher LEDD [75-83]. A study assessing PD patients treated with low dosages of DRT did not find any significant association between drug-related factors and ICDs after multivariate analysis [86].

\subsubsection{Type of Dopamine Agonist (DAA)}

Both DAA and L-dopa use was implicated in the development of ICDs in PD patients, although the odds ratio (OR) was nearly twice as high for DAAs [84]. According to numerous studies, DAA use is an independent predictor for developing an ICD in PD patients [75, 78, 83-96]. The six US Food and Drug Administration (FDA)-approved DAAs (pramipexole, ropinirole, cabergoline, bromocriptine, rotigotine, and apomorphine) had a strong signal, the strongest being pramipexole and ropinirole, which both 
have a preferential affinity for $\mathrm{D}_{3}$ receptors [91]. Several studies highlighted a potentially causal role of pramipexole $[85,90]$. However, other studies did not conclude that there were any significant associations with respect to a specific DAA [68, 86, 97].

\subsubsection{Dose of DAA}

For many authors, exposure to a higher daily dose of DAA $[70,77,81,86,90,93,98,99]$ and a higher peak DAA dose [68] were significantly associated with the development of ICDs. Only a few studies did not find any association with dosage $[80,100,101]$. Two studies assessed the dose-response relationship. Lee et al. [102] reported a DAA doseresponse relationship with compulsive shopping, gambling, and hypersexuality, and Perez-Lloret et al. [103] noted a non-linear dose-response relationship between DAAs and the frequency of ICD symptoms. Finally, a longitudinal study showed a recovery from compulsive behaviors after reducing the dosage of DAAs in 16 patients out of 22 [104].

\subsubsection{Duration of DAA Treatment}

It is difficult to draw conclusions on the link between DAA treatment duration and ICDs. For some authors, DAA treatment duration seemed to have an influence, with a longer duration being associated with the development of ICDs [105, 106], while for other authors DAA treatment duration was non-significant [68]. In long-term studies of rotigotine transdermal patches, the incidence of ICDs was relatively low during the first 30 months of exposure and higher over the next 30 months [107].

\subsubsection{DAA Formulation}

Most studies did not indicate the drug formulations employed. Yet, some recent publications have discussed the relevance of extended formulations. Todorova et al. [108] thus demonstrated that infusion therapies (apomorphine infusion and intrajejunal L-dopa infusion) were associated with the resolution or attenuation of pre-existing ICDs. ICDs could, however, develop after apomorphine infusion initiation, but the rate remained lower than that reported for oral short-acting DAAs [108]. Transdermal patches of rotigotine provide continuous drug delivery with a stable plasma concentration over $24 \mathrm{~h}$. It is suggested that extended formulations limit
ICD development compared with immediate-release (IR) formulations. Nevertheless, ICDs were reported as an adverse drug reaction in rotigotine long-term treatment [107].

\subsubsection{Biological Aspects}

From a neurobiological point of view, DAA use implies a modification of the neuronal signaling of reward expectation (mesolimbic dopaminergic hyperactivation), resulting in a sensitization towards ICDs [109]. DAAs may abate negative reinforcement in feedback-based learning [110]. A case-control study showed a significant DAA-induced reduction of neuronal activity in brain areas that are implicated in impulse control and response inhibition (lateral orbitofrontal cortex, rostral cingulated zone, amygdala, and external pallidum) in PD patients with DAA-induced pathological gambling compared with that of PD controls [111]. Furthermore, when using different forms of decision-making tasks, including delay-discounting tasks, DAA use was associated with greater choice impulsivity [79, 112], shorter reaction time [112, 113], and increased risk-taking $[114,115]$ in PD patients with ICDs compared with PD controls. Exogenous dopamine influences impulsive decision-making, which may precipitate the development of ICDs [79]. In PD patients with hypersexuality, DAA use results in an increased sexual desire after exposure to sexual content compared with nonmedicated PD patients [89].

In RLS patients, the underlying neurobiology remains less clear. Bayard et al. [72] observed reduced decisionmaking capacity where outcome probabilities were unknown, although no difference was observed between drug-free and DAA-treated patients [72]. It is important to note that DAA doses were three to five times lower in this study population than in other RLS populations.

\subsection{Patient-Related Factors}

The results relating to patient-related factors are presented in Table 3 in Appendix.

\subsubsection{Sociodemographic Characteristics}

3.3.1.1 Gender Male gender was commonly found as an independent predictor for developing ICDs $[66,77,78,97,105,116,117]$ as well as for pathological gambling or hypersexuality [102] in PD patients and in prolactinoma patients [74]. In contrast, female gender was 
associated with the resolution of ICDs in PD patients during follow-up [100]. Female gender was found to be more frequent in RLS patients with ICDs [70].

3.3.1.2 Age A younger age $[77,80,82,84,87,92$, $96,97,117-119$ ] and an age under 65 years [66] or 68 years [103] were also commonly found to be independent predictors for developing an ICD. PD patients with pathological gambling were distinguished from PD with ICDs not otherwise specified and from PD controls of a younger age [82].

3.3.1.3 Other Sociodemographic Characteristics According to Weintraub et al. [84], PD patients with ICDs were most likely unmarried and living in the USA.

\subsubsection{Co-Morbidities}

3.3.2.1 Psychiatric Symptoms Mental illness was found to be significantly correlated to the presence of an ICD [120], except in one study [87]. Depression and anxiety were the highest-ranking correlates. A history of depression [99], symptoms of depression [85, 121], and a higher score of depression $[66,80,82,95,122]$ were found to be predictors of the development of an ICD in patients with PD or RLS [123]. In a longitudinal study, Joutsa et al. [100] showed that the development of a novel ICD was associated with the concurrent increase in depression score. Conversely, one study reported only discrete symptoms of disinhibition [85]. A history of anxiety [99], trait anxiety [94], symptoms of anxiety or stress [123], and a higher anxiety score [76, 81, 82, 122] were also found to be predictors of the development of an ICD. Interestingly, a higher obsessive-compulsive score was reported in only one study [122]. PD patients with pathological gambling were distinguished from PD with ICDs not otherwise specified and from PD controls with a higher severity of psychotic symptoms [82].

3.3.2.2 Addictive Disorders In some studies, no link was found between addictive disorders and the development of an ICD [68, 87]. For others, substance use (and not a substance use disorder) of caffeine [68, 121], nicotine [68, 84, 90], stimulants (tea, mate) [96], alcohol [88], or drugs [70], as well as gambling practice [120] was found to be associated with ICDs. A family history of pathological gambling was reported in two studies [70, 84].
3.3.2.3 Sleep Problems More sleep problems were reported in patients with RLS [123] or PD [82, 96] with compulsions or ICDs.

3.3.2.4 Personality Predictably, the most assessed personality dimension was impulsivity, with authors reporting higher impulsivity scores [94, 122] and greater choice impulsivity [122]. PD patients with ICDs also made errors in perceptual decision-making tasks. Clinically, this implies that PD patients with ICDs may make disadvantageous decisions as they are often 'in a rush' to decide [113]. Similarly, a higher score of novelty-seeking [81] was found to be associated with ICDs, especially among PD patients with compulsive sexual behavior [122].

PD patients with ICDs were described as individuals with ineffective coping skills [120], a higher level of neuroticism and lower levels of agreeableness and conscientiousness [80], especially among PD patients with PG [121] or compulsive sexual behaviors [81]. EOPD patients with ICD symptoms scored higher on both self-assertive/ antisocial and reserved/schizoid personality styles [121]. For their part, PD patients with pathological gambling displayed higher scores of bizarre ideation and cynicism than those without pathological gambling or ICD [124]. Finally, somatization appeared to be higher in patients with EOPD with ICD symptoms [121].

\subsubsection{Biological Aspects}

DRD3 p.Ser9Gly (rs6280) heterozygous variant CT genotype was found to be a predictor of ICDs among PD patients [83]. Another genotyping study also indicated a significant association with tryptophan hydroxylase type 2 (TPH2) (recessive) and dopamine transporter (DAT) gene variants (dominant) in PD patients with ICD or dopamine dysregulation syndrome (DDS), all the more so when the severity of the ICD or DDS was high [125]. $\mathrm{TPH} 2$ genotype was the strongest predictor of non-remission during follow-up. Finally, variants of $D R D 1$ rs4867798, DRD1 rs4532, DRD2/ANKK1 rs1800497, and GRIN2B rs 7301328 were found to be associated with an increased risk of developing impulse control behaviors among PD patients [126]. Kraemmer et al. [127] found heritability of ICD behavior to be $57 \%$, OPRK1, HTR $2 A$, and $D D C$ genotypes being the strongest genetic predictive factors. 
An imaging study based on single photon emission computed tomography (SPECT) of the DAT concluded that the DAT density differed in PD patients with PG compared with PD patients without ICD or healthy controls. PD patients with PG showed a reduced tracer binding in the right ventral striatum, possibly reflecting either a reduction of mesolimbic projections or a lower membrane DAT expression on presynaptic terminals [128]. A recent study suggested that changes in DAT availability over time increased the risk of incident ICDs [129].

Another SPECT study showed a reduction of left putaminal and left inferior frontal gyrus tracer uptake in PD patients with ICDs compared with those without ICD [130]. This frontostriatal dysconnectivity may be related to a DA and serotonin network dysfunction centered around the left putamen, supporting the idea of a monoaminergic frontostriatal disconnection syndrome as the biological basis of ICD symptoms in PD. This may reflect either a pre-existing neuronal trait vulnerability for impulsivity or the expression of a maladaptive synaptic plasticity under non-physiological dopaminergic stimulation [130].

$\mathrm{D}_{2}$ receptor availability was no different between PD patients with or without ICDs at baseline, but a greater reduction of ventral striatum ${ }^{11} \mathrm{C}$-raclopride binding potential following L-dopa challenge with reward-related cue exposure relative to neutral cue exposure was observed [131]. PD patients with pathological gambling seemed to have dysfunctional activation of DA autoreceptors in the midbrain and low DA tone in the anterior cingulate [132]. A recent study failed to demonstrate any $\mathrm{D}_{3}$ upregulation in PD patients with ICD [133].

Finally, an imaging study showed that PD patients with ICD, compared with those without ICD and healthy controls, had a thicker cortex in the anterior cingulate and the orbitofrontal cortex, which are cortical areas linked to impulsivity and inhibition behaviors [134]. These structural abnormalities were correlated with the severity of the ICD.

\subsection{Disease-Related Factors}

A summary of the results relating to disease-related factors is presented in Table 4 in Appendix.

\subsubsection{Age of Onset}

Most studies concluded that a younger age at PD onset was an independent predictor for developing an ICD in PD patients [76-78, 80, 82, 94, 99, 102, 105, 106, 118, 135]especially when the ICD was pathological gambling [82]- or in RLS patients [70]. Recently, Krishnamoorthy et al. [83] emphasized a limit of 50 years and under in PD patients with ICDs.

\subsubsection{Disease Duration}

Similarly, a longer PD duration was found to be a factor [80, 82, 102, 137], except in a few cases [68, 85]. Rana et al. [78] identified stages 1-2 of PD as one of the five common variables among patients who developed ICDs.

\subsubsection{Type of Disease}

Compared with PD patients without ICDs, those with ICDs displayed a higher frequency of motor complications [68, 80, 102], with greater motor disease complexity [76] and motor fluctuations [93]. Conversely, PD patients with motor complications were more likely to have an ICD [75]. Furthermore, a higher score on the Movement Disorder Society-Unified Parkinson's Disease Rating Scale (MDSUPDRS) Part 1 was found in two studies [93, 94], as well as increased functional impairment, decreased motivation [122] and a higher Mini-Mental State Examination (MMSE) score [68]. Finally, patients with right-onset PD exhibited significantly higher levels of novelty-seeking than the patients with left-onset PD, which may increase the risk of developing an ICD when associated with the simultaneous use of DAAs [138]. However, Pontone et al. [85] and later Kenangil et al. [101] found no significant association between PD features and the presence of ICD, and Ramirez Gómez et al. [96] found a negative association between motor fluctuations or dyskinesias and ICDs.

\subsubsection{Biological Aspects}

To disentangle the effects of the disease process and DA medication and the development of ICDs, Al-Khaled et al. [139] compared medicated and unmedicated PD patients, RLS patients and healthy controls. Using a delay discounting task, they demonstrated that unmedicated PD patients had a higher discounting rate. Thus, impulsive decision-making in PD patients may not be a side effect of dopaminergic treatment but rather a trait marker of PD. These results were in accordance with those of Aarts et al. [140], who demonstrated the aberrant impact of rewards in $\mathrm{PD}$, a reflection of reward-related impulsivity, was directly related to the degree of dopamine neuron loss, i.e., to a factor intrinsically related to the disease pathology itself. 


\section{Discussion}

\subsection{Main Findings}

Through our review, we have shown that this topic has been extensively studied over the last 10 years, allowing for us to obtain prevalence results from large samples. Publications mostly focused on iatrogenic factors, and progressively extended to patient- and disease-related factors. All this illustrates the complexity of this type of adverse drug reaction and the need to consider ICDs as multifactorial disorders. As recently noted by Voon et al. [141], ICDs reflect the interactions of the DRT with an individual's susceptibility, and the underlying neurobiology of PD. The most robust findings, supported by several studies, include the type of DAA (having a higher selectivity for $\mathrm{D}_{3}$ receptors), dosage (higher daily dose), male gender (for PD), a younger age (although DAAs are more likely to be prescribed for younger PD patients), a history of depression and anxiety symptoms, an earlier onset of disease (it represents the same selection bias as for a younger age), a longer disease duration (for PD), and motor complications (for PD).

\subsection{Limitations}

The value of the results, however, is limited by several aspects. Firstly, it is important to note that the assessment of ICDs was to a great extent heterogeneous, based on standardized clinical interviews, self-report questionnaires, medical records, and caregiver reports. Assessments were not always based on validated tools or consensual diagnostic criteria, with an explored period that was not always specified. Sometimes, the authors reported subclinical disorders, at other times only symptoms. On other occasions, they referred to lifetime or current disorders. This heterogeneity can be seen in the number of terms employed to describe ICDs: overeating, binge eating disorder, bulimia, compulsive shopping or buying, compulsive sexual behavior, hypersexuality, gambling, excessive gambling, problem gambling, pathological gambling, compulsive behavior, impulsive and compulsive behavior, impulse control disorder, ICD-not otherwise specified, impulsive control and repetitive behavior disorder, repetitive behavior disorder, etc. Although the inclusion of excessive behaviors among ICDs (for instance, overeating) may seem surprising, one must remembered that all display a high level of impulsivity. In this respect, they are in fact quite similar to disorders that are included in the other nosographic categories (i.e., 'Feeding and Eating Disorders' and 'Substance-related and Addictive Disorders'). The prevalence of ICDS in patients using DAAs varies widely according to which assessment tool is used. It should be noted that the true frequency may be underestimated due to patients' lack of insight into ICDs or their hesitation to acknowledge an ICD out of shame or embarrassment [26].

Secondly, a large amount of heterogeneous data were collected on drugs, individuals, and underlying disease characteristics. However, the evaluation of certain factors, such as social determinants, was almost systematically neglected. Studies were not reproducible, making it difficult to draw general conclusions on the respective influence of each characteristic on the development of ICDs; this is especially true for psychological characteristics. Indeed, different studies evaluated different psychological dimensions, using different assessment tools. Poor decisionmaking and impulsivity are two dimensions regularly cited to influence ICD development. The challenge of differentiating between pre-existing personality traits, the impact of underlying disease, or the effects of DRT remains. A recent study demonstrated that exposure to pramipexole in PD patients without ICDs was associated with an increase in impulsive choices, acting essentially on decision-making processes [142]. The authors speculated that, in PD patients without ICDs, pramipexole could modulate the top-down control, which is generally impaired in PD patients with ICDs. In healthy controls, pramipexole was shown to increase the activity of the NAcc, enhancing the interaction between the NAcc and the prefrontal cortex [99]. It was suggested that pramipexole may exaggerate incentive and affective response to possible rewards, but reduce the topdown control of impulses. Furthermore, increased impulsivity may not only be dependent on medication but also on neuroanatomical abnormalities intrinsic to $\mathrm{PD}$, with gray matter atrophy in impulse-control regions [143].

Thirdly, we lack information relative to the drug formulations used in all trials. Indeed, extended-release (ER) forms of DAAs were progressively introduced, and several randomized controlled trials have compared their safety with immediate-release (IR) forms in the past few years. For instance, according to the review by Fishman [144], the prevalence of ICDs is similar in both the IR and the ER forms of pramipexole. However, according to Stocchi et al. [145], the relative recent marketing of the new ER DAAs has not yet resulted in conclusive data on the incidence of ICDs during their use. Thus, transdermal ragotidine and ER pramipexole may have a safer profile than IR pramipexole and IR/ER 
ropinirole [146]. ER forms provide a better stability of plasmatic drug concentrations. Pharmacokinetic factors (rate of onset, half-life) are thought to be a critical determinant of the reinforcing effects and abuse potential of a drug. Some authors consider ICDs as additive disorders, even if only gambling disorder has been included in the "SubstanceRelated and Addictive Disorders" chapter in DSM-5 [12]. We may assume that pharmacokinetic parameters could be involved, at least partly, in the development of ICDs. This is consistent with the fact that more ICDs have been described with DAA than with L-dopa, which is a prodrug needing a biotransformation to become an agonist (corresponding to an ER-like form). It is hypothesized that the acute release of DA in the ventral striatum in relation to a pulsed therapy could underlie the development of ICDs [108].

Fourthly, most of the studies were cross-sectional, which is not an optimal strategy for the observation of personality traits or psychiatric co-morbidities and for determining whether or not they are predisposing factors or rather a consequence of an adverse drug reaction or the underlying disease. Nevertheless, two studies conducted in drug-naive PD patients compared with healthy controls concluded that PD itself did not seem to confer an increased risk of development of an ICD [147, 148].

Fifthly, some authors conducted multiple comparisons without applying corrections or using multivariate analysis and concluded several significant associations irrespective of the risk of the type I error.

Finally, the MeSH term "Dopamine Agonists" used for this review did not include partial DAA drugs that are also known to cause ICDs, such as aripiprazole [9, 149] and flupentixole [150].

\subsection{Recommendations}

Recommendations are based on two key principles: the prevention of ICDs and the treatment of ICDs when they occur. Several studies were recently published that provide guidelines for the management of ICDs in PD patients $[45,51,151]$. Part of these recommendations could also be used to address RLS or prolactinoma.

\subsection{1 "Prevention is Better than Cure": How to Achieve 'P4 Medicine'?}

'P4 medicine' can be achieved by adhering to the following recommendations:
- By encouraging a more systematic comprehensive assessment of patients to help in identifying those who are at risk of developing an ICD, sustained by the concept of predictive medicine;

- By better adapting the treatment strategy (avoiding drugs that are the most selective of $D_{3}$ receptors in patients who are at greatest risk), sustained by the concept of personalized medicine;

- By providing full and clear information on these potential adverse drug reactions to patients and by raising awareness of the risk among caregivers, to promote early detection and medical intervention, sustained by the concept of participatory medicine;

- By preferring the prescription of ER formulations that have proven to be non-inferior to the IR formulations, and are better tolerated, and by routinely monitoring the patients, sustained by the concept of preventive medicine.

\subsubsection{When an ICD Occurs, it is Not Too Late}

The priority is to stop or to control excessive behavior, with the objective of harm minimization. The first stage aims at optimizing the DA treatment by:

- Reducing the L-dopa equivalent daily dose or discontinuing the DAA [104], but with the risk of motor function deterioration and the occurrence of DAA withdrawal syndrome;

- Switching from one DAA to another that is less selective of the $\mathrm{D}_{3}$ receptors $[3,27]$;

- Combining oral DAA at a lower dose with apomorphine [27] or orally disintegrating selegiline, which is a selective inhibitor of the monoamine oxydase type B [152].

The second stage is to propose non-pharmacological approaches, especially cognitive and behavioral therapy (CBT) focusing on ICD [153]. This implies promoting links between neurologists and psychiatrists and tailoring CBT to the particular characteristics of these patients in order to decrease the risk of relapse and dropout during treatment [153].

In the event of a negative outcome, the third stage involves less conventional treatment options:

- Bilateral subthalamic nucleus (STN) deep-brain stimulation (DBS): case reports have shown an 
improvement after DBS [154], but a recent review provided inconsistent results [155].

- Specific pharmacological treatment of ICDs: several molecules were tested in a (very) small number of PD patients with ICDs. Antiepileptic drugs, such as topiramate [156], valproate [157], or zonisamide [158], and anti-craving drugs, such as naltrexone [159], could be effective therapeutic options, whereas antidepressant drugs, such as serotonin reuptake inhibitors [160], or atypical antipsychotics, such as quetiapine [161] or risperidone [6], were met with mixed results. Clozapine was tested with encouraging results in a few patients [162], but one must keep in mind its serious adverse effects and consider risks versus benefits for patients on an individual level.

\section{Conclusion and Future Directions}

The prevalence of ICDs ranged from 2.6 to $34.8 \%$ in PD patients, and from 7.1 to $11.4 \%$ in RLS patients. There are insufficient data available on prolactinoma to draw a conclusion with respect to prevalence. This review suggests that DAA use is associated with an increased risk in the occurrence of ICDs, under the combined influence of various factors. The most robust findings include the type of DAA (having a higher selectivity for $\mathrm{D}_{3}$ receptors), dosage (higher daily dose), male gender (for PD), a younger age (although DAAs are more likely to be prescribed in younger PD patients), a history of depression and anxiety symptoms, an earlier onset of disease (this pertains to the same selection bias as younger PD patients), a longer disease duration (for PD), and motor complications (for PD). Recently, a new clinical-genetic prediction model that has reached high accuracy was proposed [127]. Guidelines to help in the prevention of ICDs and in their treatment when required do exist. Thus, identifying who is at risk of developing an ICD is crucial. Progress is still to be made to improve the evaluation of individual patients, using validated and consensual assessment tools, and by also integrating social factors. Further longitudinal studies including patients who have not yet developed an ICD would be useful in determining premorbid risk factors. Conducting literature-based meta-analysis, although difficult to achieve due to the heterogeneity of the data collected, could provide insight into the relative importance of the associated factors. Finally, large samples are needed to better characterize subtypes of patients with co-morbid ICD because beyond the associated factors reported in our review, it appears that they do not constitute a homogeneous group. This clinical intuition is well-supported by empirical evidence suggesting different evolutions after reduction or discontinuation of the DAA alleged to have cause the ICD. For some patients, DAA reduction or discontinuation is sufficient to obtain complete resolution of the ICD, while for others it is necessary to associate other measures. In the first case, one can imagine that the development of an ICD is a 'real' adverse drug reaction, linked to a particular sensitivity to DAAs, and which may be reversible by reducing DDA dosage under a specific threshold for each patient. In the second case, there may also be an addictive vulnerability involving biological, psychological, and environmental factors. DAA use would then only act as a catalyst, with the ICD finally evolving on its own. In these cases, the ICD also requires specialized addiction care.

Acknowledgements We would like to sincerely thank A.F. Goalic and R. Patissier for their assistance in the manuscript preparation, and Andrew Spiers for language editing.

\section{Compliance with Ethical Standards}

Funding sources No funding was received for this work.

Conflict of interest Marie Grall-Bronnec, Yann Donnio, Juliette Leboucher, Morgane Rousselet, Elsa Thiabaud, Nicolas Zreika, and Gaëlle Challet-Bouju declare that the Addictology and Psychiatry Department has received funding directly from the University Hospital of Nantes and gambling industry operators (FDJ and PMU). Scientific independence towards gambling industry operators is warranted. There were no constraints on publishing. Caroline Victorri-Vigneau and Pascal Derkinderen declare that they have no conflicts of interest.

Open Access This article is distributed under the terms of the Creative Commons Attribution-NonCommercial 4.0 International License (http://creativecommons.org/licenses/by-nc/4.0/), which permits any noncommercial use, distribution, and reproduction in any medium, provided you give appropriate credit to the original author(s) and the source, provide a link to the Creative Commons license, and indicate if changes were made.

\section{Appendix}




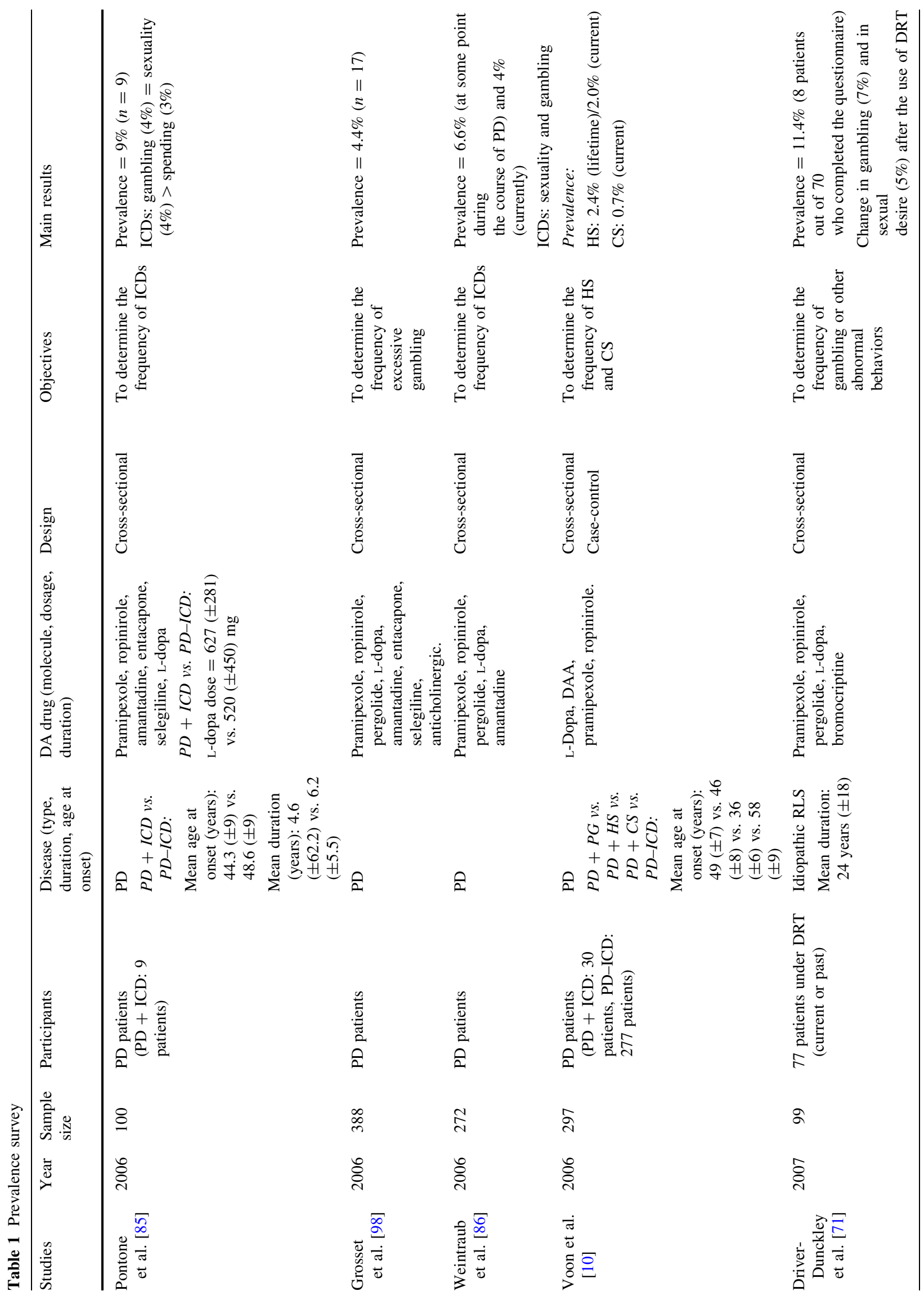




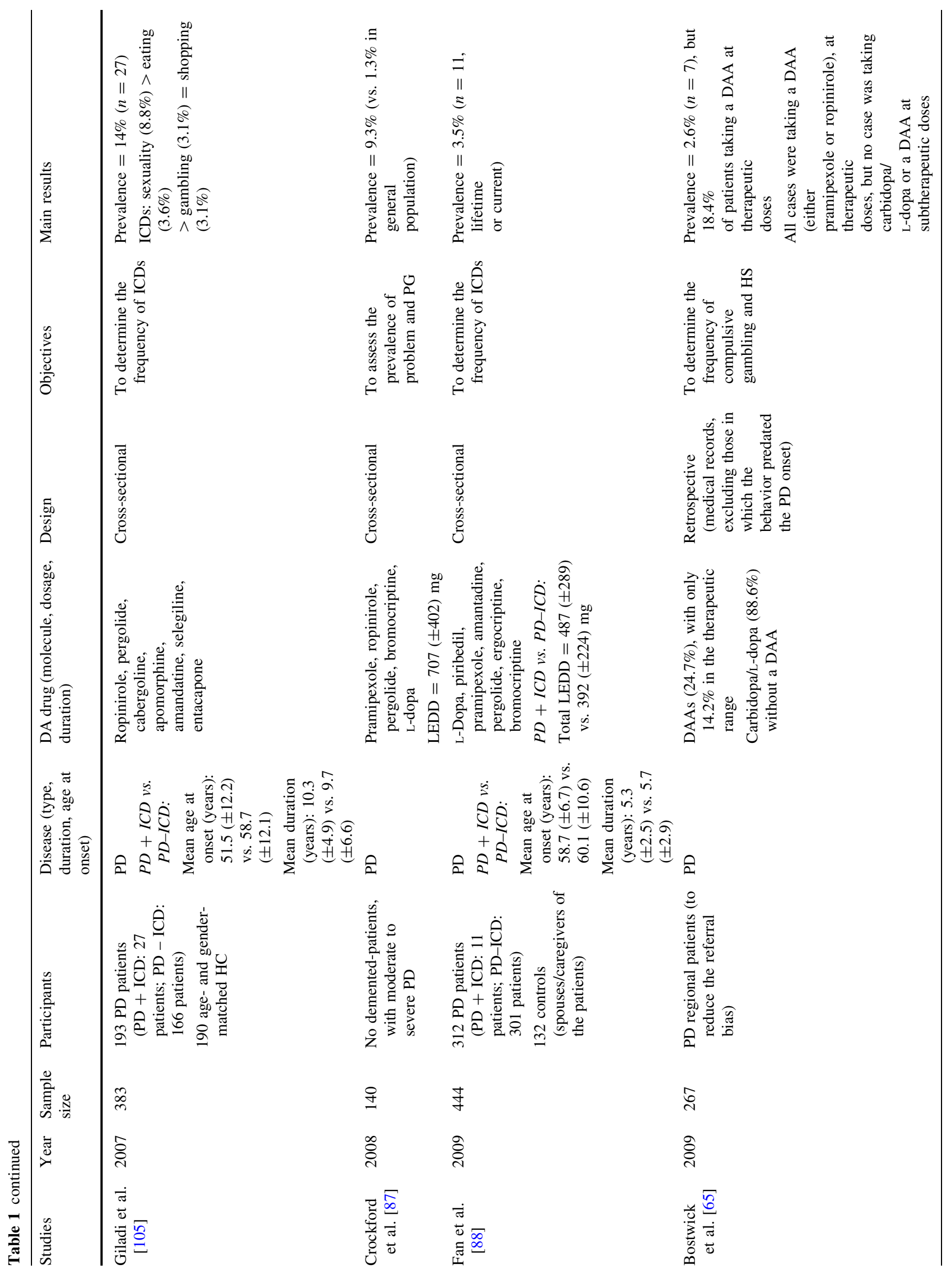




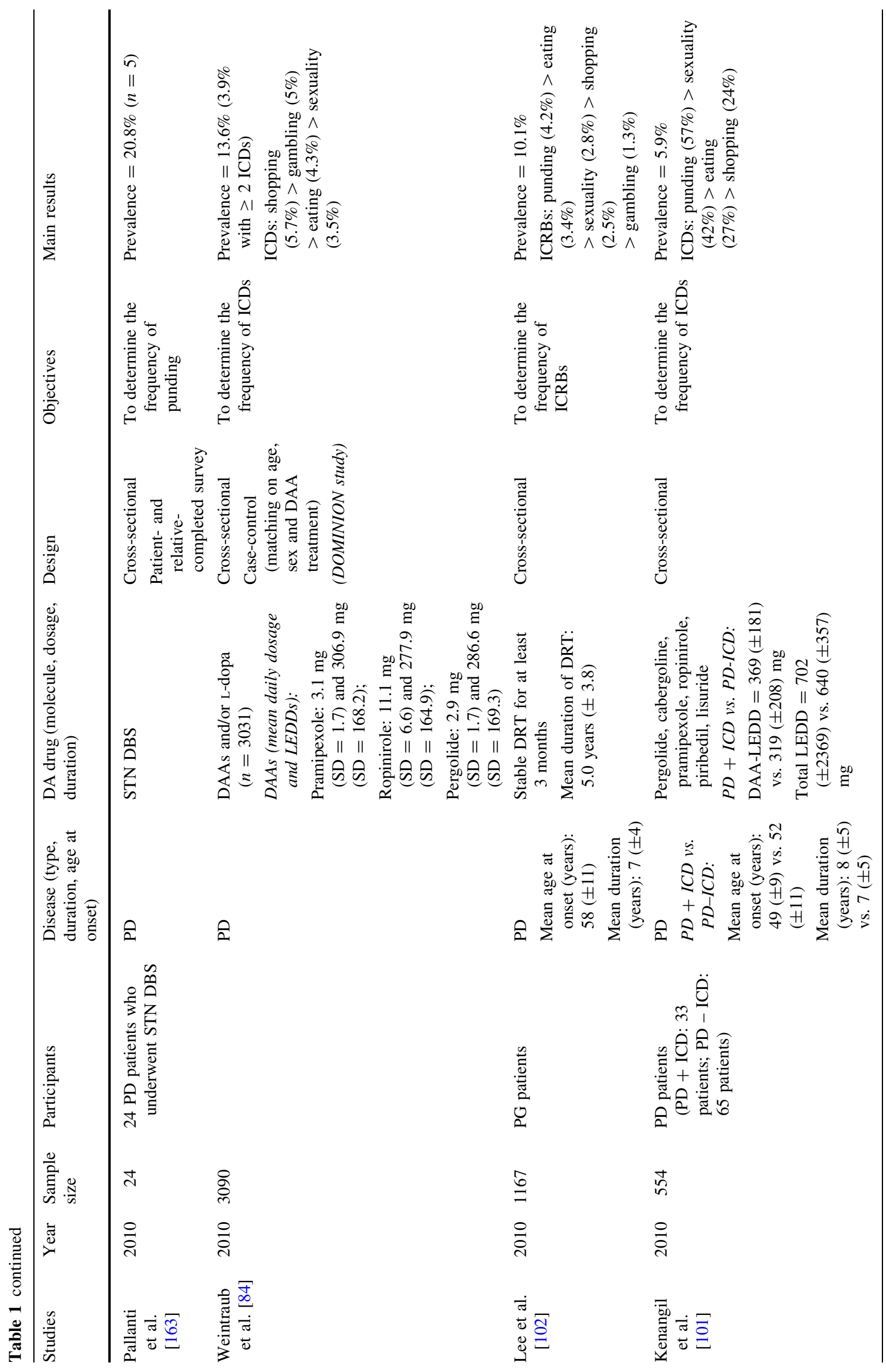




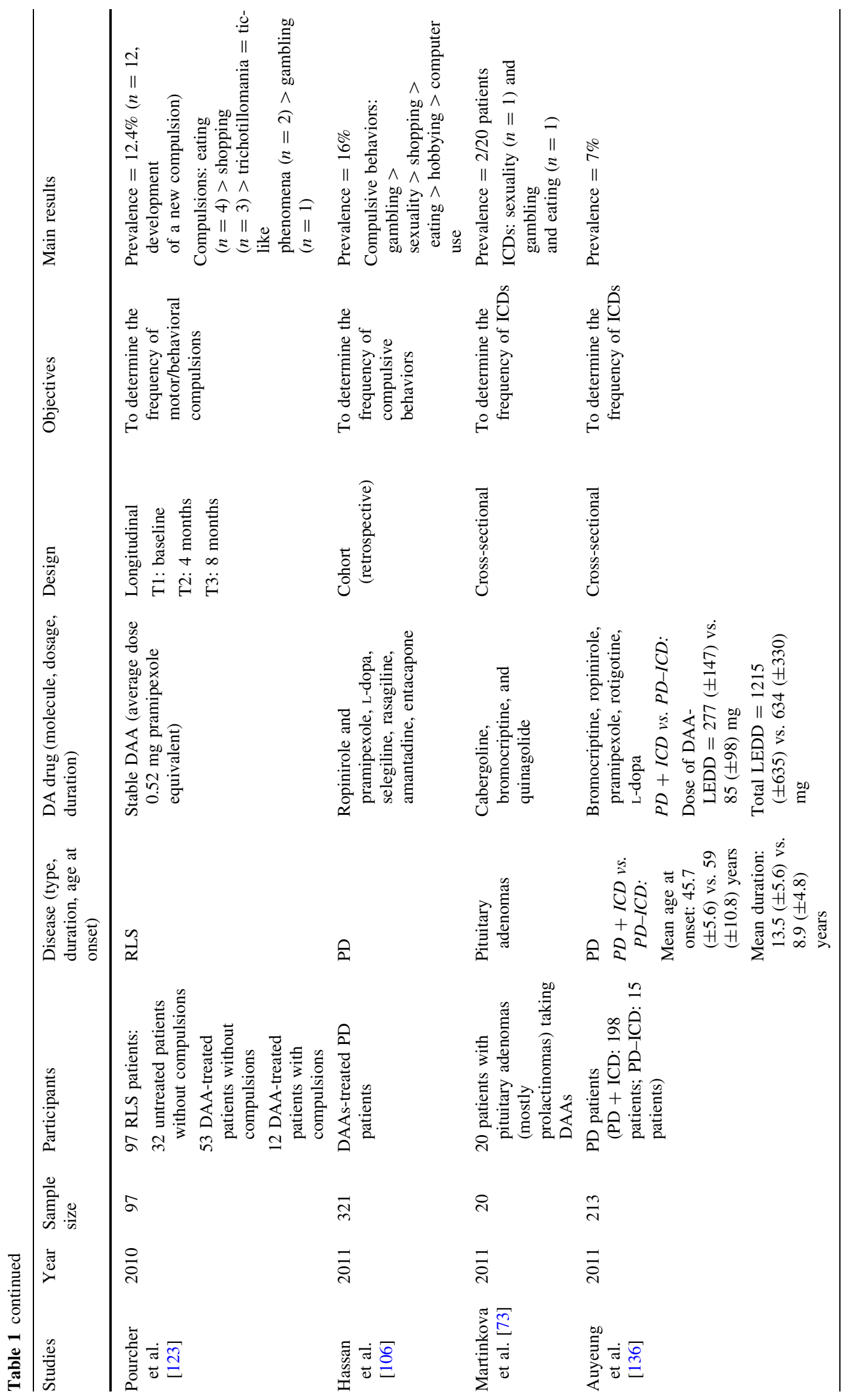




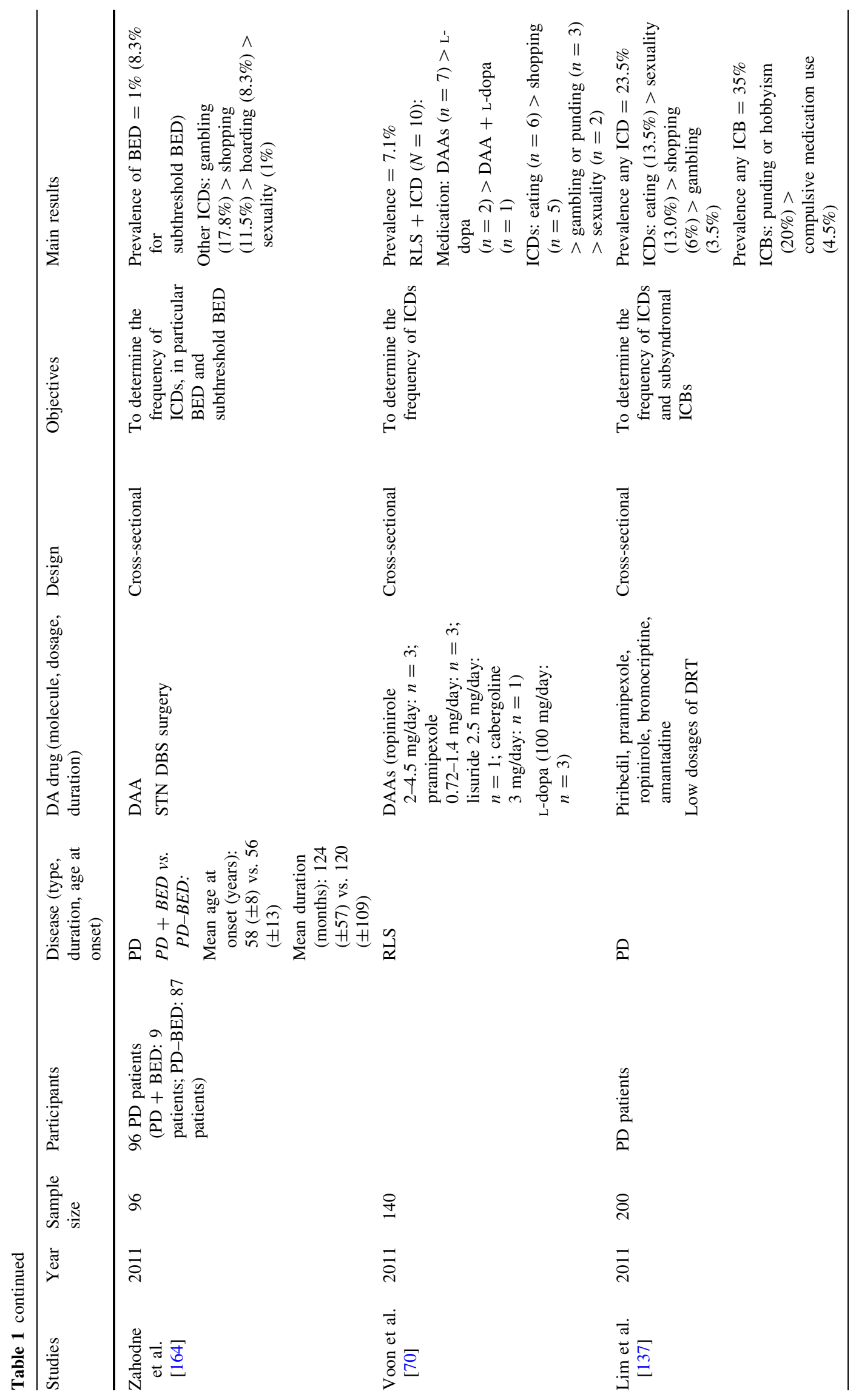




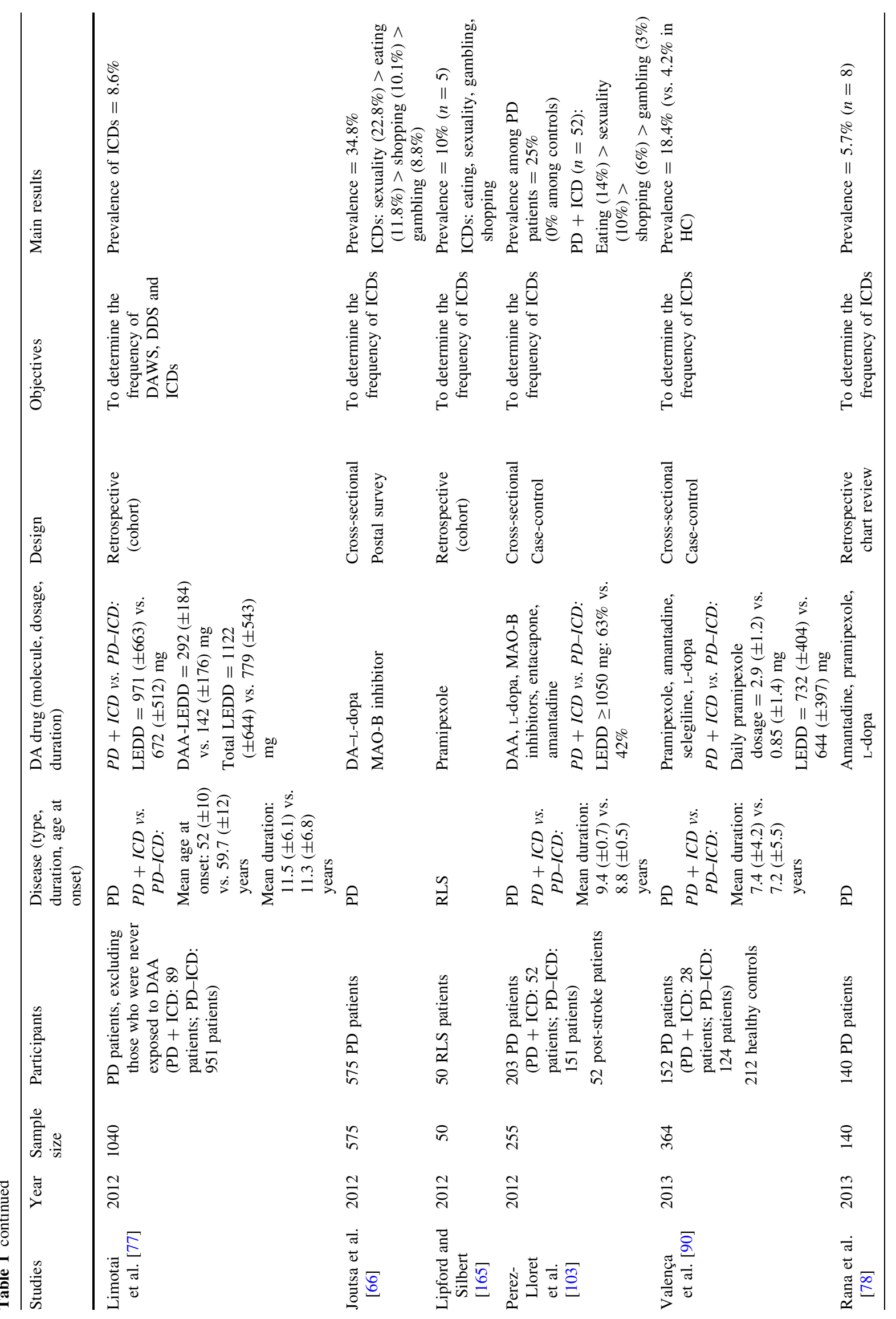




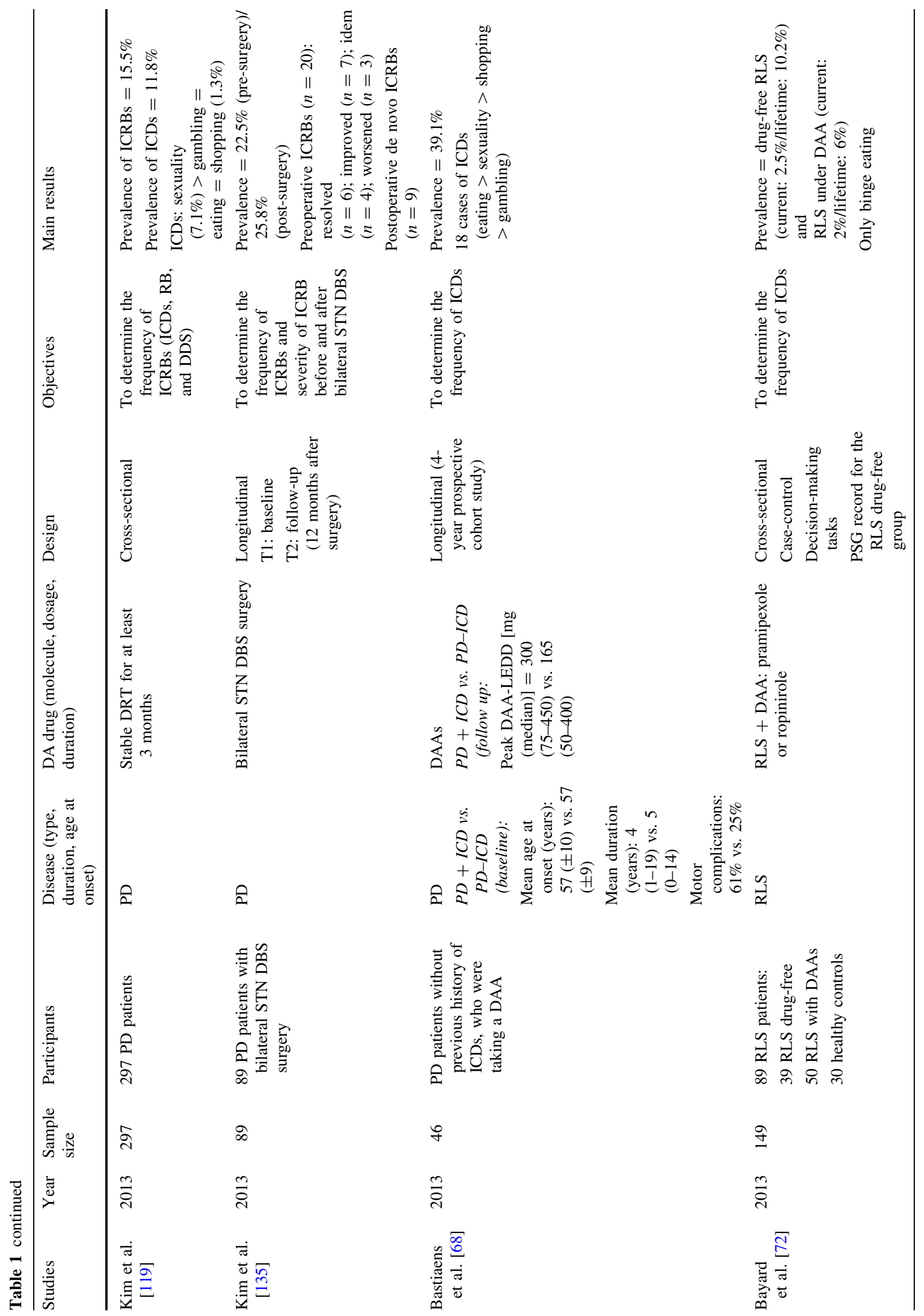




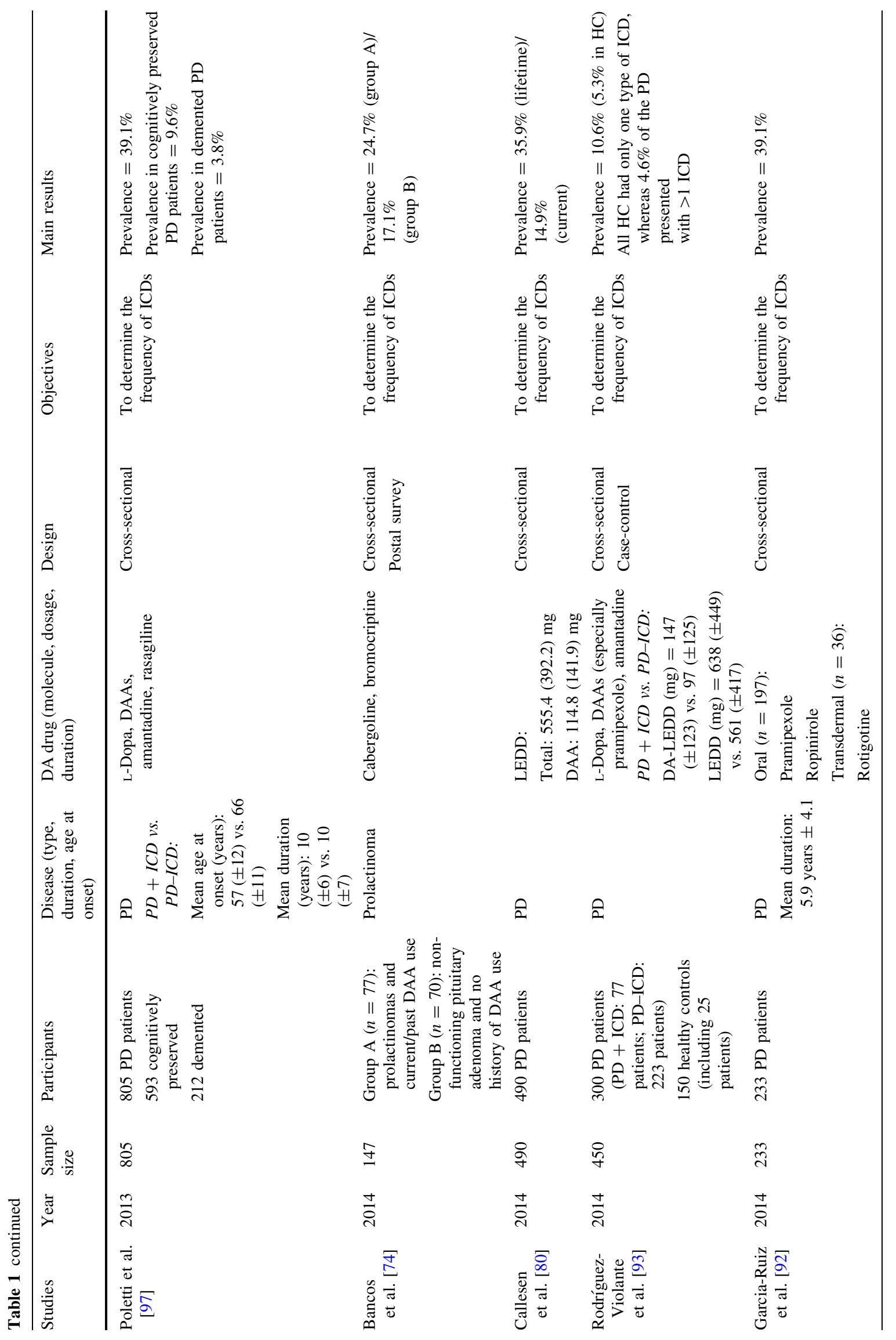




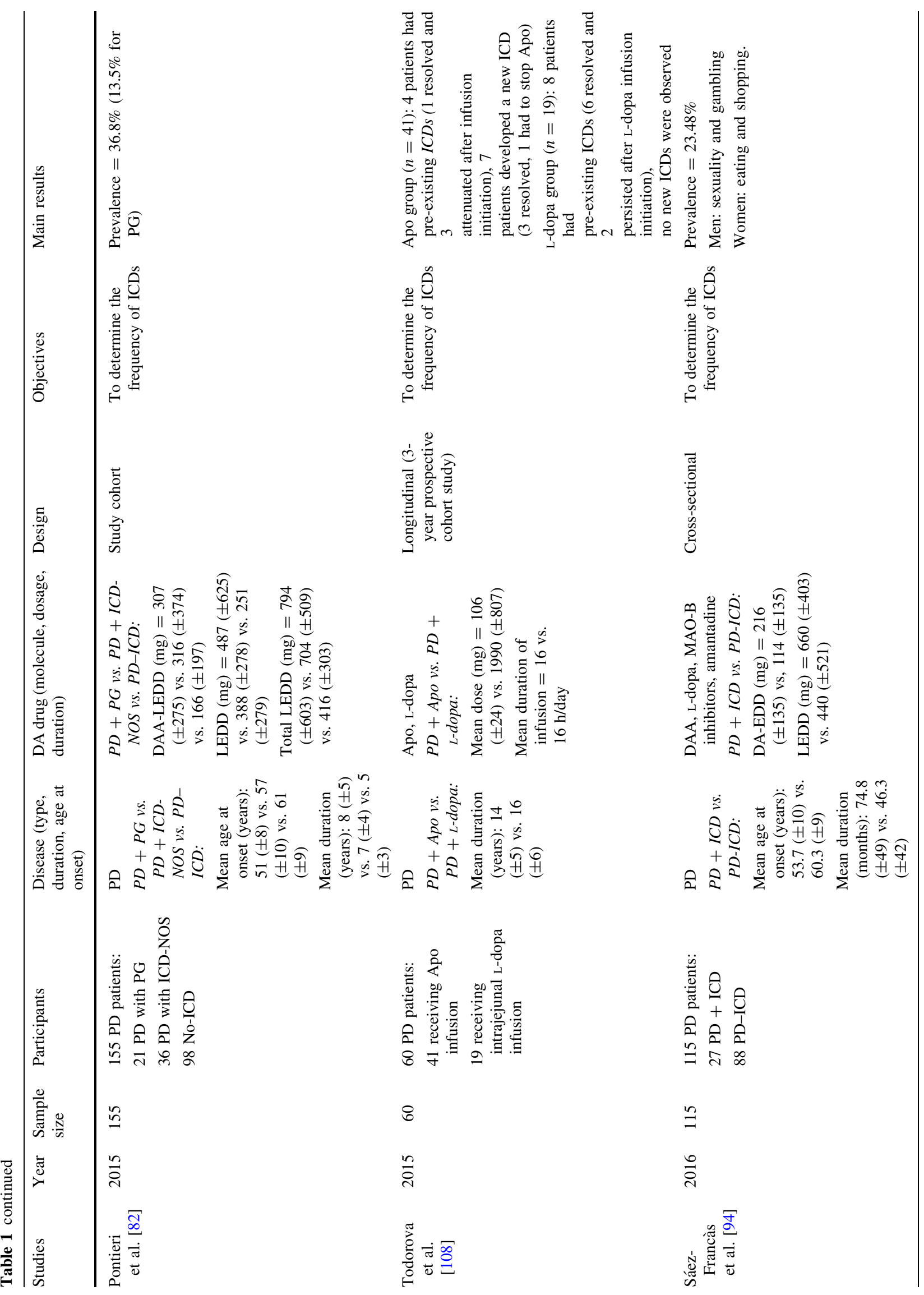




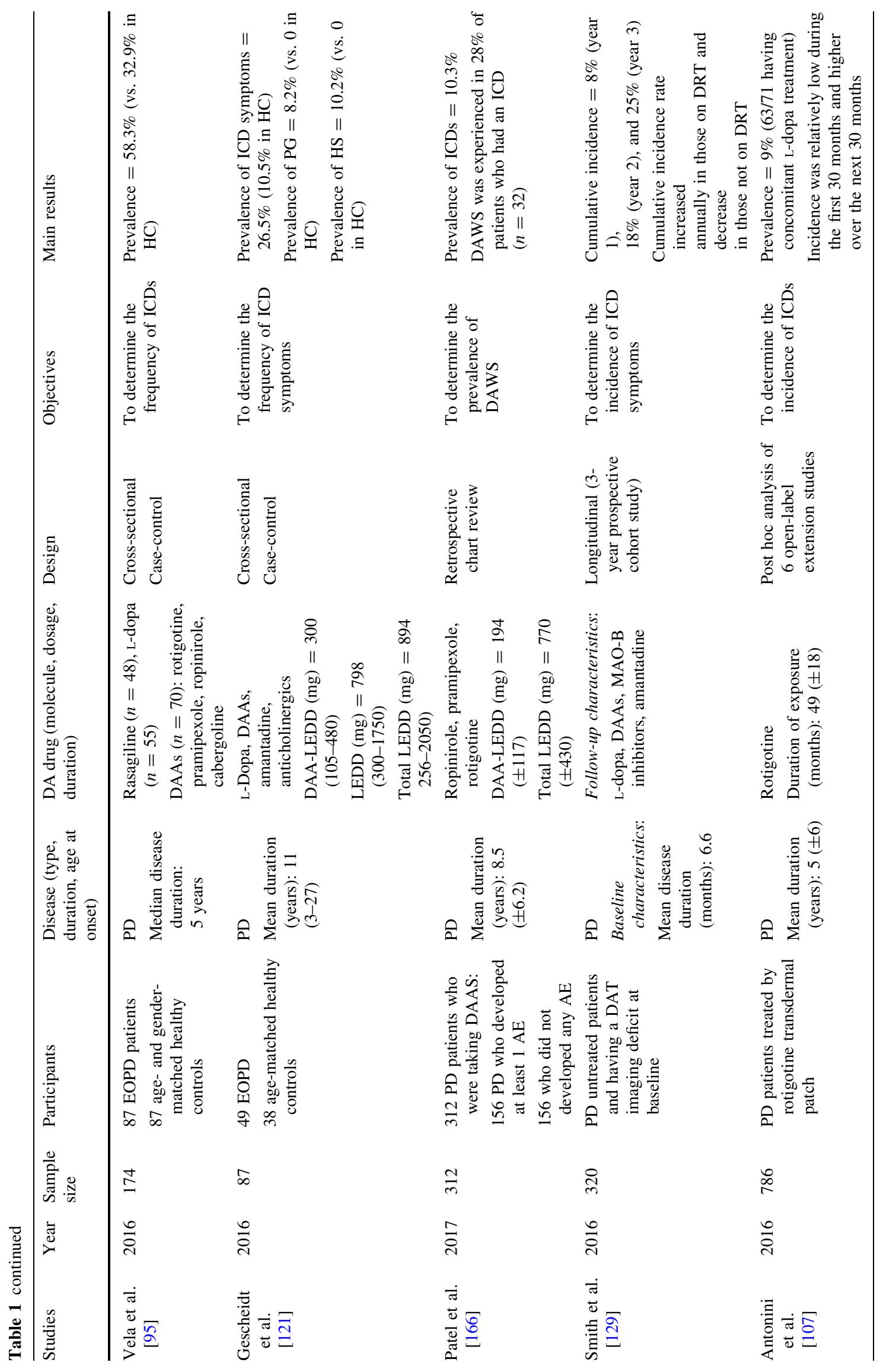




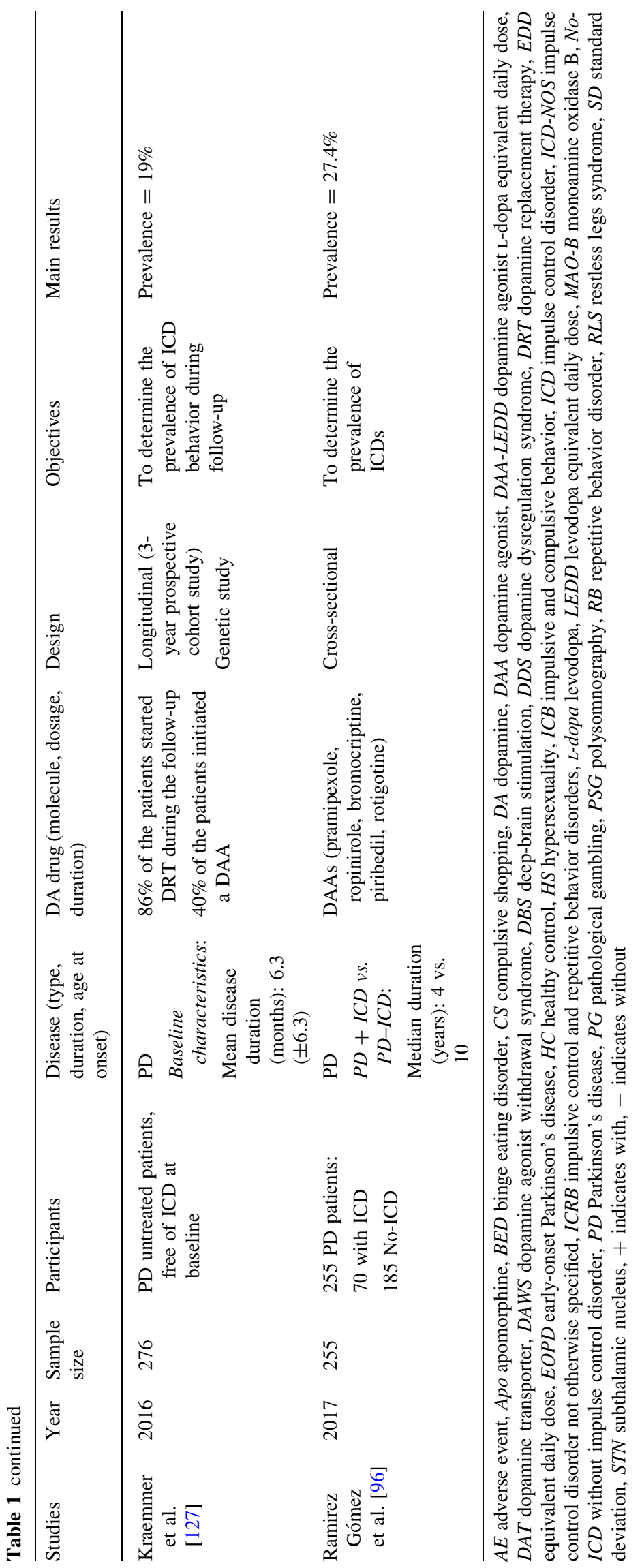




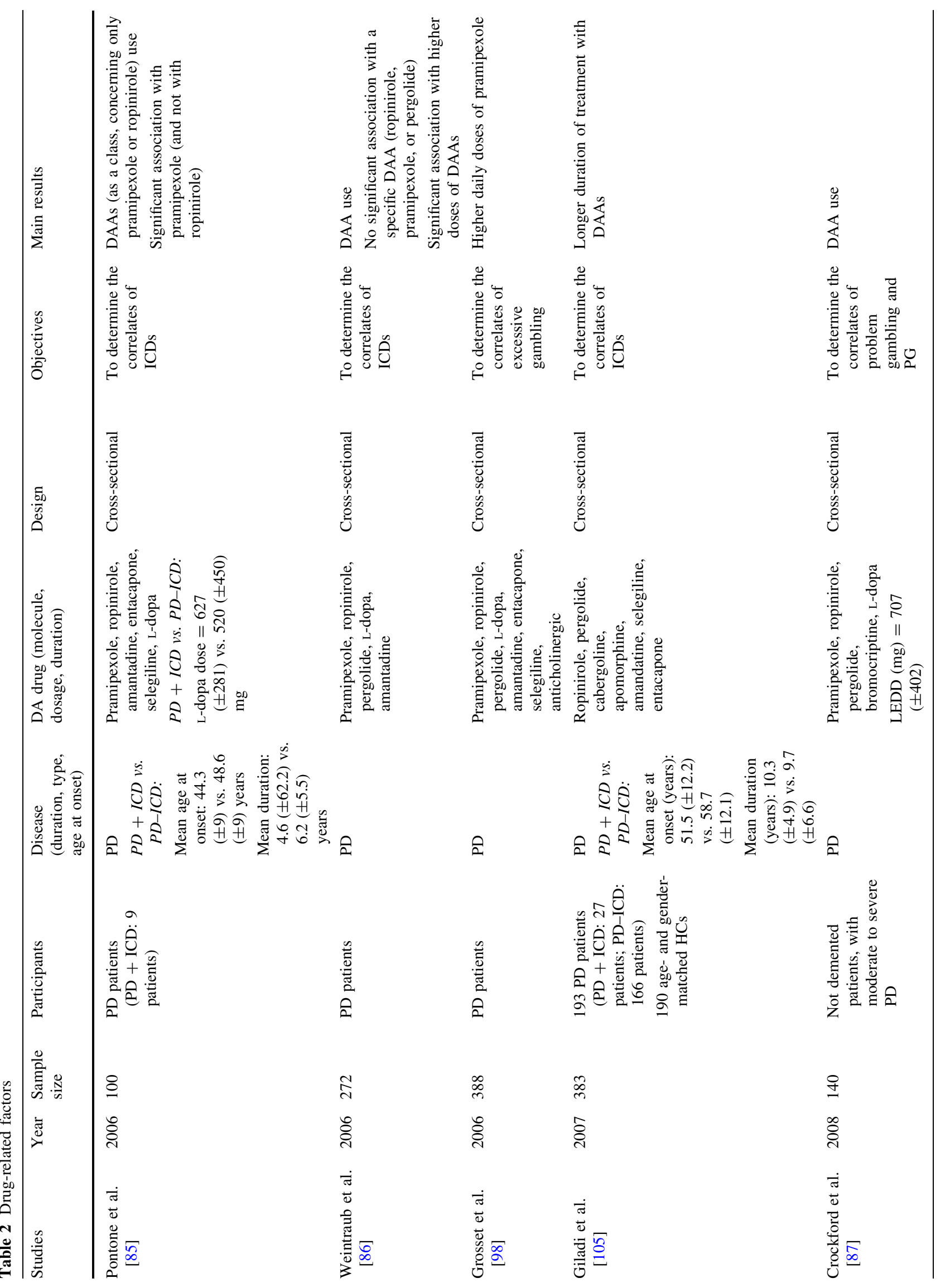




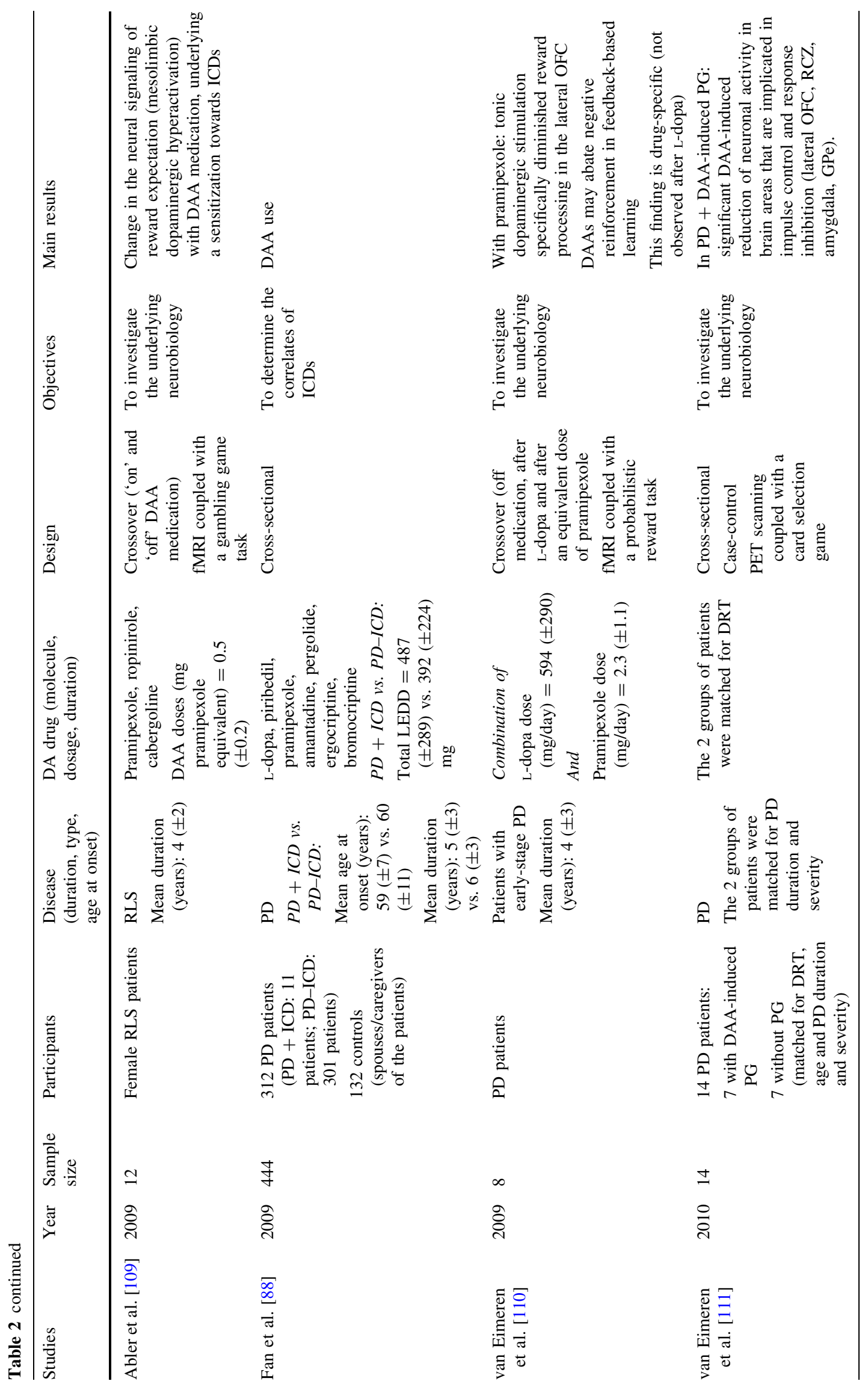




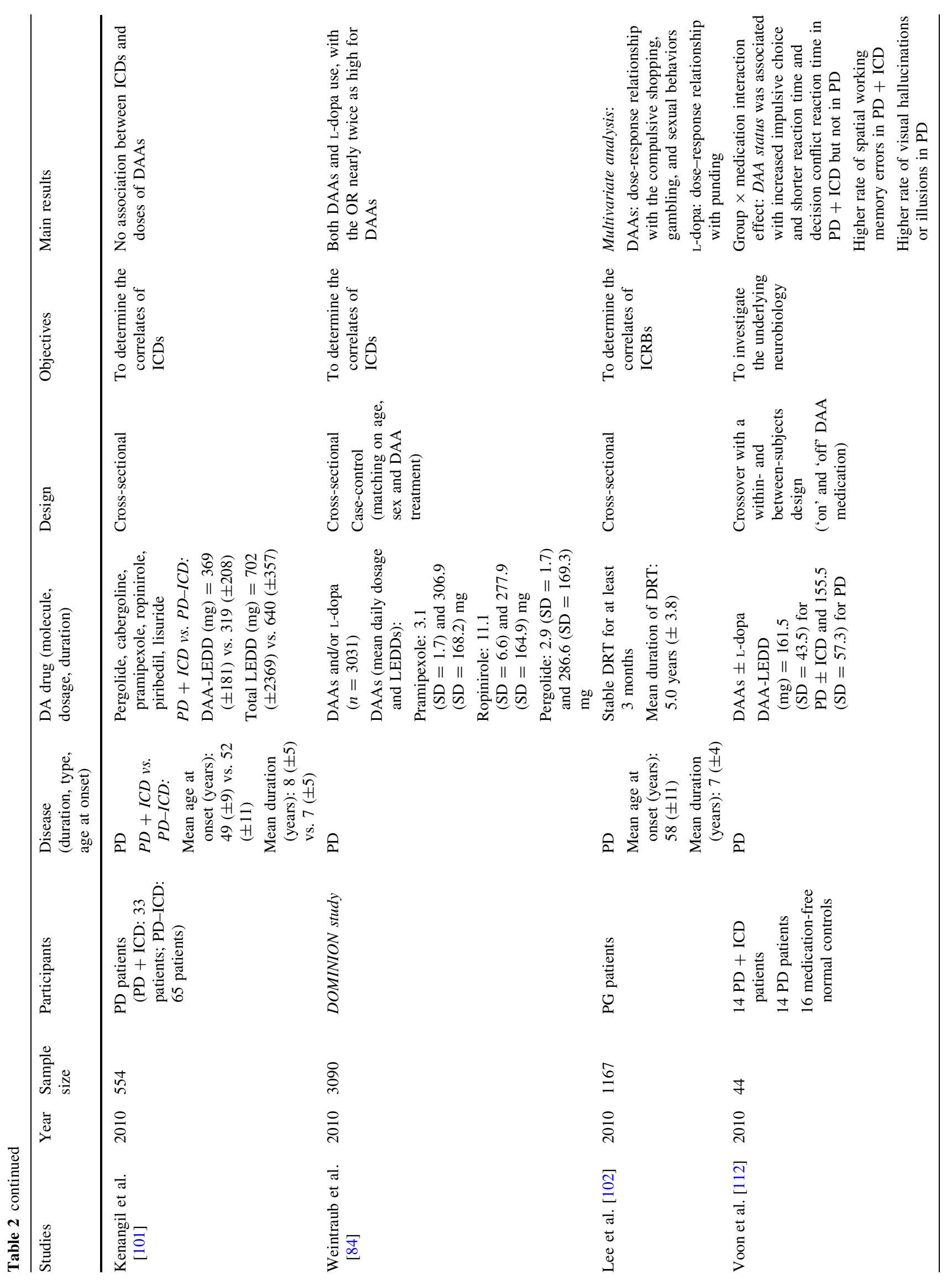




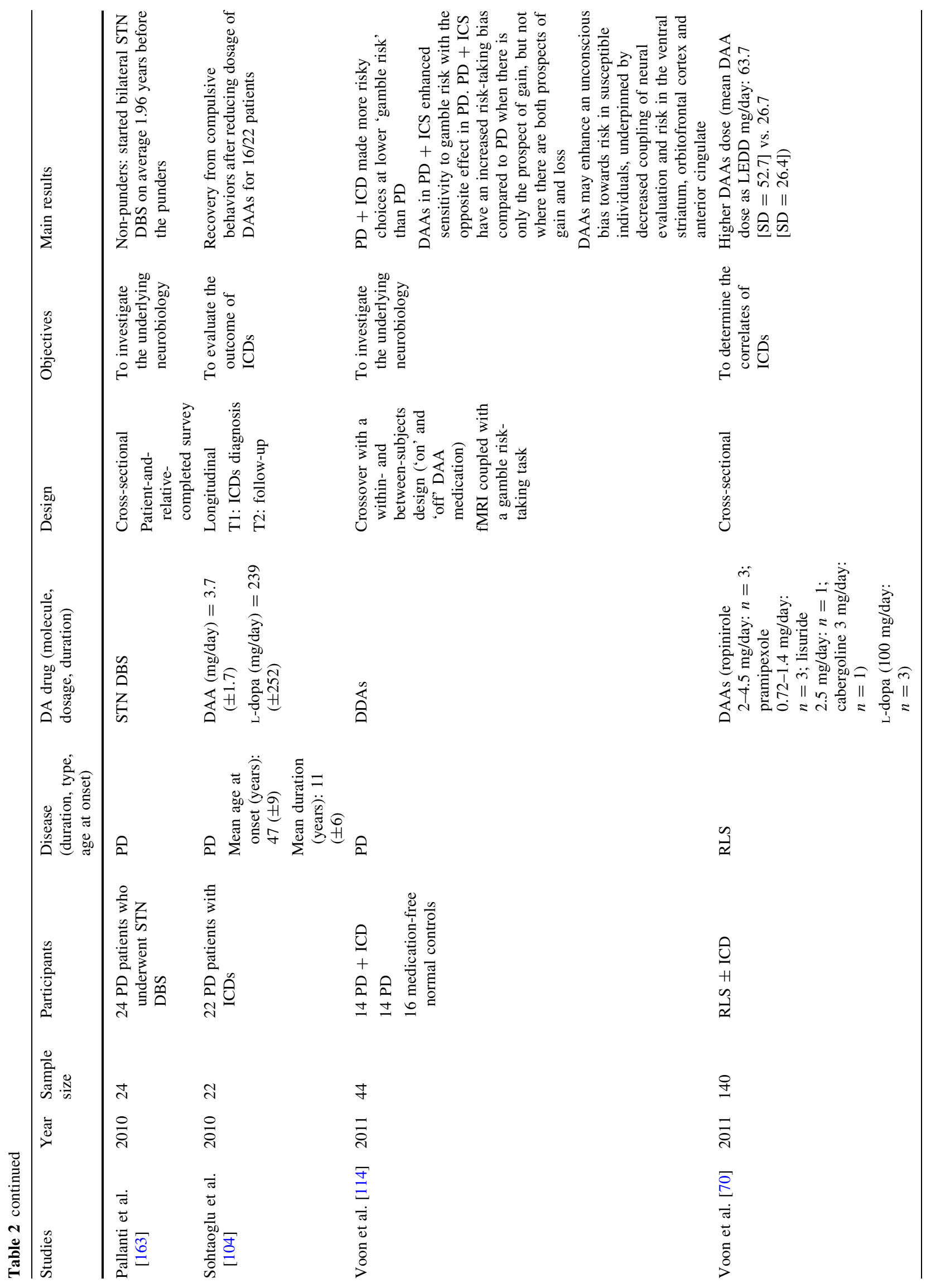




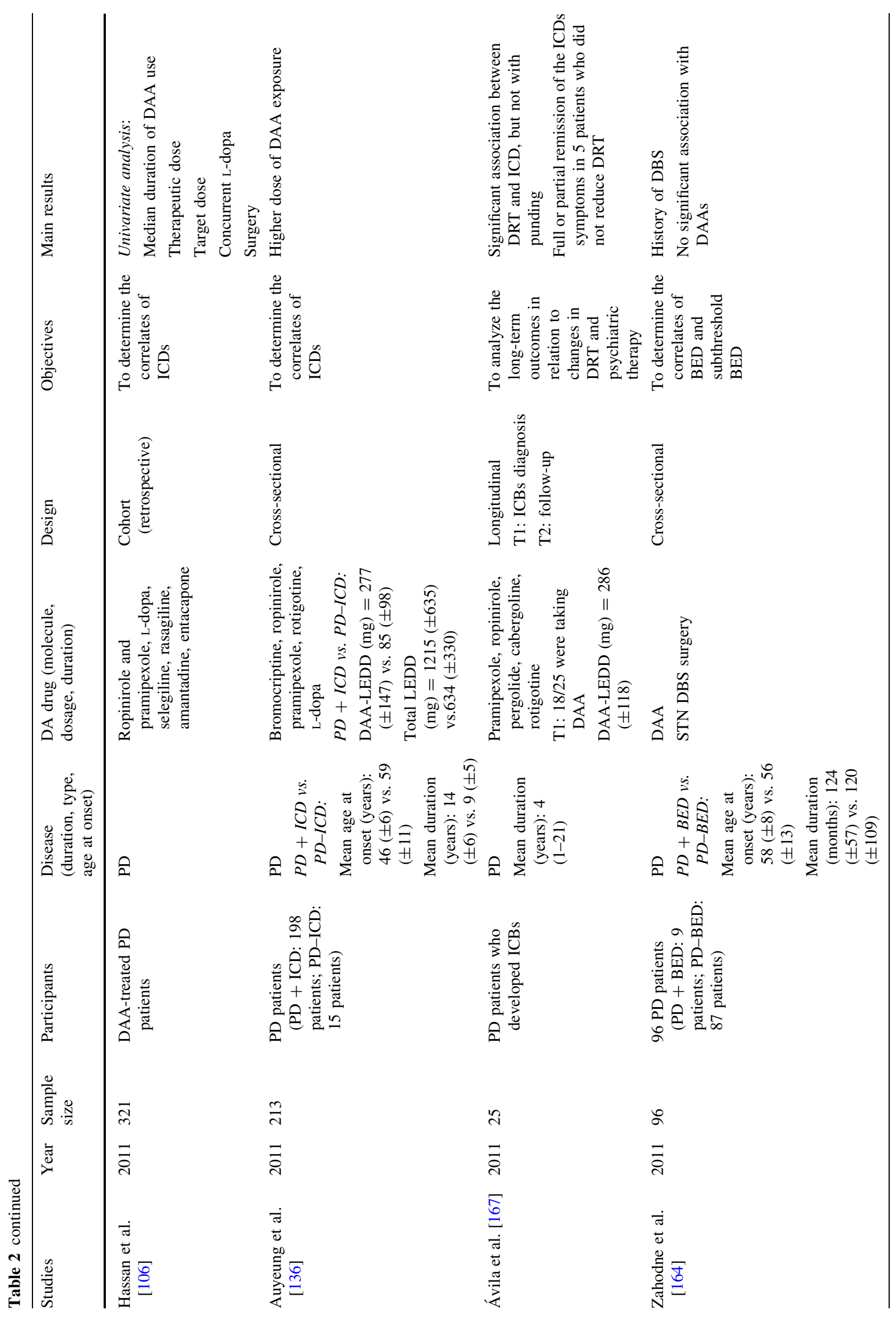




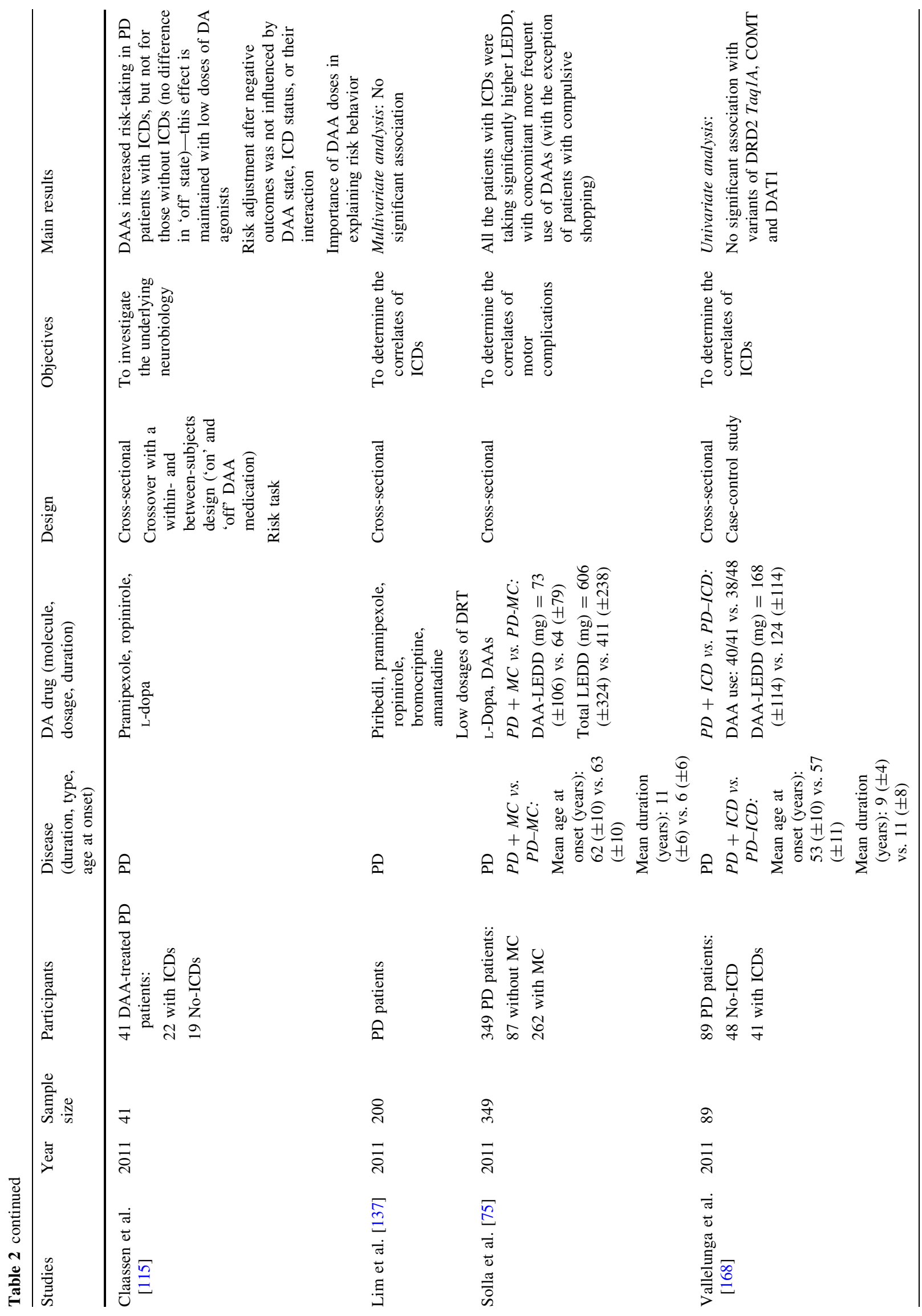




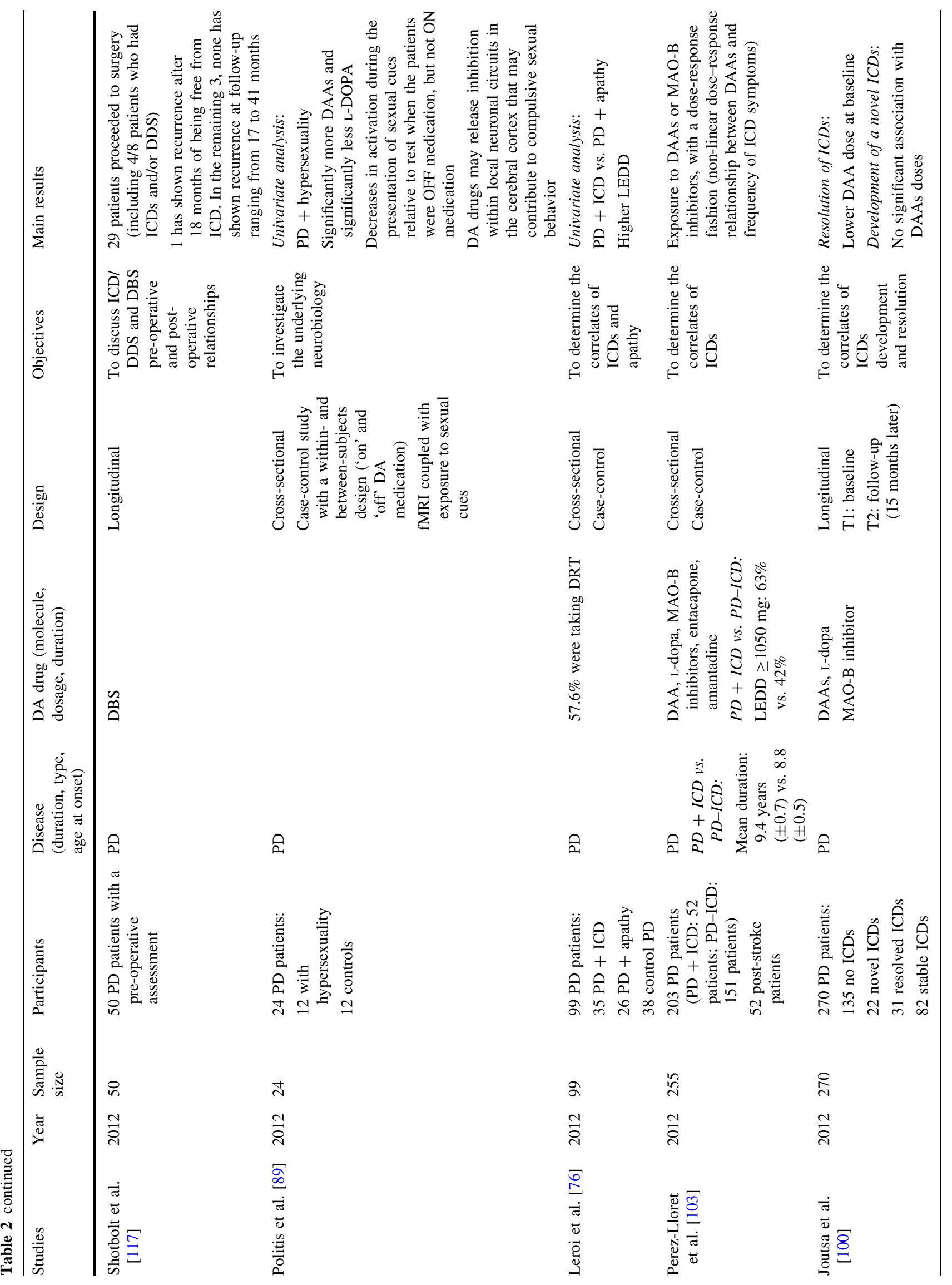




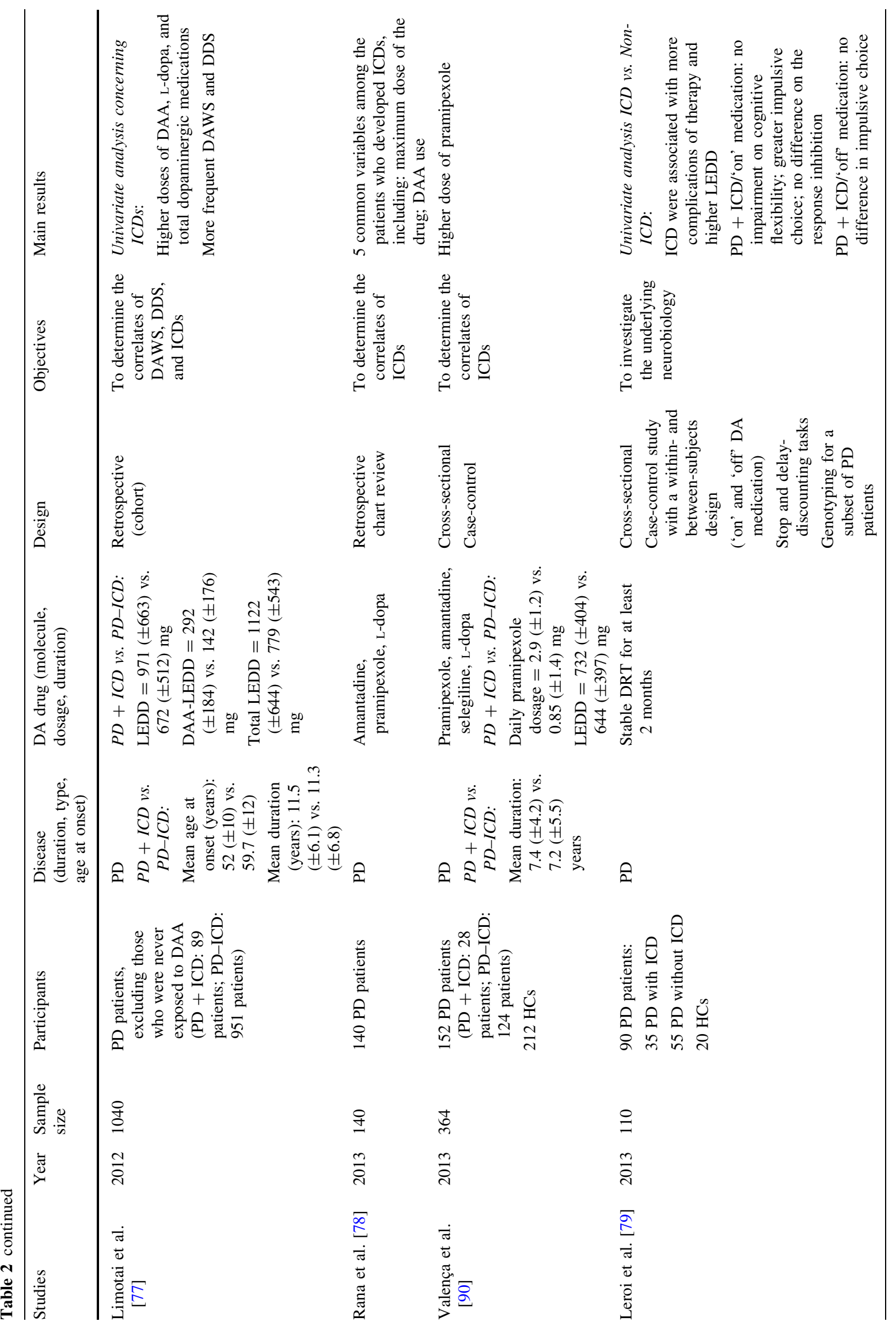




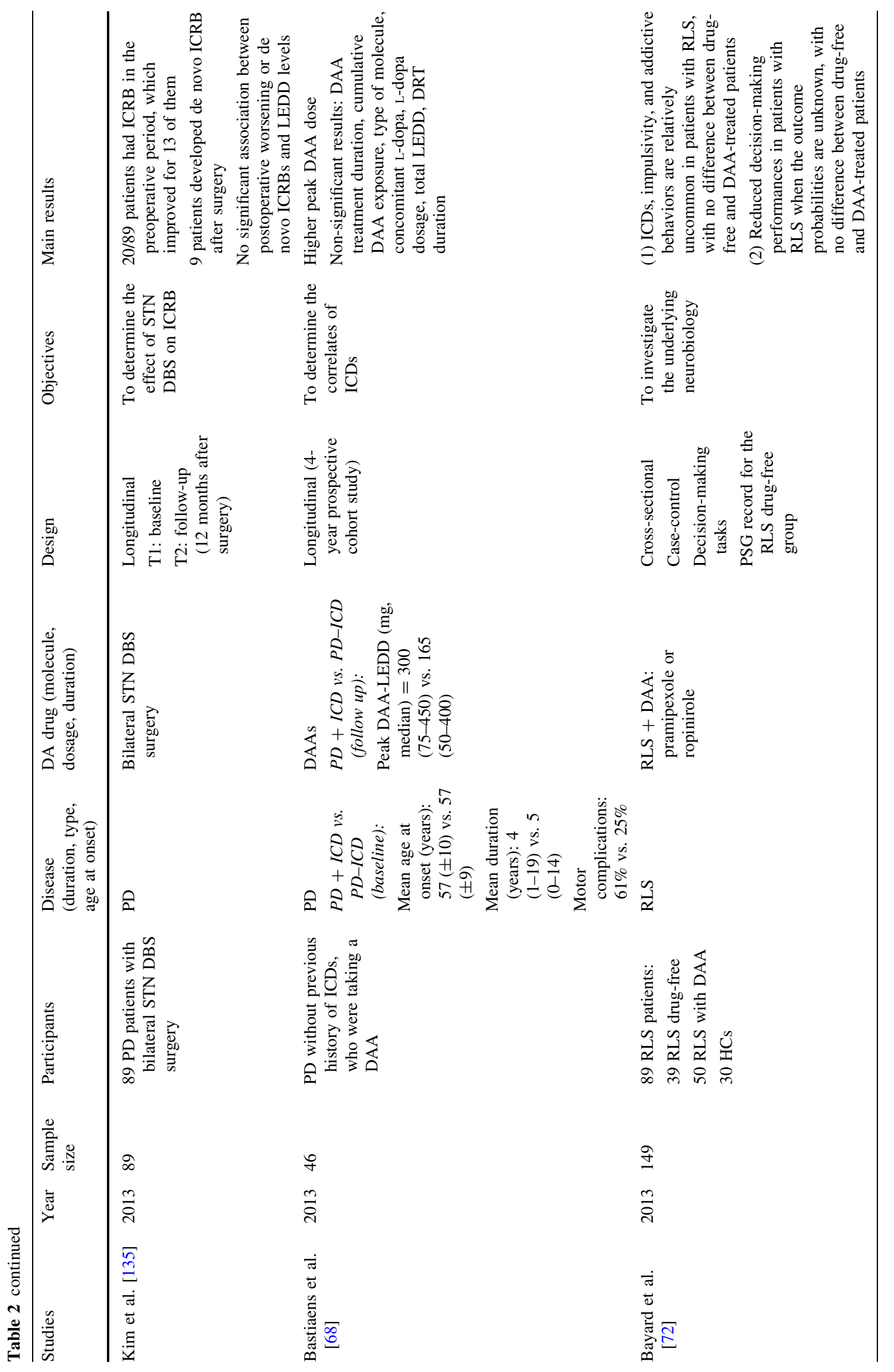




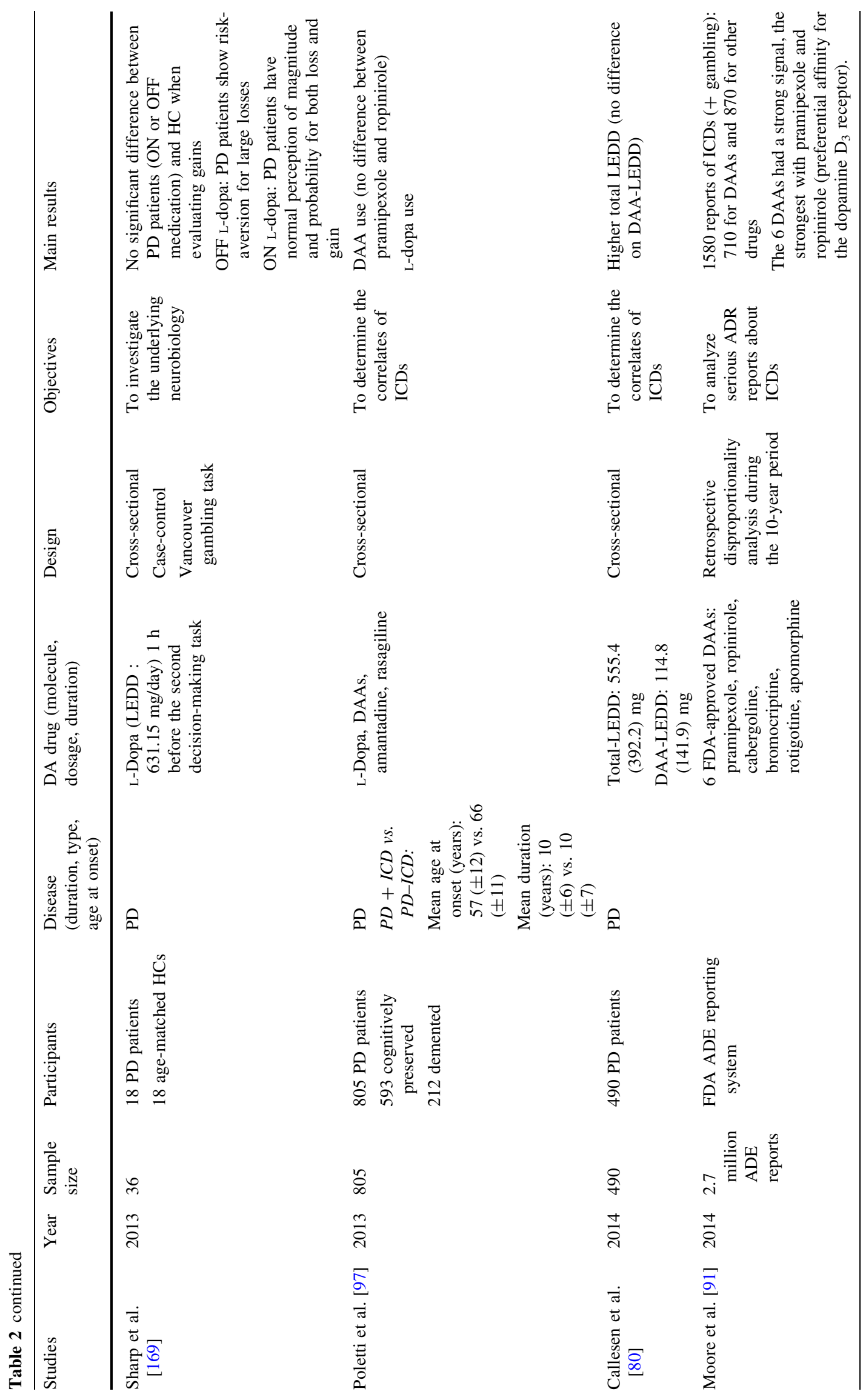




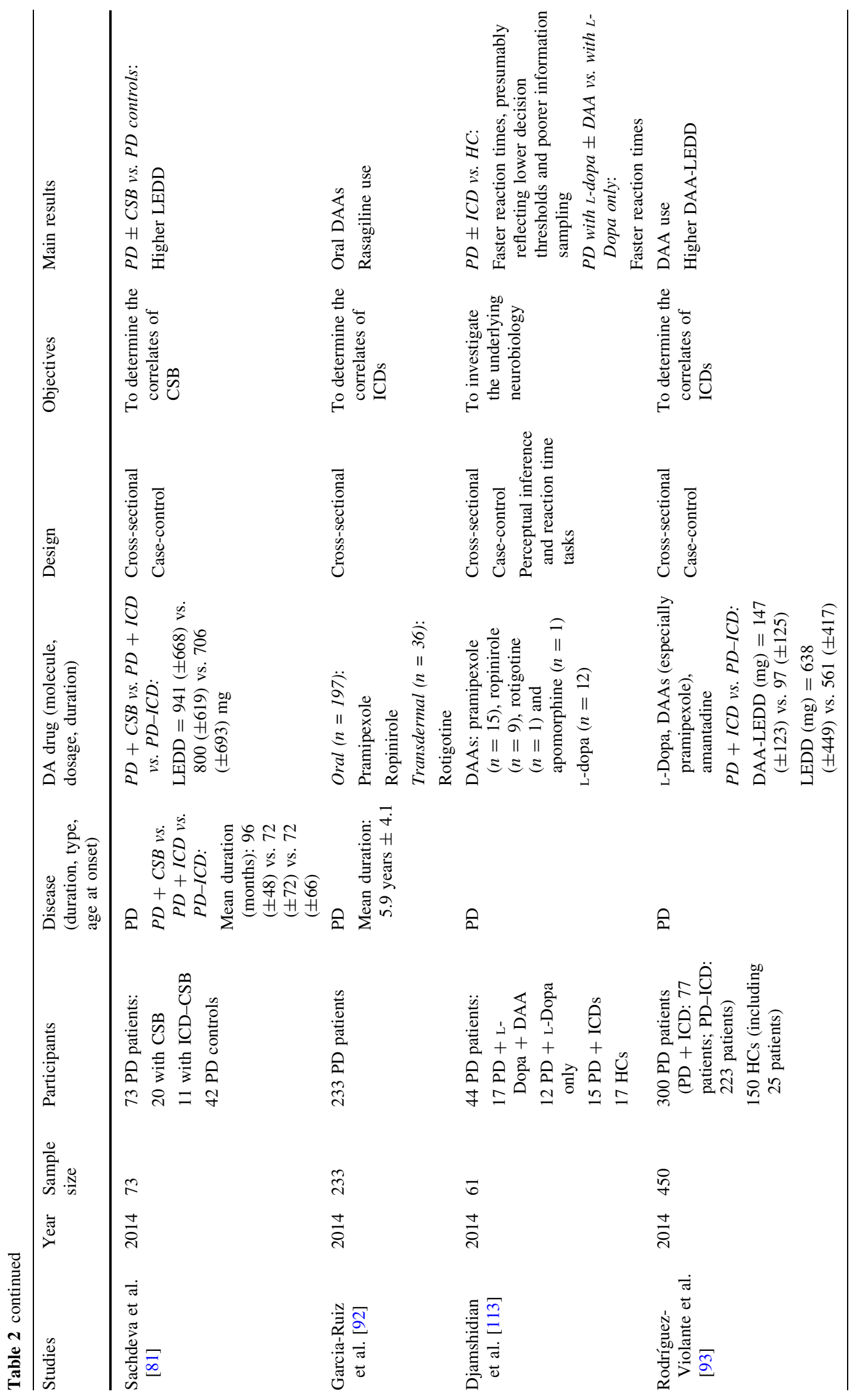




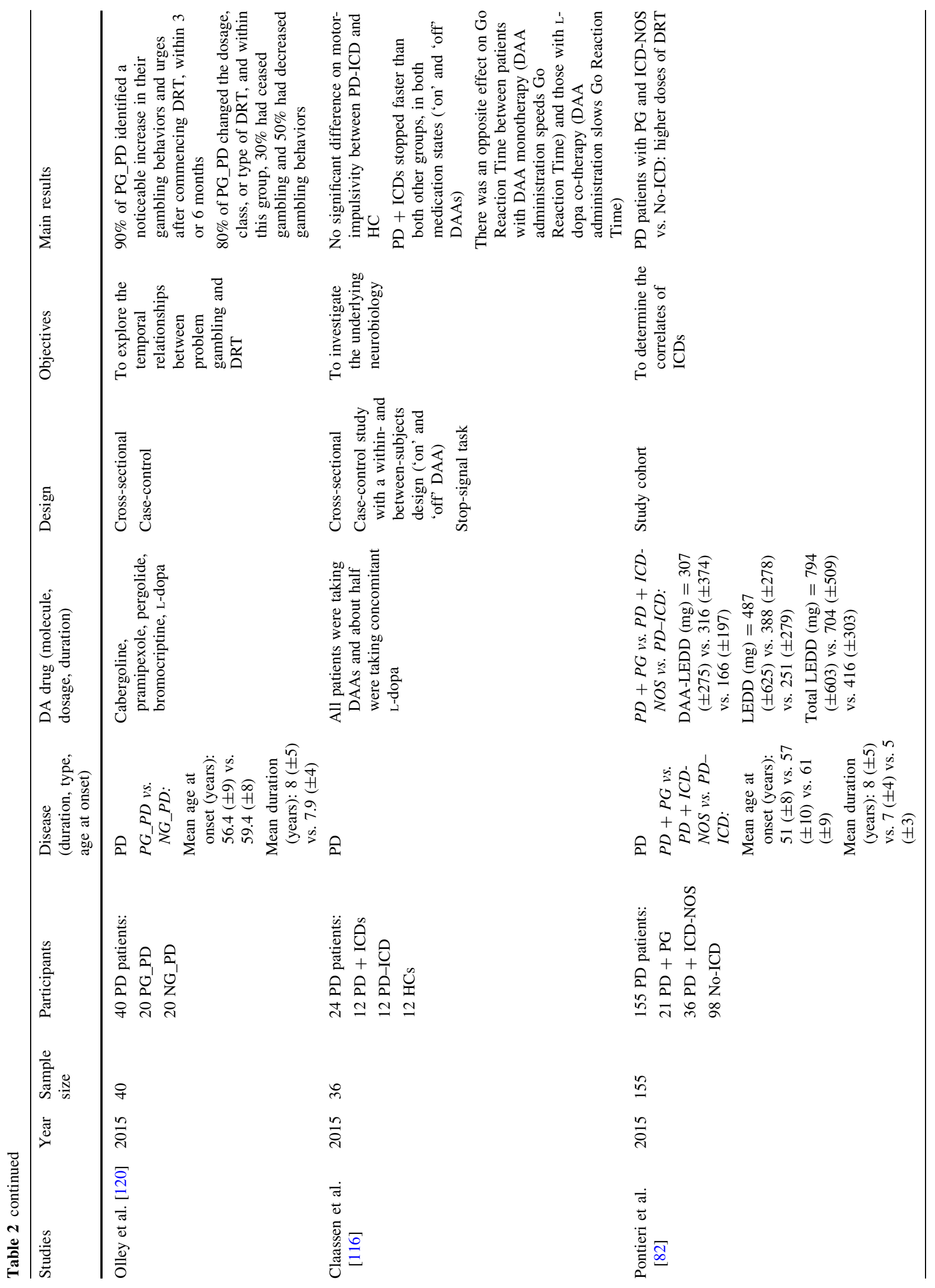




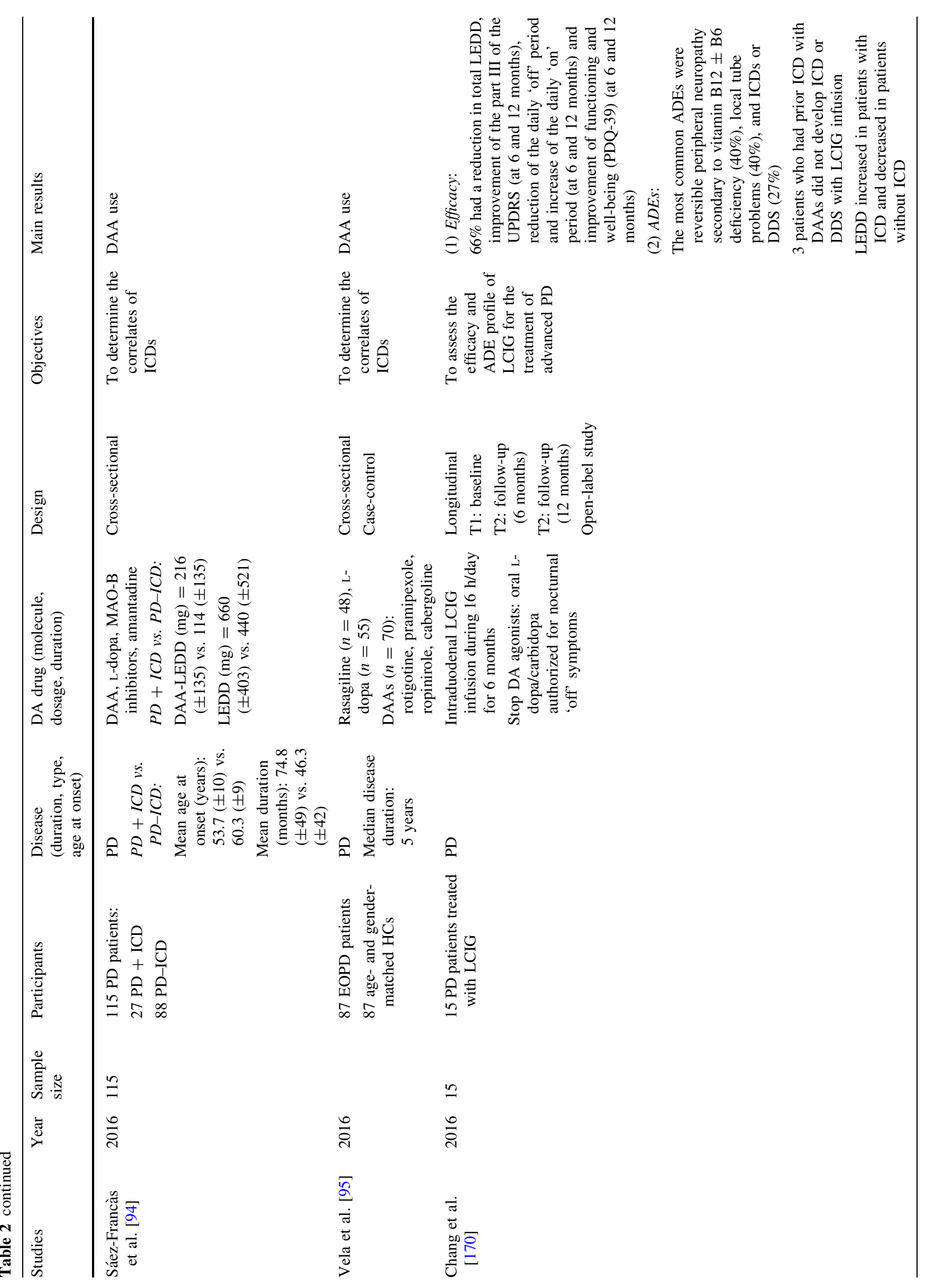




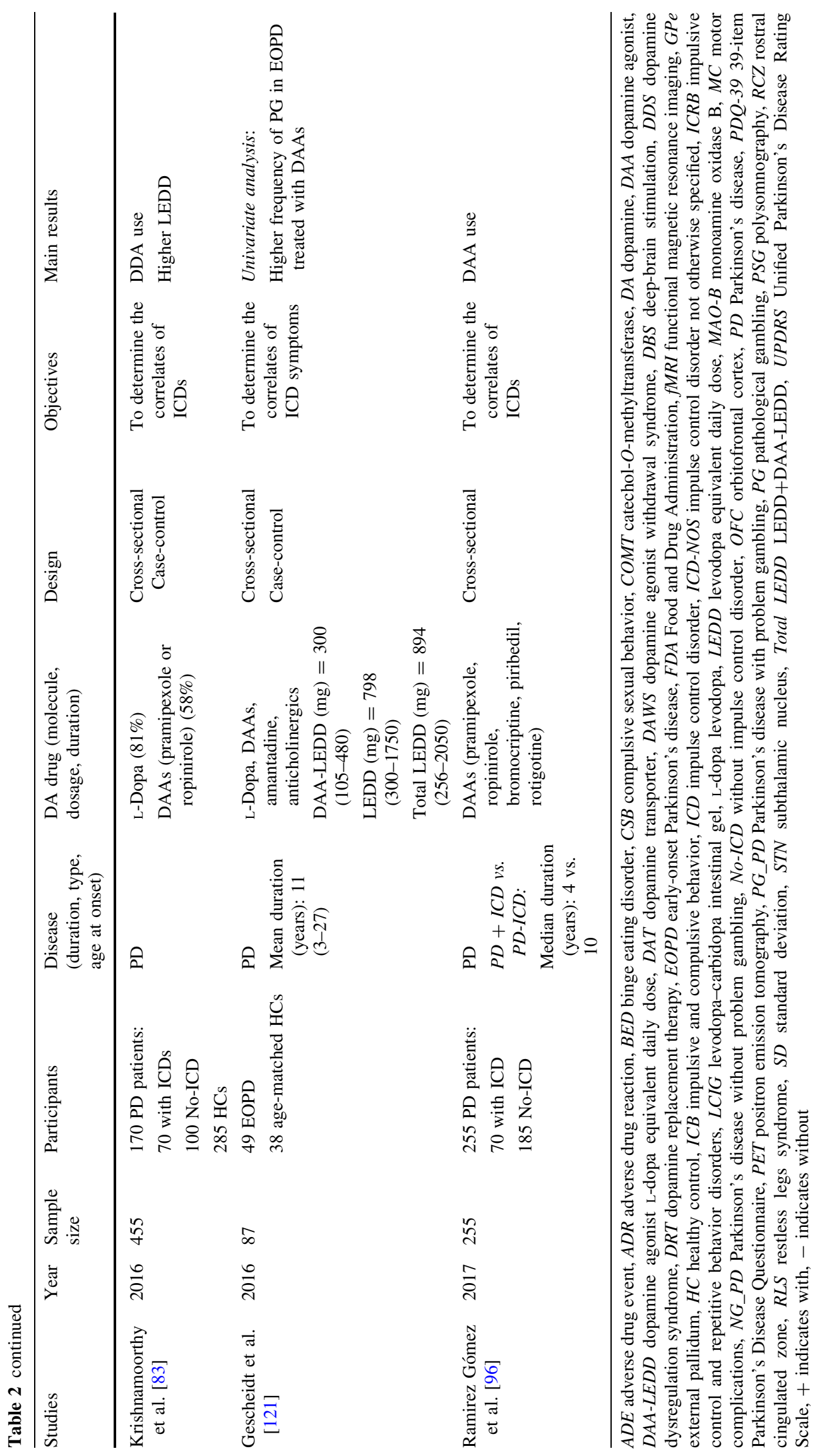




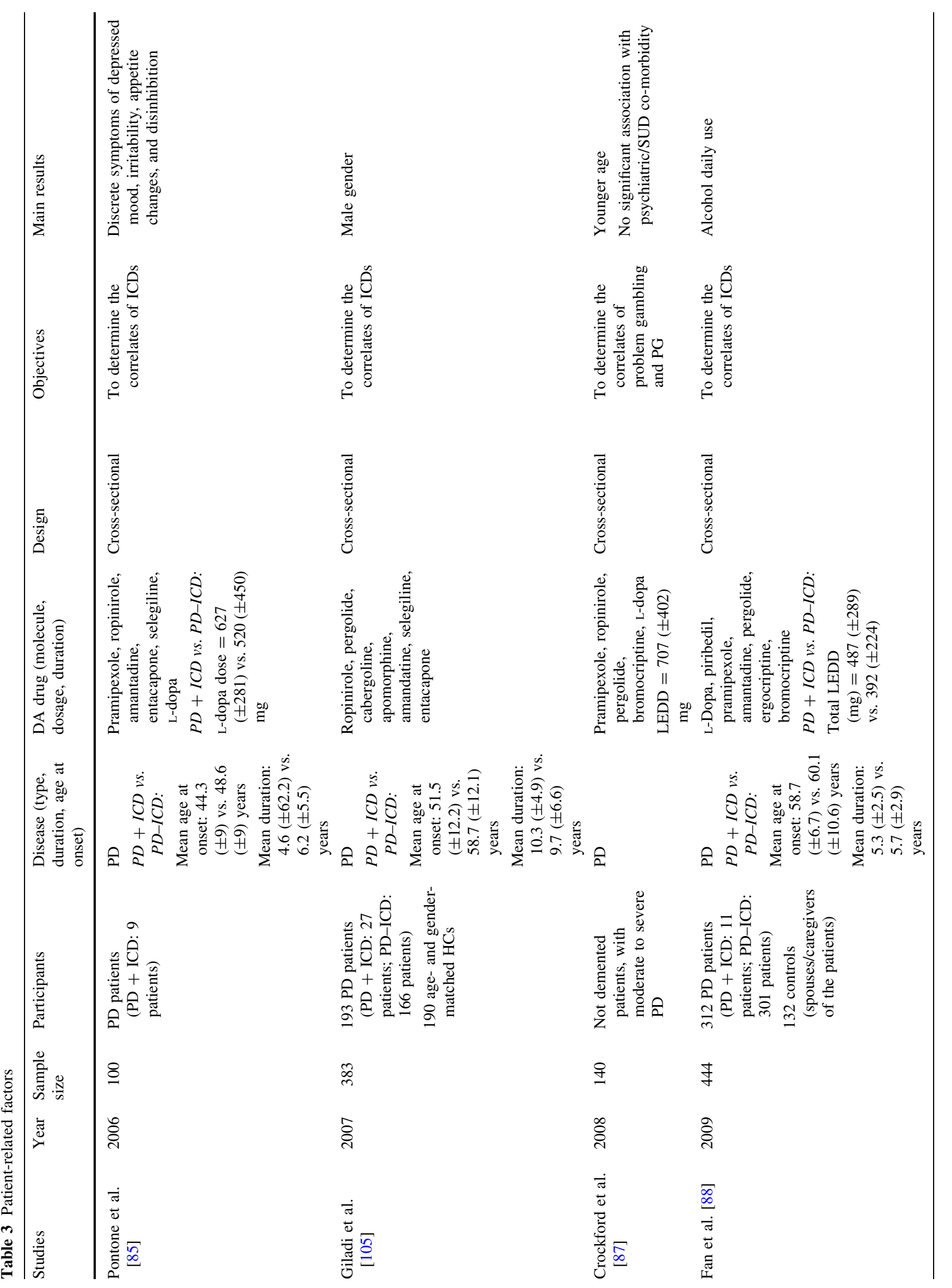




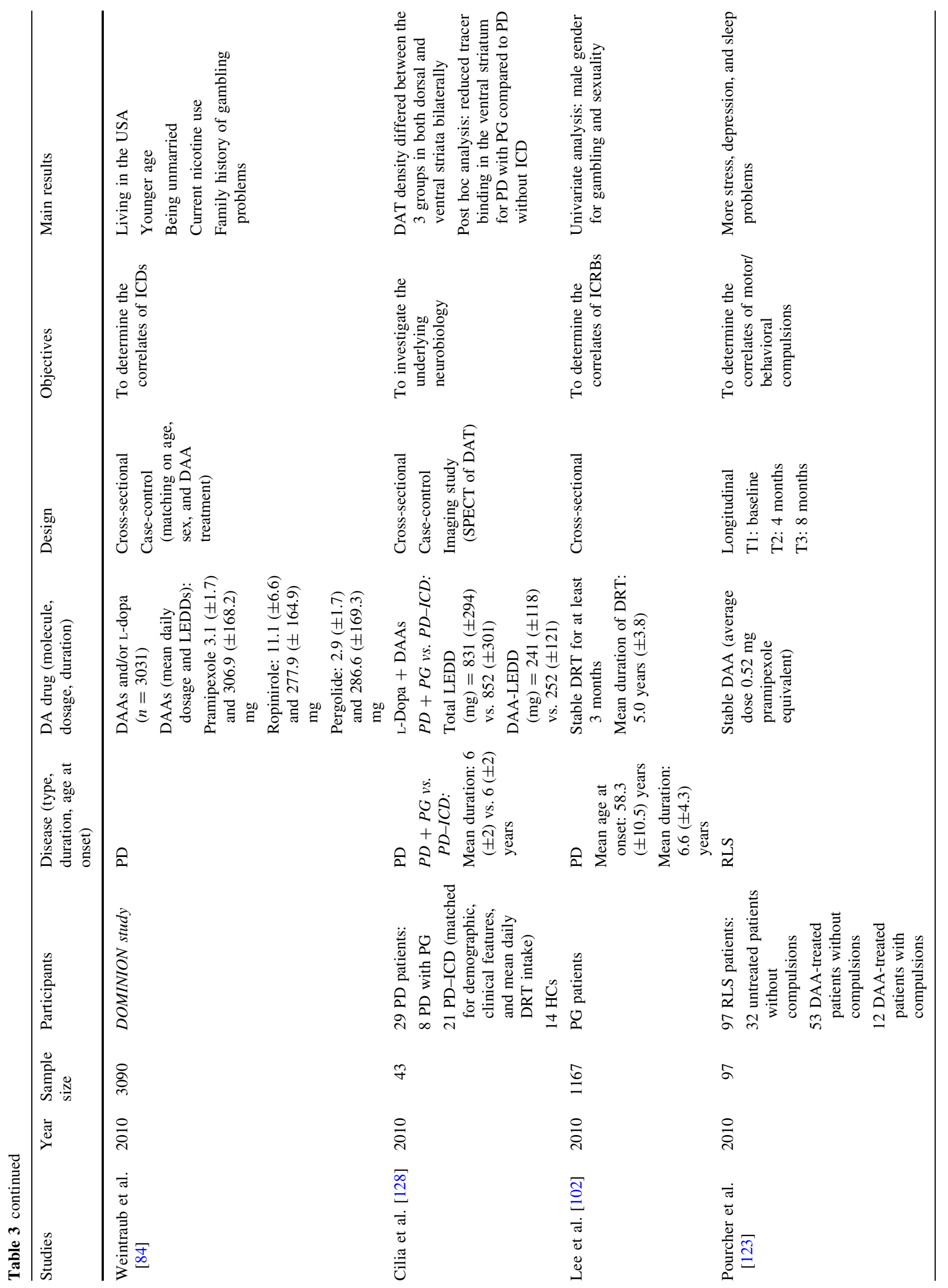




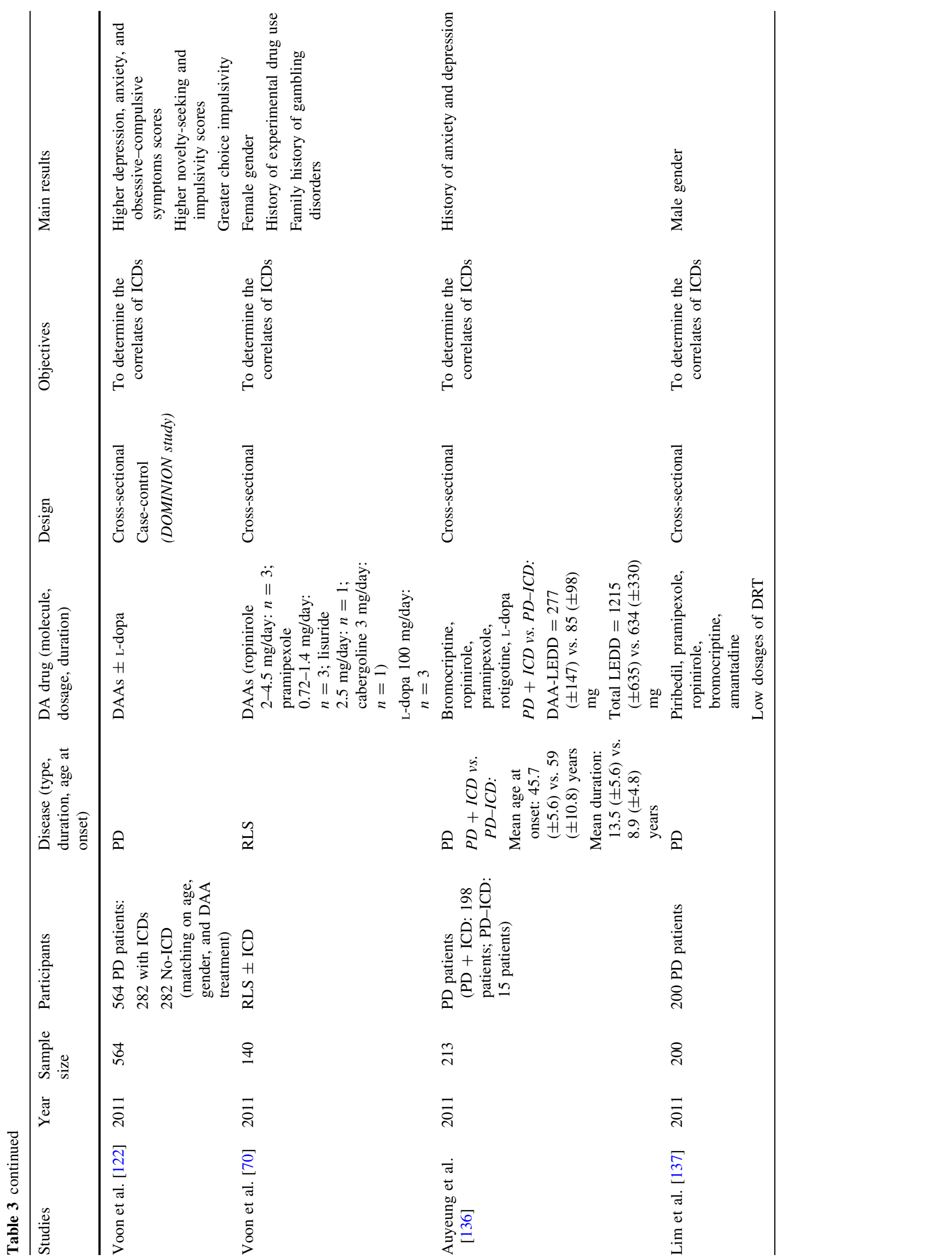




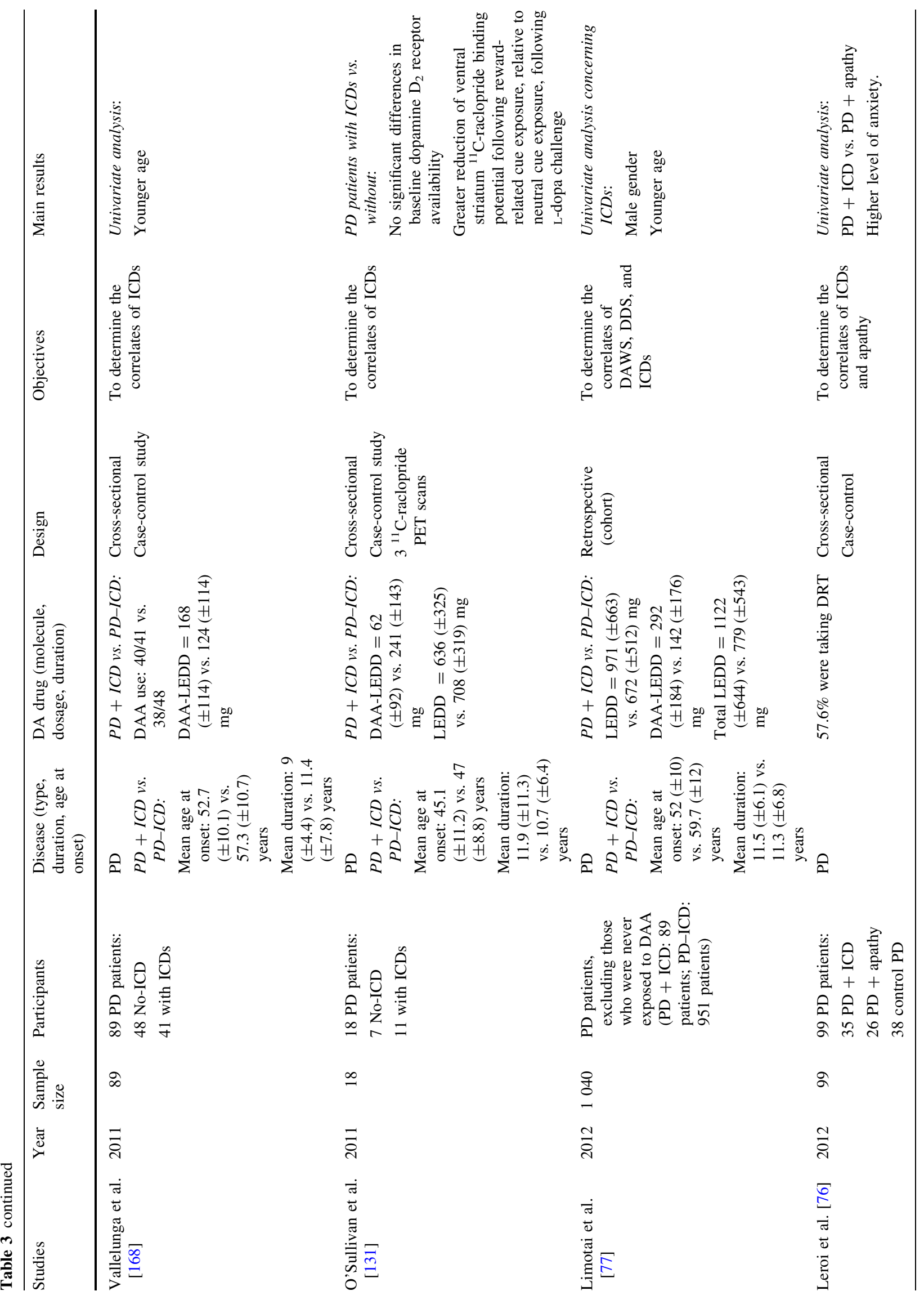




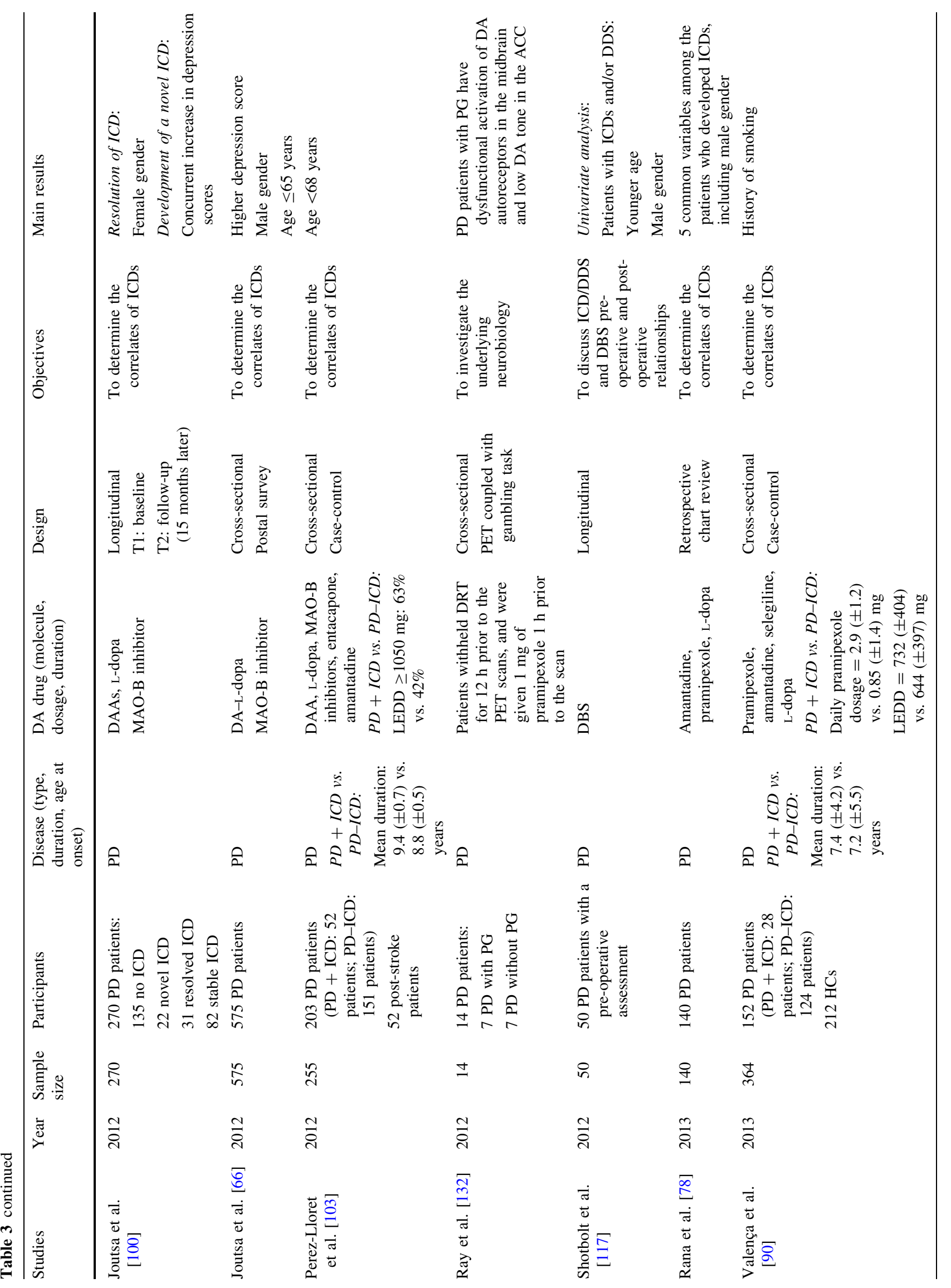




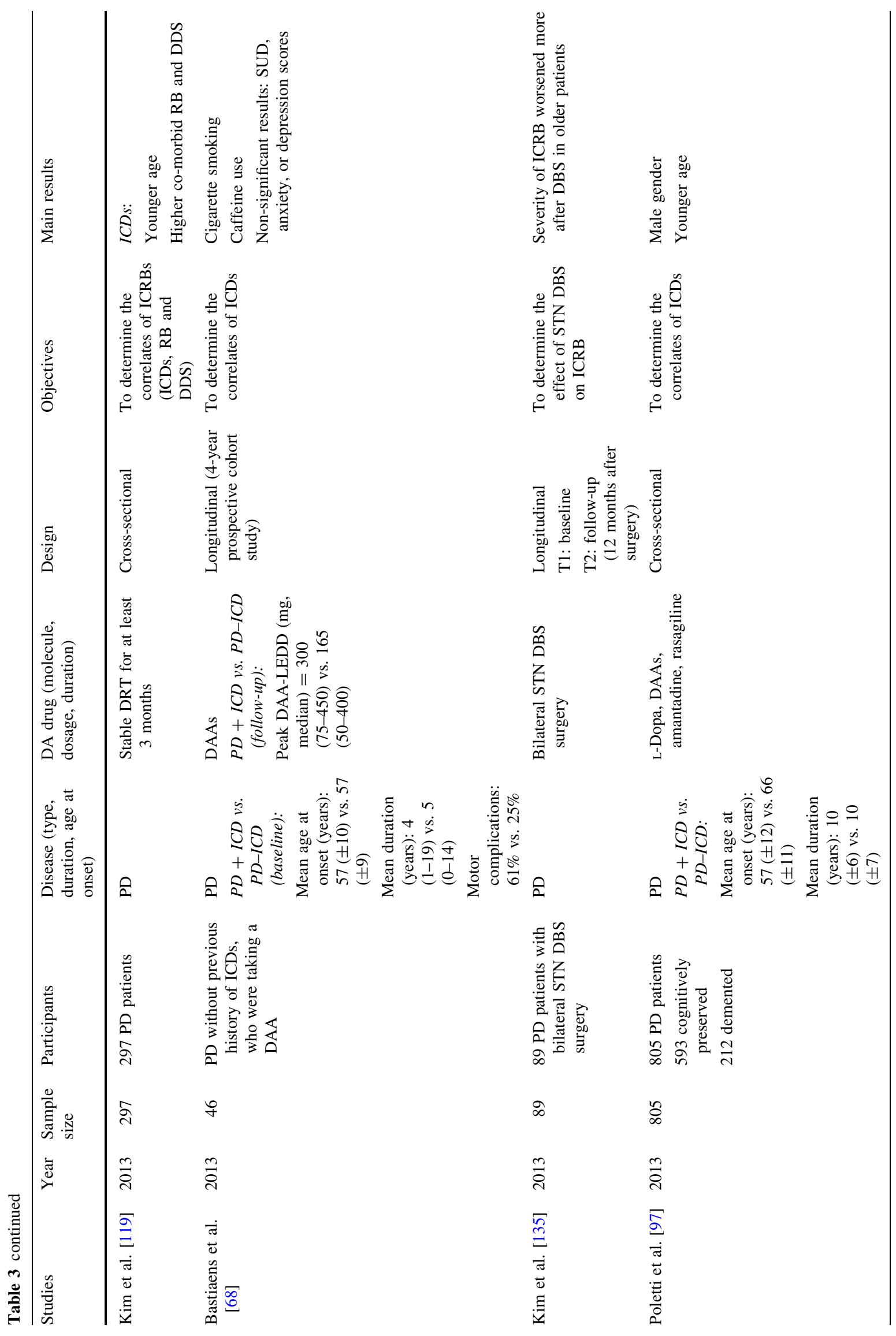




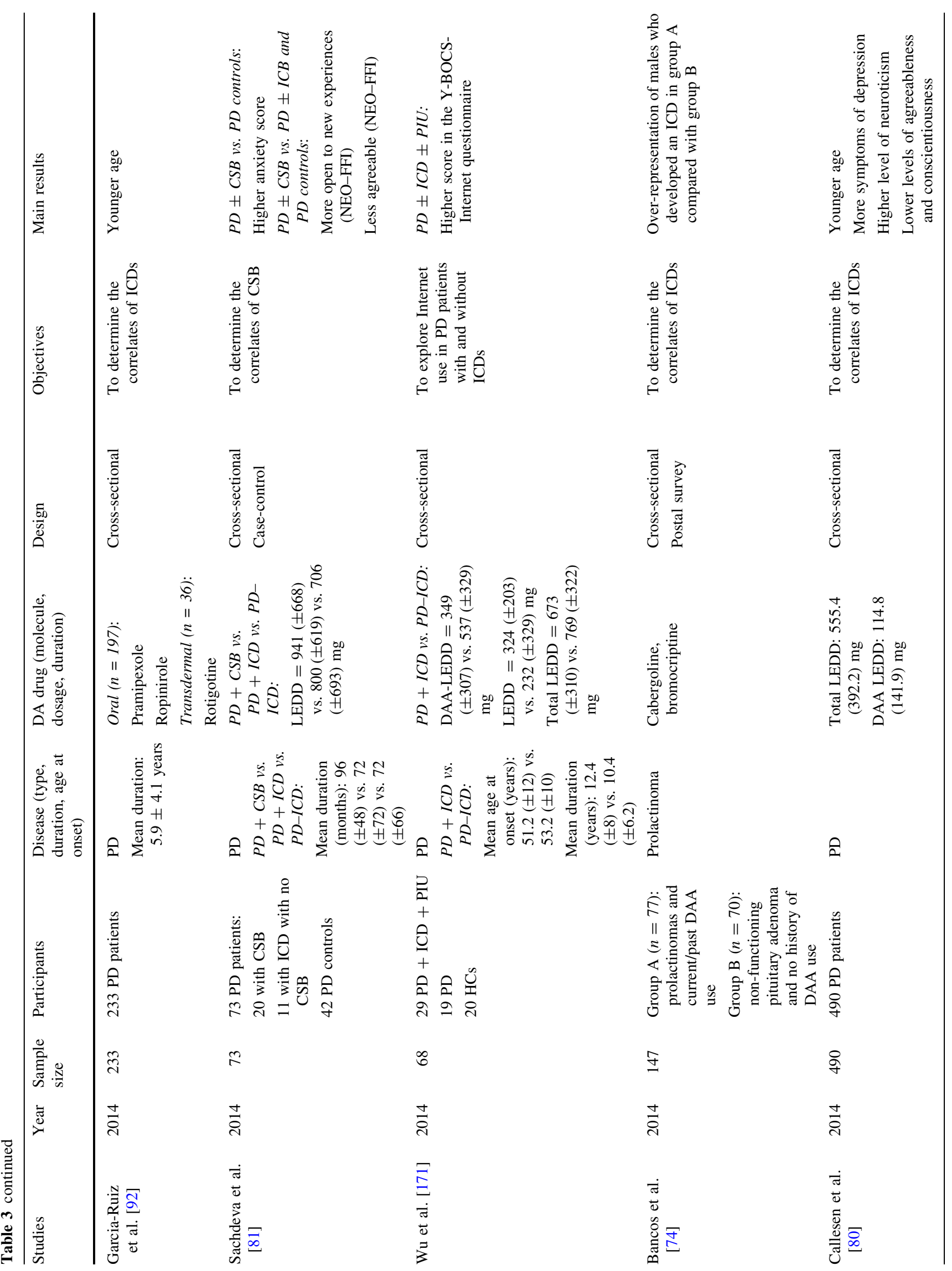




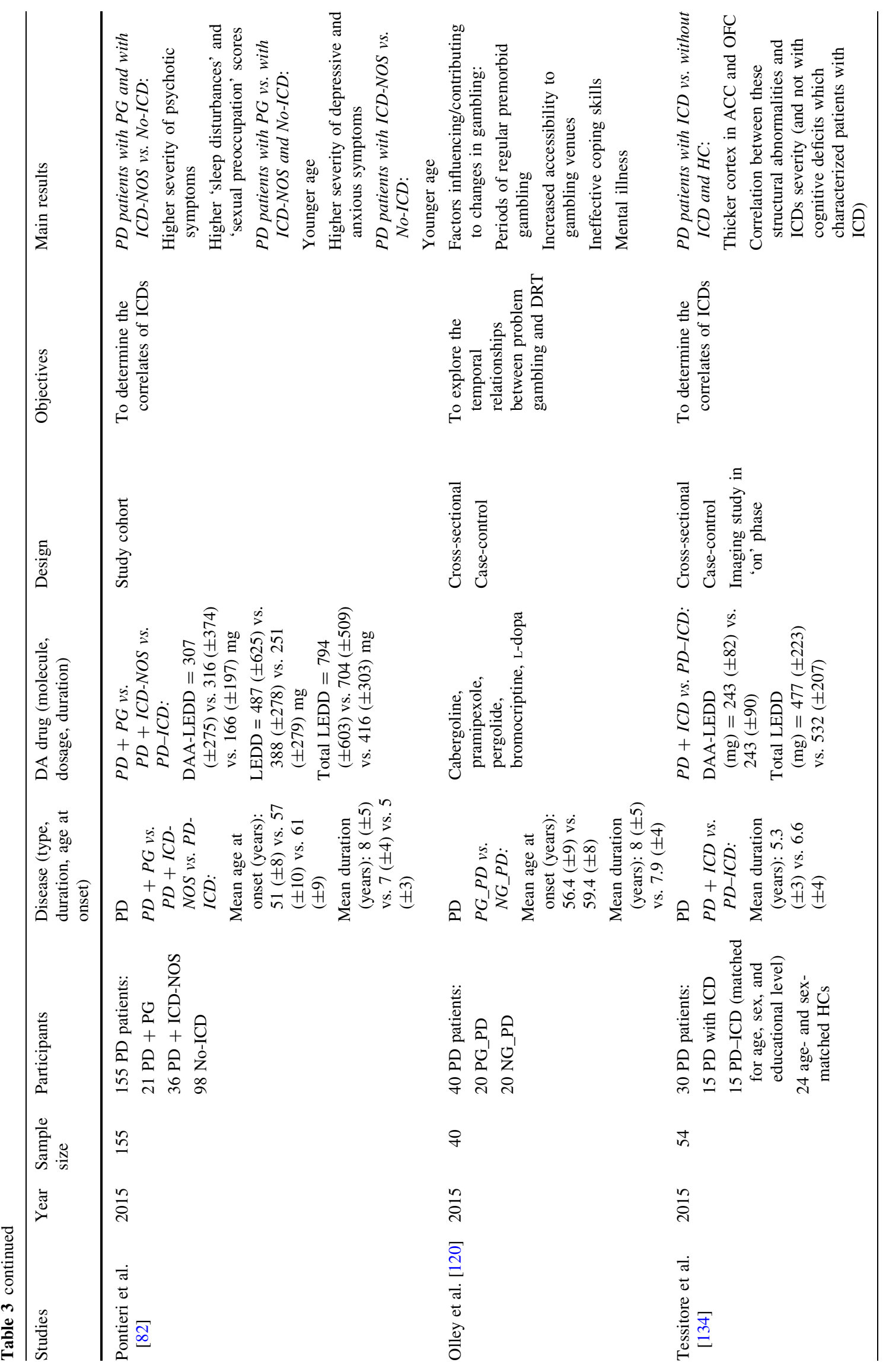




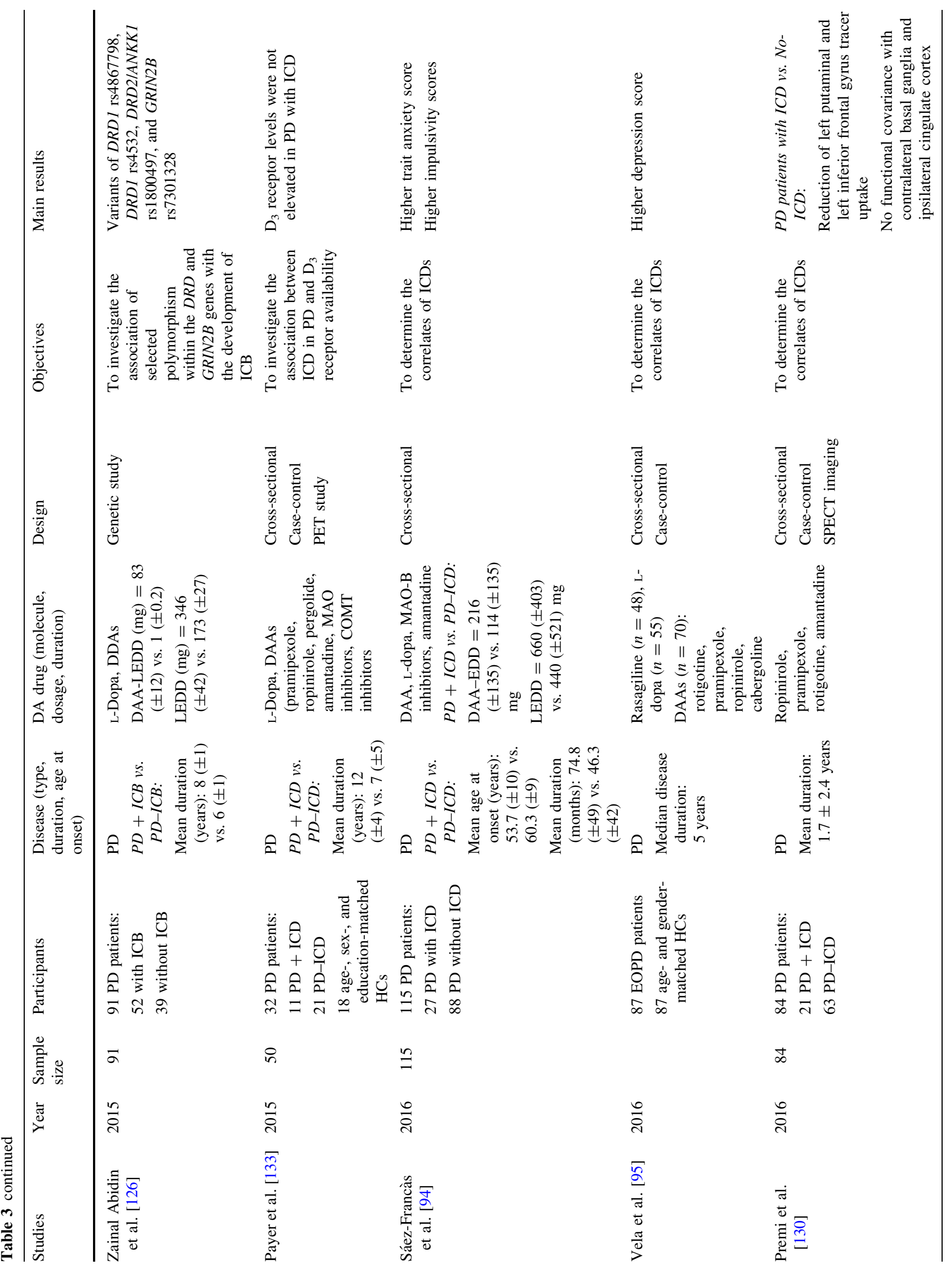




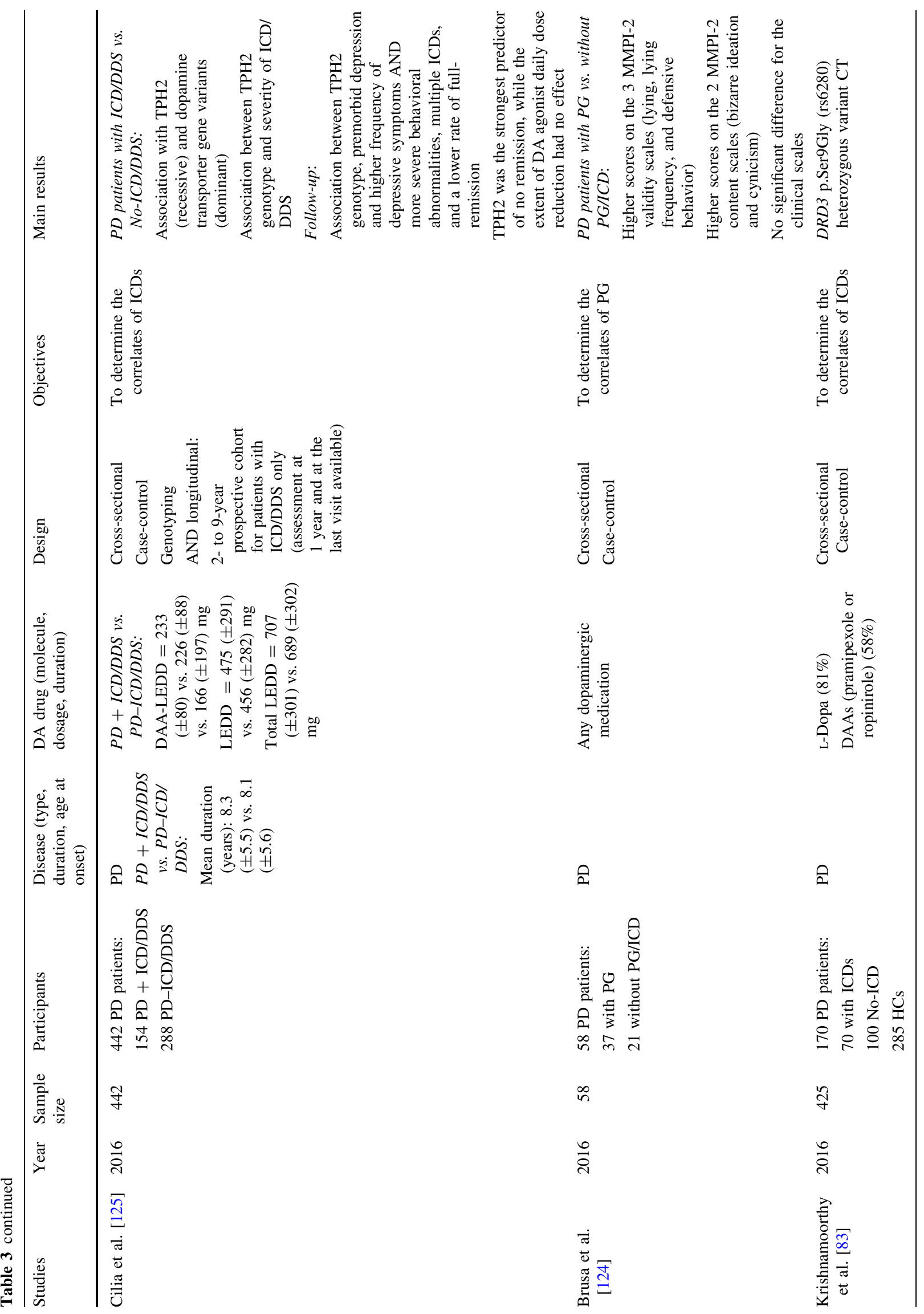




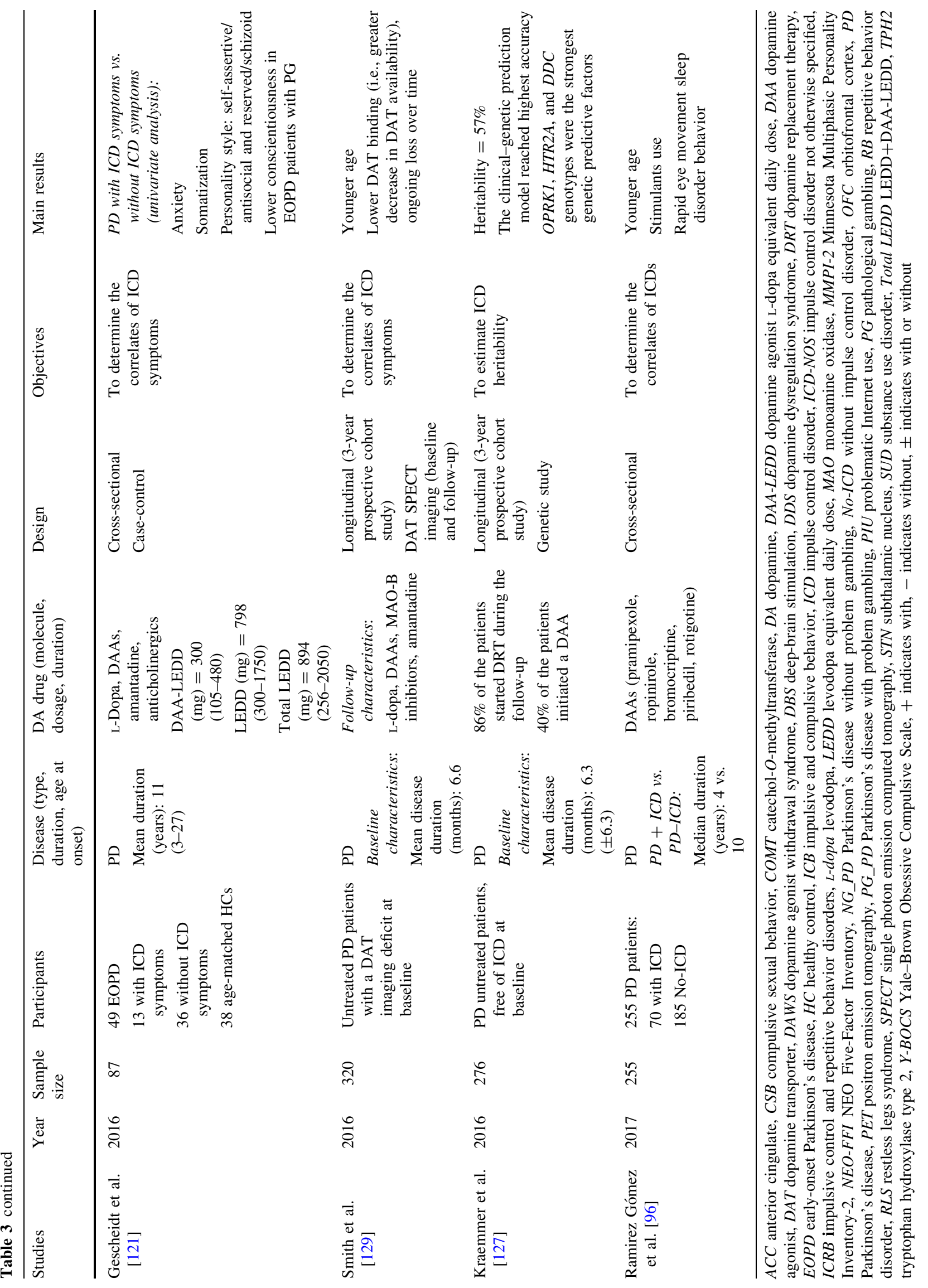




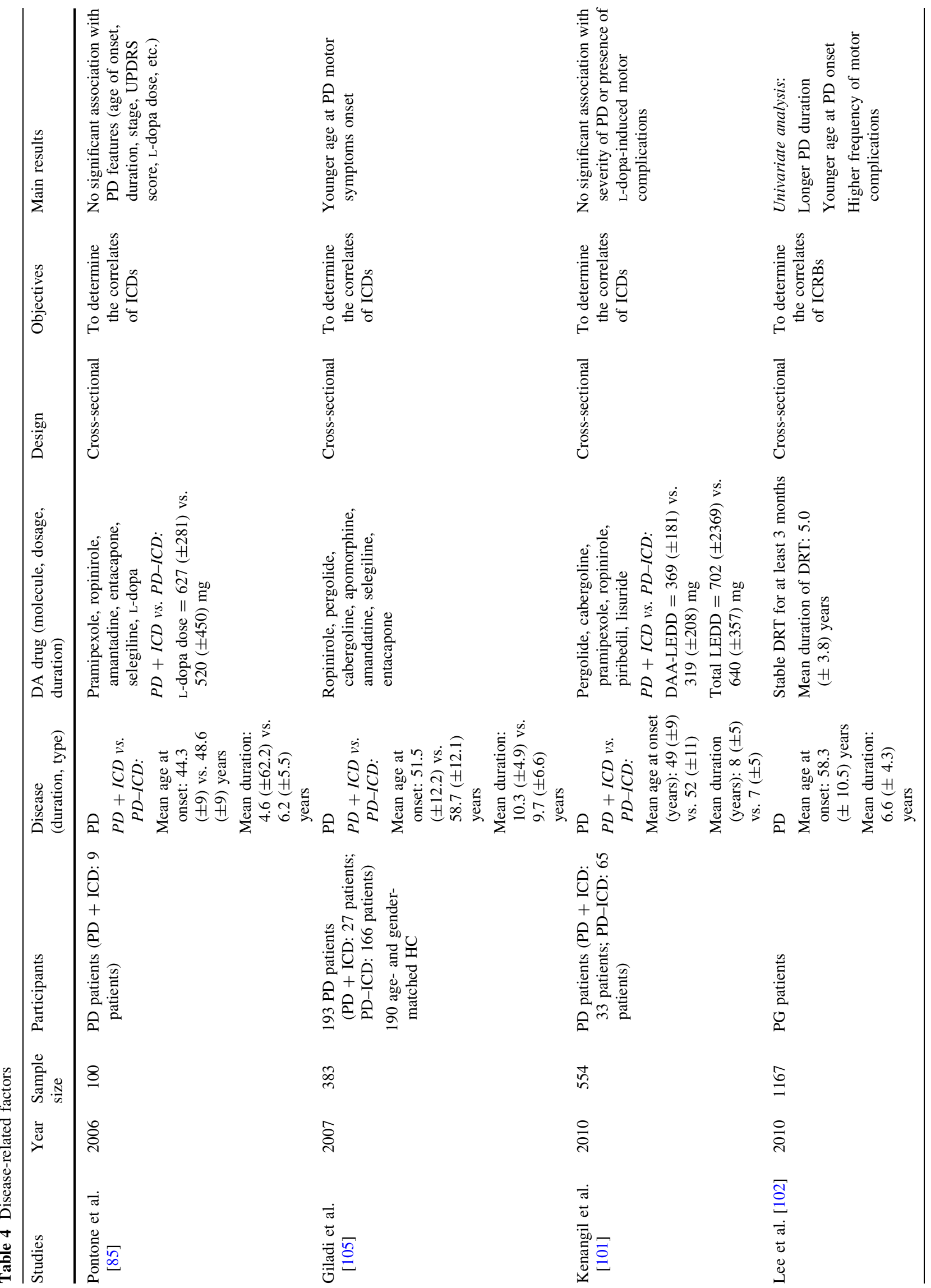




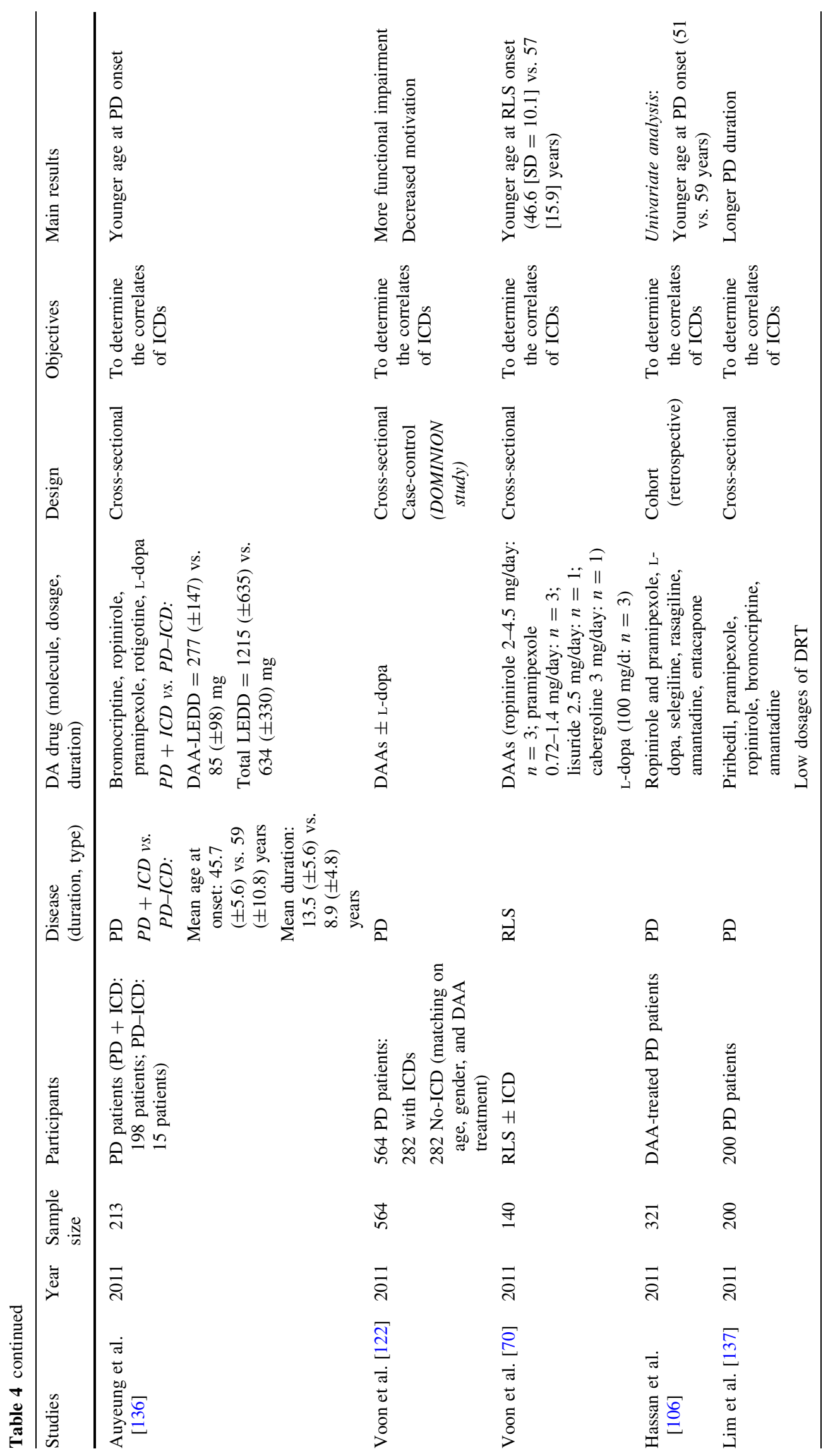




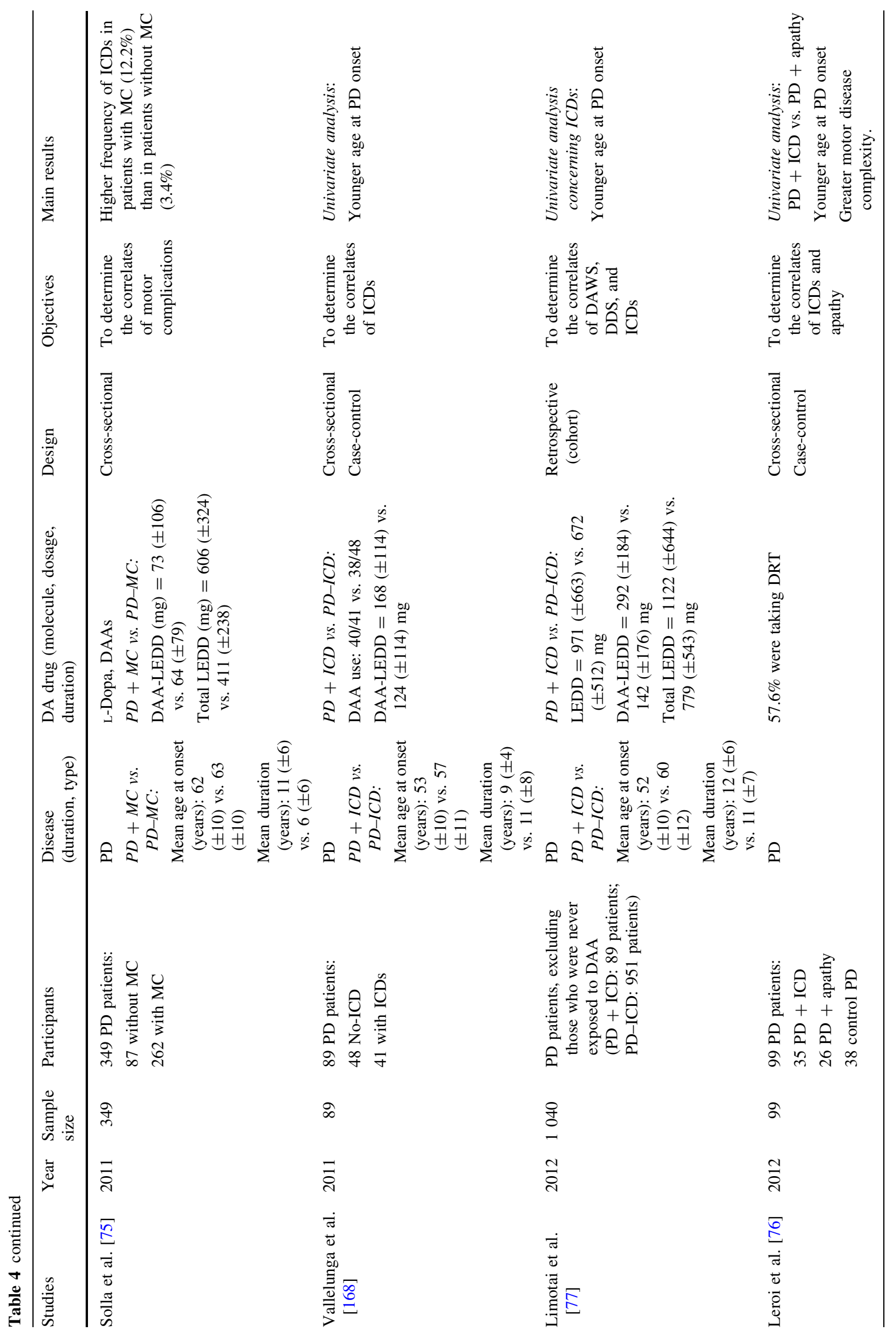




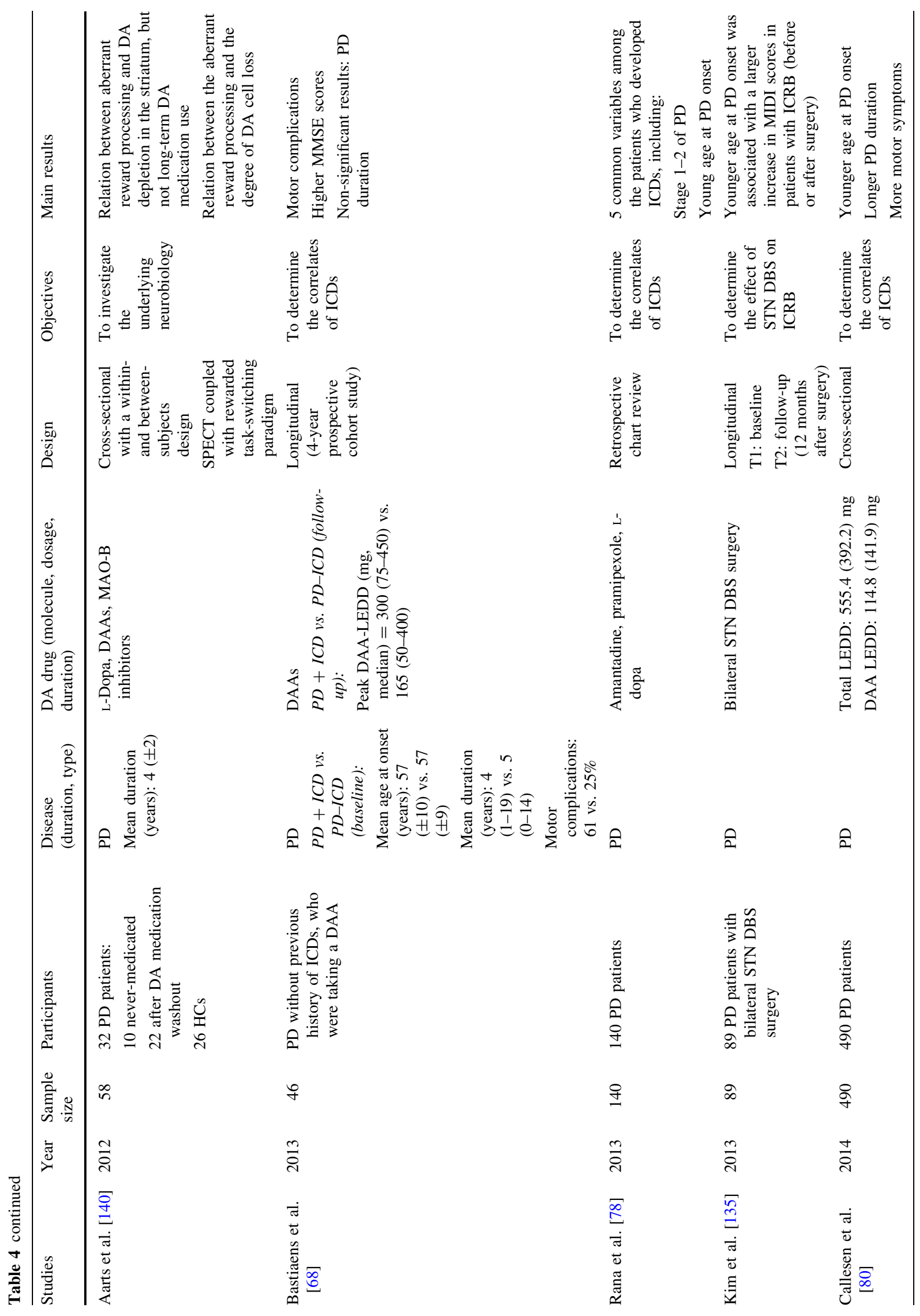




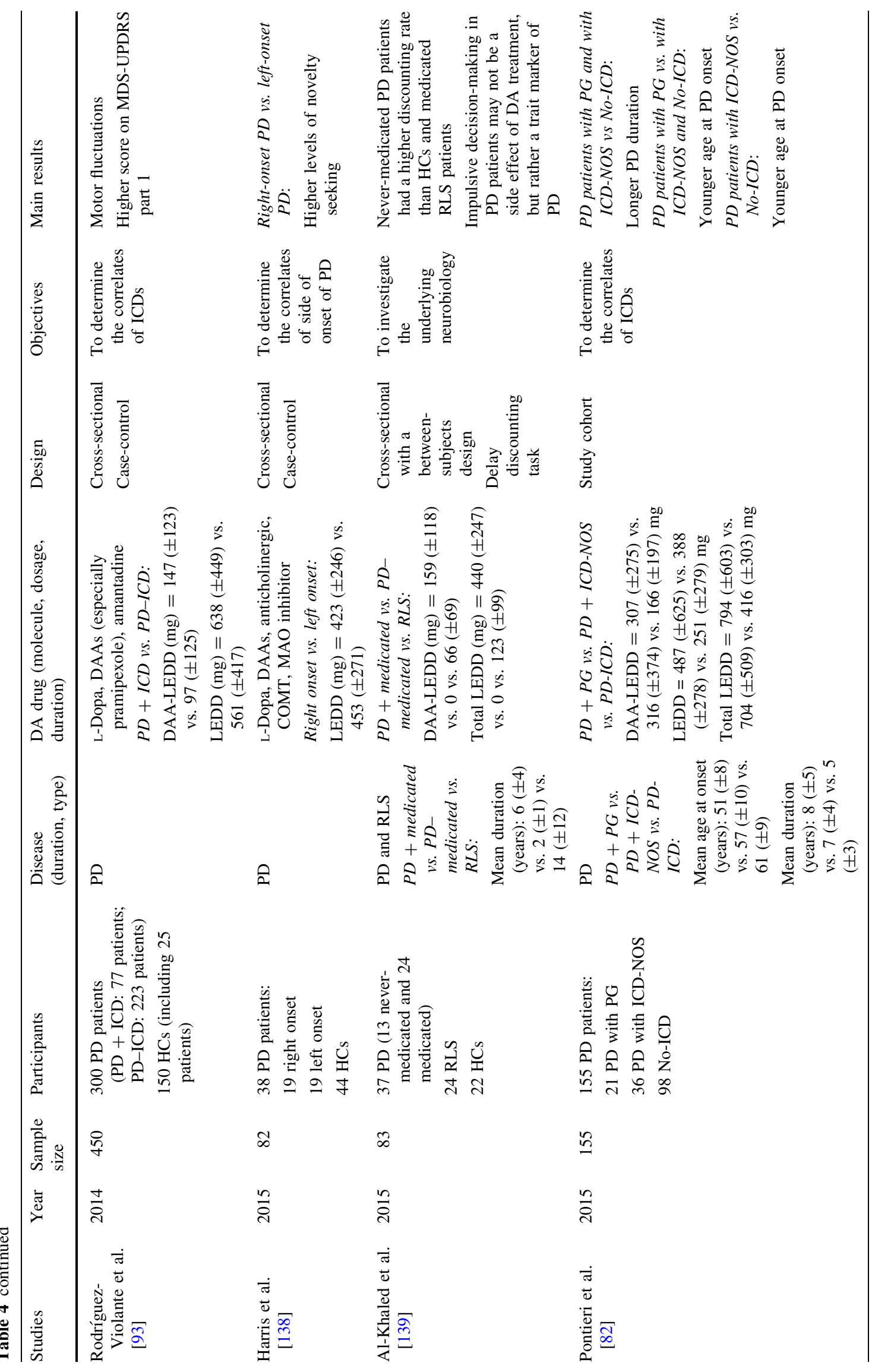




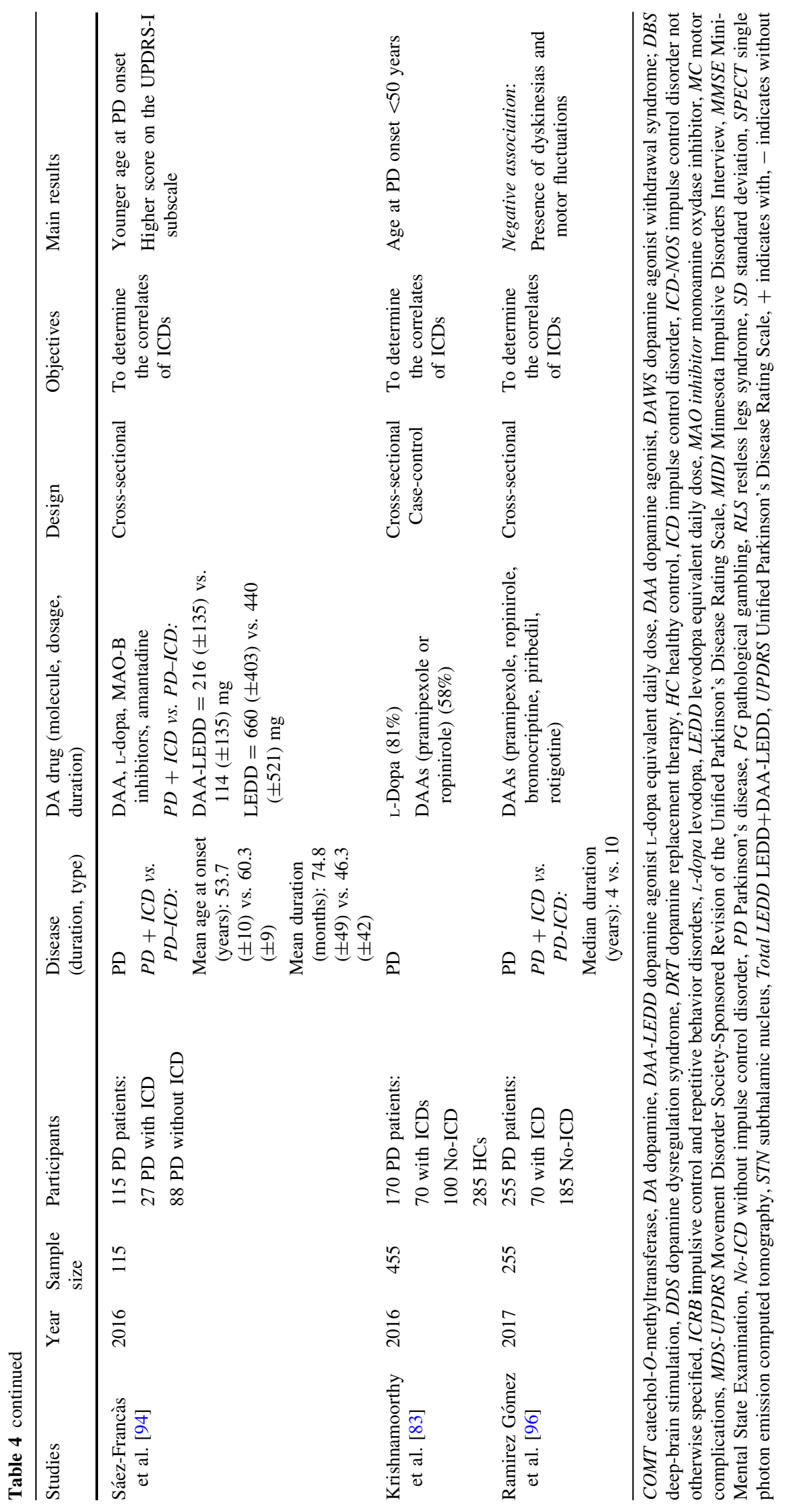




\section{References}

1. Rang HP, Dale MM, Ritter JM, Flower RJ, Henderson G. Rang \& Dale's pharmacology. 7th ed. Edinburgh: Elsevier Churchill Livingstone; 2012.

2. Ahlskog JE. Pathological behaviors provoked by dopamine agonist therapy of Parkinson's disease. Physiol Behav. 2011;104(1):168-72.

3. Seeman P. Parkinson's disease treatment may cause impulsecontrol disorder via dopamine D3 receptors. Synapse. 2015;69(4):183-9.

4. Holman AJ. Impulse control disorder behaviors associated with pramipexole used to treat fibromyalgia. J Gambl Stud. 2009;25(3):425-31.

5. Porta F, Ponzone A, Spada M. Long-term safety and effectiveness of pramipexole in tetrahydrobiopterin deficiency. Eur $\mathbf{J}$ Paediatr Neurol. 2016;20(6):839-42.

6. Seedat S, Kesler S, Niehaus DJ, Stein DJ. Pathological gambling behaviour: emergence secondary to treatment of Parkinson's disease with dopaminergic agents. Depress Anxiety. 2000;11(4):185-6.

7. Molina JA, Sainz-Artiga MJ, Fraile A, Jimenez-Jimenez FJ, Villanueva C, Orti-Pareja M, et al. Pathologic gambling in Parkinson's disease: a behavioral manifestation of pharmacologic treatment?. Mov Disord. 2000;15(5):869-72.

8. Gallagher DA, O'Sullivan SS, Evans AH, Lees AJ, Schrag A. Pathological gambling in Parkinson's disease: risk factors and differences from dopamine dysregulation. An analysis of published case series. Mov Disord. 2007;22(12):1757-63.

9. Grall-Bronnec M, Sauvaget A, Perrouin F, Leboucher J, Etcheverrigaray F, Challet-Bouju G, et al. Pathological gambling associated with aripiprazole or dopamine replacement therapy: do patients share the same features? A review. J Clin Psychopharmacol. 2016;36(1):63-70.

10. Voon V, Hassan K, Zurowski M, de Souza M, Thomsen T, Fox $\mathrm{S}$, et al. Prevalence of repetitive and reward-seeking behaviors in Parkinson's disease. Neurology. 2006;67(7):1254-7.

11. Weintraub D, Potenza MN. Impulse control disorders in Parkinson's disease. Curr Neurol Neurosci Rep. 2006;6(4):302-6.

12. APA. Diagnostic and statistical manual of mental disorders, fifth edition. Washington, DC: APA; 2013.

13. Atmaca M. Drug-induced impulse control disorders: a review. Curr Clin Pharmacol. 2014;9(1):70-4.

14. Dang D, Cunnington D, Swieca J. The emergence of devastating impulse control disorders during dopamine agonist therapy of the restless legs syndrome. Clin Neuropharmacol. 2011;34(2):66-70.

15. d'Orsi G, Demaio V, Specchio LM. Pathological gambling plus hypersexuality in restless legs syndrome: a new case. Neurol Sci. 2011;32(4):707-9.

16. Evans AH, Butzkueven H. Dopamine agonist-induced pathological gambling in restless legs syndrome due to multiple sclerosis. Mov Disord. 2007;22(4):590-1.

17. Evans AH, Stegeman JR. Punding in patients on dopamine agonists for restless leg syndrome. Mov Disord. 2009;24(1):140-1.

18. Jones HB, George S. 'You never told me I would turn into a gambler': a first person account of dopamine agonist-induced gambling addiction in a patient with restless legs syndrome. BMJ Case Rep. 2011;2011. doi:10.1136/bcr.07.2011.4459.

19. Kolla BP, Mansukhani MP, Barraza R, Bostwick JM. Impact of dopamine agonists on compulsive behaviors: a case series of pramipexole-induced pathological gambling. Psychosomatics. 2010;51(3):271-3.
20. Leu-Semenescu S, Karroum E, Brion A, Konofal E, Arnulf I. Dopamine dysregulation syndrome in a patient with restless legs syndrome. Sleep Med. 2009;10(4):494-6.

21. Quickfall J, Suchowersky O. Pathological gambling associated with dopamine agonist use in restless legs syndrome. Parkinsonism Relat Disord. 2007;13(8):535-6.

22. Schreglmann SR, Gantenbein AR, Eisele G, Baumann CR. Transdermal rotigotine causes impulse control disorders in patients with restless legs syndrome. Parkinsonism Relat Disord. 2012;18(2):207-9.

23. Tippmann-Peikert M, Park JG, Boeve BF, Shepard JW, Silber MH. Pathologic gambling in patients with restless legs syndrome treated with dopaminergic agonists. Neurology. 2007;68(4):301-3.

24. Almanzar S, Zapata-Vega MI, Raya JA. Dopamine agonist-induced impulse control disorders in a patient with prolactinoma. Psychosomatics. 2013;54(4):387-91.

25. Thondam SK, Alusi S, O'Driscoll K, Gilkes CE, Cuthbertson DJ, Daousi C. Impulse control disorder in a patient on long-term treatment with bromocriptine for a macroprolactinoma. Clin Neuropharmacol. 2013;36(5):170-2.

26. Aarons S, Peisah C, Wijeratne C. Neuropsychiatric effects of Parkinson's disease treatment. Australas J Ageing. 2012;31(3):198-202.

27. Alonso Cánovasa A, Luquin Piudo R, García Ruiz-Espigac P, Burguera JA, Campos Arillo V, Castro A, et al. Dopaminergic agonists in Parkinson's disease. Neurología (English Edition). 2014;29(4):230-41.

28. Ambermoon P, Carter A, Hall WD, Dissanayaka NN, O'Sullivan JD. Impulse control disorders in patients with Parkinson's disease receiving dopamine replacement therapy: evidence and implications for the addictions field. Addiction. 2011;106(2):283-93.

29. Antonelli F, Ray N, Strafella AP. Impulsivity and Parkinson's disease: more than just disinhibition. J Neurol Sci. 2011;310(1-2):202-7.

30. Antonini A, Tolosa E, Mizuno Y, Yamamoto M, Poewe WH. A reassessment of risks and benefits of dopamine agonists in Parkinson's disease. Lancet Neurol. 2009;8(10):929-37.

31. Balarajah S, Cavanna AE. The pathophysiology of impulse control disorders in Parkinson disease. Behav Neurol. 2013;26(4):237-44.

32. Bugalho P, Oliveira-Maia AJ. Impulse control disorders in Parkinson's disease: crossroads between neurology, psychiatry and neuroscience. Behav Neurol. 2013;27(4):547-57.

33. Cilia R. How neurodegeneration, dopamine and maladaptive behavioral learning interact to produce impulse control disorders in Parkinson's disease. Basal Ganglia. 2012;2(4):195-9.

34. Cilia R, van Eimeren T. Impulse control disorders in Parkinson's disease: seeking a roadmap toward a better understanding. Brain Struct Funct. 2011;216(4):289-99.

35. Dagher A, Robbins TW. Personality, addiction, dopamine: insights from Parkinson's disease. Neuron. 2009;61(4):502-10.

36. Delaney M, Leroi I, Simpson J, Overton PG. Impulse control disorders in Parkinson's disease: a psychosocial perspective. J Clin Psychol Med Settings. 2012;19(3):338-46.

37. Djamshidian A, Averbeck BB, Lees AJ, O’Sullivan SS. Clinical aspects of impulsive compulsive behaviours in Parkinson's disease. J Neurol Sci. 2011;310(1-2):183-8.

38. Djamshidian A, Cardoso F, Grosset D, Bowden-Jones H, Lees AJ. Pathological gambling in Parkinson's disease-a review of the literature. Mov Disord. 2011;26(11):1976-84.

39. Driver-Dunckley E, Samanta J, Stacy M. Pathological gambling associated with dopamine agonist therapy in Parkinson's disease. Neurology. 2003;61(3):422-3. 
40. Evans A. Dopamine agonist-induced substance addiction: the next piece of the puzzle. J Clin Neurosci. 2011;18(2):191-2.

41. Evans AH, Strafella AP, Weintraub D, Stacy M. Impulsive and compulsive behaviors in Parkinson's disease. Mov Disord. 2009;24(11):1561-70.

42. Fenu S, Wardas J, Morelli M. Impulse control disorders and dopamine dysregulation syndrome associated with dopamine agonist therapy in Parkinson's disease. Behav Pharmacol. 2009;20(5-6):363-79.

43. Grosset D. Dopamine agonists and therapy compliance. Neurol Sci. 2008;29(Suppl 5):S375-6.

44. Hou J-GG, Lai EC. Non-motor symptoms of Parkinson's disease. Int J Gerontol. 2007;1(2):53-64.

45. Jiménez-Urbieta H, Gago B, de la Riva P, Delgado-Alvarado M, Marin C, Rodriguez-Oroz MC. Dyskinesias and impulse control disorders in Parkinson's disease: from pathogenesis to potential therapeutic approaches. Neurosci Biobehav Rev. 2015;56:294-314.

46. Katzenschlager R. Dopaminergic dysregulation syndrome in Parkinson's disease. J Neurol Sci. 2011;310(1-2):271-5.

47. Lee JY, Jeon BS. Maladaptive reward-learning and impulse control disorders in patients with Parkinson's disease: a clinical overview and pathophysiology update. J Mov Disord. 2014;7(2):67-76.

48. Nakum S, Cavanna AE. The prevalence and clinical characteristics of hypersexuality in patients with Parkinson's disease following dopaminergic therapy: a systematic literature review. Parkinsonism Relat Disord. 2016;25:10-6.

49. Pirritano D, Plastino M, Bosco D, Gallelli L, Siniscalchi A, De Sarro G. Gambling disorder during dopamine replacement treatment in Parkinson's disease: a comprehensive review. Biomed Res Int. 2014;2014:728038.

50. Poletti M, Bonuccelli U. Impulse control disorders in Parkinson's disease: the role of personality and cognitive status. J Neurol. 2012;259(11):2269-77.

51. Samuel M, Rodriguez-Oroz M, Antonini A, Brotchie JM, Ray Chaudhuri K, Brown RG, et al. Management of impulse control disorders in Parkinson's disease: controversies and future approaches. Mov Disord. 2015;30(2):150-9.

52. Santangelo G, Barone P, Trojano L, Vitale C. Pathological gambling in Parkinson's disease. A comprehensive review. Parkinsonism Relat Disord. 2013;19(7):645-53.

53. Sierra M, Carnicella S, Strafella AP, Bichon A, Lhommée E, Castrioto A, et al. Apathy and impulse control disorders: yin \& yang of dopamine dependent behaviors. J Parkinsons Dis. 2015;5(3):625-36.

54. Stocchi F. Pathological gambling in Parkinson's disease. Lancet Neurol. 2005;4(10):590-2.

55. Tanwani P, Fernie BA, Nikčević AV, Spada MM. A systematic review of treatments for impulse control disorders and related behaviours in Parkinson's disease. Psychiatry Res. 2015;225(3):402-6.

56. Villa C, Pascual-Sedano B, Pagonabarraga J, Kulisevsky J. Impulse control disorders and dopaminergic treatments in Parkinson's disease. Rev Neurol (Paris). 2011;167(11): 827-32.

57. Voon V, Fernagut P-O, Wickens J, Baunez C, Rodriguez M, Pavon N, et al. Chronic dopaminergic stimulation in Parkinson's disease: from dyskinesias to impulse control disorders. Lancet Neurol. 2009;8(12):1140-9.

58. Voon V, Potenza MN, Thomsen T. Medication-related impulse control and repetitive behaviors in Parkinson's disease. Curr Opin Neurol. 2007;20(4):484-92.

59. Vriend C, Pattij T, van der Werf YD, Voorn P, Booij J, Rutten S, et al. Depression and impulse control disorders in Parkinson's disease: two sides of the same coin? Neurosci Biobehav Rev. 2014;38:60-71.
60. Weintraub D. Dopamine and impulse control disorders in Parkinson's disease. Ann Neurol. 2008;64(Suppl 2):S93-100.

61. Weintraub D, David AS, Evans AH, Grant JE, Stacy M. Clinical spectrum of impulse control disorders in Parkinson's disease. Mov Disord. 2015;30(2):121-7.

62. Wu K, Politis M, Piccini P. Parkinson disease and impulse control disorders: a review of clinical features, pathophysiology and management. Postgrad Med J. 1009;2009(85):590-6.

63. Zand R. Is dopamine agonist therapy associated with developing pathological gambling in Parkinson's disease patients? Eur Neurol. 2008;59(3-4):183-6.

64. Moher D, Liberati A, Tetzlaff J, Altman DG. Preferred reporting items for systematic reviews and meta-analyses: the PRISMA statement. J Clin Epidemiol. 2009;62(10):1006-12.

65. Bostwick JM, Hecksel KA, Stevens SR, Bower JH, Ahlskog JE. Frequency of new-onset pathologic compulsive gambling or hypersexuality after drug treatment of idiopathic Parkinson disease. Mayo Clin Proc. 2009;84(4):310-6.

66. Joutsa J, Martikainen K, Vahlberg T, Voon V, Kaasinen V. Impulse control disorders and depression in Finnish patients with Parkinson's disease. Parkinsonism Relat Disord. 2012;18(2):155-60.

67. Tomlinson CL, Stowe R, Patel S, Rick C, Gray R, Clarke CE. Systematic review of levodopa dose equivalency reporting in Parkinson's disease. Mov Disord. 2010;25(15):2649-53.

68. Bastiaens J, Dorfman BJ, Christos PJ, Nirenberg MJ. Prospective cohort study of impulse control disorders in Parkinson's disease. Mov Disord. 2013;28(3):327-33.

69. van Holst RJ, van den Brink W, Veltman DJ, Goudriaan AE. Why gamblers fail to win: a review of cognitive and neuroimaging findings in pathological gambling. Neurosci Biobehav Rev. 2010;34(1):87-107.

70. Voon V, Schoerling A, Wenzel S, Ekanayake V, Reiff J, Trenkwalder C, et al. Frequency of impulse control behaviours associated with dopaminergic therapy in restless legs syndrome. BMC Neurol. 2011;11:117.

71. Driver-Dunckley ED, Noble BN, Hentz JG, Evidente VG, Caviness JN, Parish J, et al. Gambling and increased sexual desire with dopaminergic medications in restless legs syndrome. Clin Neuropharmacol. 2007;30(5):249-55.

72. Bayard S, Langenier MC, Dauvilliers Y. Decision-making, reward-seeking behaviors and dopamine agonist therapy in restless legs syndrome. Sleep. 2013;36(10):1501-7.

73. Martinkova J, Trejbalova L, Sasikova M, Benetin J, Valkovic P. Impulse control disorders associated with dopaminergic medication in patients with pituitary adenomas. Clin Neuropharmacol. 2011;34(5):179-81.

74. Bancos I, Nannenga MR, Bostwick JM, Silber MH, Erickson D, Nippoldt TB. Impulse control disorders in patients with dopamine agonist-treated prolactinomas and nonfunctioning pituitary adenomas: a case-control study. Clin Endocrinol (Oxf). 2014;80(6):863-8.

75. Solla P, Cannas A, Floris GL, Orofino G, Costantino E, Boi A, et al. Behavioral, neuropsychiatric and cognitive disorders in Parkinson's disease patients with and without motor complications. Prog Neuropsychopharmacol Biol Psychiatry. 2011;35(4):1009-13.

76. Leroi I, Andrews M, McDonald K, Harbishettar V, Elliott R, Byrne EJ, et al. Apathy and impulse control disorders in Parkinson's disease: a direct comparison. Parkinsonism Relat Disord. 2012;18(2):198-203.

77. Limotai N, Oyama G, Go C, Bernal O, Ong T, Moum SJ, et al. Addiction-like manifestations and Parkinson's disease: a large single center 9-year experience. Int $\mathbf{J}$ Neurosci. 2012;122(3):145-53.

78. Rana AQ, Mansoor W, Hussaini S, Al Mosabbir A, Rahman M, Rahman L. Factors associated with the development of impulse 
compulsive disorders in Parkinson patients. Int $\mathrm{J}$ Neurosci. 2013;123(7):503-6.

79. Leroi I, Barraclough M, McKie S, Hinvest N, Evans J, Elliott R, et al. Dopaminergic influences on executive function and impulsive behaviour in impulse control disorders in Parkinson's disease. J Neuropsychol. 2013;7(2):306-25.

80. Callesen MB, Weintraub D, Damholdt MF, Møller A. Impulsive and compulsive behaviors among Danish patients with Parkinson's disease: prevalence, depression, and personality. Parkinsonism Relat Disord. 2014;20(1):22-6.

81. Sachdeva J, Harbishettar V, Barraclough M, McDonald K, Leroi I. Clinical profile of compulsive sexual behaviour and paraphilia in Parkinson's disease. J Parkinsons Dis. 2014;4(4):665-70.

82. Pontieri FE, Assogna F, Pellicano C, Cacciari C, Pannunzi S, Morrone A, et al. Sociodemographic, neuropsychiatric and cognitive characteristics of pathological gambling and impulse control disorders NOS in Parkinson's disease. Eur Neuropsychopharmacol. 2015;25(1):69-76.

83. Krishnamoorthy S, Rajan R, Banerjee M, Kumar H, Sarma G, Krishnan S, et al. Dopamine D3 receptor Ser9Gly variant is associated with impulse control disorders in Parkinson's disease patients. Parkinsonism Relat Disord. 2016;30:13-7.

84. Weintraub D, Koester J, Potenza MN, Siderowf AD, Stacy M, Voon $\mathrm{V}$, et al. Impulse control disorders in Parkinson disease: a crosssectional study of 3090 patients. Arch Neurol. 2010;67(5):589-95.

85. Pontone G, Williams JR, Bassett SS, Marsh L. Clinical features associated with impulse control disorders in Parkinson disease. Neurology. 2006;67(7):1258-61.

86. Weintraub D, Siderowf AD, Potenza MN, Goveas J, Morales $\mathrm{KH}$, Duda JE, et al. Association of dopamine agonist use with impulse control disorders in Parkinson disease. Arch Neurol. 2006;63(7):969-73.

87. Crockford D, Quickfall J, Currie S, Furtado S, Suchowersky O, El-Guebaly N. Prevalence of problem and pathological gambling in Parkinson's disease. J Gambl Stud. 2008;24(4):411-22.

88. Fan W, Ding H, Ma J, Chan P. Impulse control disorders in Parkinson's disease in a Chinese population. Neurosci Lett. 2009;465(1):6-9.

89. Politis M, Loane C, Wu K, O'Sullivan SS, Woodhead Z, Kiferle $\mathrm{L}$, et al. Neural response to visual sexual cues in dopamine treatment-linked hypersexuality in Parkinson's disease. Brain. 2013;136(Pt 2):400-11.

90. Valença GT, Glass PG, Negreiros NN, Duarte MB, Ventura LM, Mueller M, et al. Past smoking and current dopamine agonist use show an independent and dose-dependent association with impulse control disorders in Parkinson's disease. Parkinsonism Relat Disord. 2013;19(7):698-700.

91. Moore TJ, Glenmullen J, Mattison DR. Reports of pathological gambling, hypersexuality, and compulsive shopping associated with dopamine receptor agonist drugs. JAMA Intern Med. 2014;174(12):1930-3.

92. Garcia-Ruiz PJ, Martinez Castrillo JC, Alonso-Canovas A, Herranz Barcenas A, Vela L, Sanchez Alonso P, et al. Impulse control disorder in patients with Parkinson's disease under dopamine agonist therapy: a multicentre study. J Neurol Neurosurg Psychiatry. 2014;85(8):840-4.

93. Rodríguez-Violante M, González-Latapi P, Cervantes-Arriaga A, Camacho-Ordoñez A, Weintraub D. Impulse control and related disorders in Mexican Parkinson's disease patients. Parkinsonism Relat Disord. 2014;20(8):907-10.

94. Sáez-Francàs N, Martí Andrès G, Ramírez N, de Fàbregues O, Álvarez-Sabín J, Casas M, et al. Clinical and psychopathological factors associated with impulse control disorders in Parkinson's disease. Neurología (English Edition). 2016;31(4):231-8.

95. Vela L, Martínez Castrillo JC, García Ruiz P, Gasca-Salas C, Macías Macías Y, Pérez Fernández E, et al. The high prevalence of impulse control behaviors in patients with early-onset Parkinson's disease: a cross-sectional multicenter study. J Neurol Sci. 2016;368:150-4.

96. Ramirez Gómez CC, Serrano Dueñas M, Bernal O, Araoz N, Sáenz Farret M, Aldinio V, et al. A multicenter comparative study of impulse control disorder in Latin American patients with Parkinson disease. Clin Neuropharmacol. 2017;40(2):51-5.

97. Poletti M, Logi C, Lucetti C, Del Dotto P, Baldacci F, Vergallo A, et al. A single-center, cross-sectional prevalence study of impulse control disorders in Parkinson disease: association with dopaminergic drugs. J Clin Psychopharmacol. 2013;33(5):691-4.

98. Grosset KA, Macphee G, Pal G, Stewart D, Watt A, Davie J, et al. Problematic gambling on dopamine agonists: not such a rarity. Mov Disord. 2006;21(12):2206-8.

99. Ye Z, Hammer A, Camara E, Munte TF. Pramipexole modulates the neural network of reward anticipation. Hum Brain Mapp. 2011;32(5):800-11.

100. Joutsa J, Martikainen K, Vahlberg T, Kaasinen V. Effects of dopamine agonist dose and gender on the prognosis of impulse control disorders in Parkinson's disease. Parkinsonism Relat Disord. 2012;18(10):1079-83.

101. Kenangil G, Ozekmekci S, Sohtaoglu M, Erginoz E. Compulsive behaviors in patients with Parkinson's disease. Neurologist. 2010;16(3): 192-5.

102. Lee J-Y, Kim J-M, Kim JW, Cho J, Lee WY, Kim H-J, et al. Association between the dose of dopaminergic medication and the behavioral disturbances in Parkinson disease. Parkinsonism Relat Disord. 2010;16(3):202-7.

103. Perez-Lloret S, Rey MV, Fabre N, Ory F, Spampinato U, BrefelCourbon C, et al. Prevalence and pharmacological factors associated with impulse-control disorder symptoms in patients with Parkinson disease. Clin Neuropharmacol. 2012;35(6):261-5.

104. Sohtaoglu M, Demiray DY, Kenangil G, Ozekmekci S, Erginoz E. Long term follow-up of Parkinson's disease patients with impulse control disorders. Parkinsonism Relat Disord. 2010;16(5):334-7.

105. Giladi N, Weitzman N, Schreiber S, Shabtai H, Peretz C. New onset heightened interest or drive for gambling, shopping, eating or sexual activity in patients with Parkinson's disease: the role of dopamine agonist treatment and age at motor symptoms onset. J Psychopharmacol. 2007;21(5):501-6.

106. Hassan A, Bower JH, Kumar N, Matsumoto JY, Fealey RD, Josephs KA, et al. Dopamine agonist-triggered pathological behaviors: surveillance in the PD clinic reveals high frequencies. Parkinsonism Relat Disord. 2011;17(4):260-4.

107. Antonini A, Chaudhuri KR, Boroojerdi B, Asgharnejad M, Bauer L, Grieger F, et al. Impulse control disorder related behaviours during long-term rotigotine treatment: a post hoc analysis. Eur J Neurol. 2016;23(10):1556-65.

108. Todorova A, Samuel M, Brown RG, Chaudhuri KR. Infusion therapies and development of impulse control disorders in advanced Parkinson disease: clinical experience after 3 years' follow-up. Clin Neuropharmacol. 2015;38(4):132-4.

109. Abler B, Hahlbrock R, Unrath A, Gron G, Kassubek J. At-risk for pathological gambling: imaging neural reward processing under chronic dopamine agonists. Brain. 2009;132(Pt 9):2396-402.

110. van Eimeren T, Ballanger B, Pellecchia G, Miyasaki JM, Lang AE, Strafella AP. Dopamine agonists diminish value sensitivity of the orbitofrontal cortex: a trigger for pathological gambling in Parkinson's disease? Neuropsychopharmacology. 2009;34(13):2758-66.

111. van Eimeren T, Pellecchia G, Cilia R, Ballanger B, Steeves TD, Houle $\mathrm{S}$, et al. Drug-induced deactivation of inhibitory networks predicts pathological gambling in PD. Neurology. 2010;75(19):1711-6.

112. Voon V, Reynolds B, Brezing C, Gallea C, Skaljic M, Ekanayake $\mathrm{V}$, et al. Impulsive choice and response in dopamine 
agonist-related impulse control behaviors. Psychopharmacology. 2010;207(4):645-59.

113. Djamshidian A, O'Sullivan SS, Lawrence AD, Foltynie T, Aviles-Olmos I, Magdalinou N, et al. Perceptual decisionmaking in patients with Parkinson's disease. J Psychopharmacol. 2014;28(12):1149-54.

114. Voon V, Gao J, Brezing C, Symmonds M, Ekanayake V, Fernandez $\mathrm{H}$, et al. Dopamine agonists and risk: impulse control disorders in Parkinson's disease. Brain. 2011;134(Pt 5):1438-46.

115. Claassen DO, van den Wildenberg WP, Ridderinkhof KR, Jessup CK, Harrison MB, Wooten GF, et al. The risky business of dopamine agonists in Parkinson disease and impulse control disorders. Behav Neurosci. 2011;125(4):492-500.

116. Claassen DO, van den Wildenberg WP, Harrison MB, van Wouwe NC, Kanoff K, Neimat JS, et al. Proficient motor impulse control in Parkinson disease patients with impulsive and compulsive behaviors. Pharmacol Biochem Behav. 2015;129:19-25.

117. Shotbolt P, Moriarty J, Costello A, Jha A, David A, Ashkan K, et al. Relationships between deep brain stimulation and impulse control disorders in Parkinson's disease, with a literature review. Parkinsonism Relat Disord. 2012;18(1):10-6.

118. Vallelunga A, Flaibani R, Formento-Dojot P, Biundo R, Facchini S, Antonini A. Role of genetic polymorphisms of the dopaminergic system in Parkinson's disease patients with impulse control disorders. Parkinsonism Relat Disord. 2012;18(4):397-9.

119. Kim J, Kim M, Kwon DY, Seo WK, Kim JH, Baik JS, et al. Clinical characteristics of impulse control and repetitive behavior disorders in Parkinson's disease. J Neurol. 2013;260(2):429-37.

120. Olley J, Blaszczynski A, Lewis S. Dopaminergic medication in Parkinson's disease and problem gambling. J Gambl Stud. 2015;31(3):1085-106.

121. Gescheidt T, Majerová V, Menšíková K, Dušek L, Czekóová K, Kotková P, et al. ID 16-Impulse control disorders in young-onset patients with Parkinson's disease: Cross-sectional study seeking associated factors with regard of personal characteristics. Clin Neurophysiol. 2016;127(3):e70.

122. Voon V, Sohr M, Lang AE, Potenza MN, Siderowf AD, Whetteckey $\mathrm{J}$, et al. Impulse control disorders in Parkinson disease: a multicenter case-control study. Ann Neurol. 2011;69(6):986-96.

123. Pourcher E, Remillard S, Cohen H. Compulsive habits in restless legs syndrome patients under dopaminergic treatment. J Neurol Sci. 2010;290(1-2):52-6.

124. Brusa L, Pavino V, Massimetti MC, Ceravolo R, Stefani S, Stanzione P. Pathological gambling in Parkinson's disease patients: dopaminergic medication or personality traits fault? J Neurol Sci. 2016;366:167-70.

125. Cilia R, Benfante R, Asselta R, Marabini L, Cereda E, Siri C, et al. Tryptophan hydroxylase type 2 variants modulate severity and outcome of addictive behaviors in Parkinson's disease. Parkinsonism Relat Disord. 2016;29:96-103.

126. Zainal Abidin S, Tan EL, Chan SC, Jaafar A, Lee AX, Abd Hamid MH, et al. DRD and GRIN2B polymorphisms and their association with the development of impulse control behaviour among Malaysian Parkinson's disease patients. BMC Neurol. 2015;15:59.

127. Kraemmer J, Smith K, Weintraub D, Guillemot V, Nalls MA, Cormier-Dequaire $\mathrm{F}$, et al. Clinical-genetic model predicts incident impulse control disorders in Parkinson's disease. J Neurol Neurosurg Psychiatry. 2016;87(10):1106-11.

128. Cilia R, Ko JH, Cho SS, van Eimeren T, Marotta G, Pellecchia $\mathrm{G}$, et al. Reduced dopamine transporter density in the ventral striatum of patients with Parkinson's disease and pathological gambling. Neurobiol Dis. 2010;39(1):98-104.
129. Smith KM, Xie SX, Weintraub D. Incident impulse control disorder symptoms and dopamine transporter imaging in Parkinson disease. J Neurol Neurosurg Psychiatry. 2016;87(8):864-70.

130. Premi E, Pilotto A, Garibotto V, Bigni B, Turrone R, Alberici A, et al. Impulse control disorder in PD: A lateralized monoaminergic frontostriatal disconnection syndrome? Parkinsonism Relat Disord. 2016;30:62-6.

131. O'Sullivan SS, Wu K, Politis M, Lawrence AD, Evans AH, Bose SK, et al. Cue-induced striatal dopamine release in Parkinson's disease-associated impulsive-compulsive behaviours. Brain. 2011;134(Pt 4):969-78.

132. Ray NJ, Miyasaki JM, Zurowski M, Ko JH, Cho SS, Pellecchia $\mathrm{G}$, et al. Extrastriatal dopaminergic abnormalities of DA homeostasis in Parkinson's patients with medication-induced pathological gambling: a [11C] FLB-457 and PET study. Neurobiol Dis. 2012;48(3):519-25.

133. Payer DE, Guttman M, Kish SJ, Tong J, Strafella A, Zack M, et al. [(1)(1)C]-(+)-PHNO PET imaging of dopamine $\mathrm{D}(2 / 3)$ receptors in Parkinson's disease with impulse control disorders. Mov Disord. 2015;30(2):160-6.

134. Tessitore A, Santangelo G, De Micco R, Vitale C, Giordano A, Raimo S, et al. Cortical thickness changes in patients with Parkinson's disease and impulse control disorders. Parkinsonism Relat Disord. 2016;24:119-25.

135. Kim YE, Kim HJ, Kim H-J, Lee J-Y, Yun JY, Kim J-Y, et al. Impulse control and related behaviors after bilateral subthalamic stimulation in patients with Parkinson's disease. J Clin Neurosci. 2013;20(7):964-9.

136. Auyeung M, Tsoi TH, Tang WK, Cheung CM, Lee CN, Li R, et al. Impulse control disorders in Chinese Parkinson's disease patients: the effect of ergot derived dopamine agonist. Parkinsonism Relat Disord. 2011;17(8):635-7.

137. Lim S-Y, Tan ZK, Ngam PI, Lor TL, Mohamed H, Schee JP, et al. Impulsive-compulsive behaviors are common in Asian Parkinson's disease patients: assessment using the QUIP. Parkinsonism Relat Disord. 2011;17(10):761-4.

138. Harris E, McNamara P, Durso R. Novelty seeking in patients with right- versus left-onset Parkinson disease. Cogn Behav Neurol. 2015;28(1):11-6.

139. Al-Khaled M, Heldmann M, Bolstorff I, Hagenah J, Münte TF. Intertemporal choice in Parkinson's disease and restless legs syndrome. Parkinsonism Relat Disord. 2015;21(11):1330-5.

140. Aarts E, Helmich RC, Janssen MJR, Oyen WJG, Bloem BR, Cools $\mathrm{R}$. Aberrant reward processing in Parkinson's disease is associated with dopamine cell loss. NeuroImage. 2012;59(4):3339-46.

141. Voon V, Napier TC, Frank MJ, Sgambato-Faure V, Grace AA, Rodriguez-Oroz M, et al. Impulse control disorders and levodopa-induced dyskinesias in Parkinson's disease: an update. Lancet Neurol. 2017;16(3):238-50.

142. Antonelli F, Ko JH, Miyasaki J, Lang AE, Houle S, Valzania F, et al. Dopamine-agonists and impulsivity in Parkinson's disease: impulsive choices vs. impulsive actions. Hum Brain Mapp. 2014;35(6):2499-506.

143. O'Callaghan C, Hornberger M. Screening for impulse control symptoms in patients with de novo Parkinson disease: a casecontrol study. Neurology. 2013;81(7):694-5.

144. Fishman PS. Pramipexole and its extended release formulation for Parkinson's disease. J Cent Nerv Syst Dis. 2011;3:169-78.

145. Stocchi F, Torti M, Fossati C. Advances in dopamine receptor agonists for the treatment of Parkinson's disease. Expert Opin Pharmacother. 2016;17(14):1889-902.

146. Rizos A, Sauerbier A, Antonini A, Weintraub D, MartinezMartin P, Kessel B, et al. A European multicentre survey of impulse control behaviours in Parkinson's disease patients treated with short- and long-acting dopamine agonists. Eur J Neurol. 2016;23(8):1255-61. 
147. Weintraub D, Papay K, Siderowf A. Screening for impulse control symptoms in patients with de novo Parkinson disease: a case-control study. Neurology. 2013;80(2):176-80.

148. Antonini A, Siri C, Santangelo G, Cilia R, Poletti M, Canesi M, et al. Impulsivity and compulsivity in drug-naive patients with Parkinson's disease. Mov Disord. 2011;26(3):464-8.

149. Gaboriau L, Victorri-Vigneau C, Gerardin M, Allain-Veyrac G, Jolliet-Evin P, Grall-Bronnec M. Aripiprazole: a new risk factor for pathological gambling? A report of 8 case reports. Addict Behav. 2014;39(3):562-5.

150. Grotsch P, Lange C, Wiesbeck GA, Lang U. Pathological gambling induced by dopamine antagonists: a case report. J Gambl Stud. 2015;31(1):295-7.

151. Macphee GJ, Chaudhuri KR, David AS, Worth P, Wood B. Managing impulse control behaviours in Parkinson's disease: practical guidelines. Br J Hosp Med (Lond). 2013;74(3):160-6.

152. Lyons KE, Friedman JH, Hermanowicz N, Isaacson SH, Hauser RA, Hersh BP, et al. Orally disintegrating selegiline in Parkinson patients with dopamine agonist-related adverse effects. Clin Neuropharmacol. 2010;33(1):5-10.

153. Jimenez-Murcia S, Bove FI, Israel M, Steiger H, FernandezAranda F, Alvarez-Moya E, et al. Cognitive-behavioral therapy for pathological gambling in Parkinson's disease: a pilot controlled study. Eur Addict Res. 2012;18(6):265-74.

154. Bandini F, Primavera A, Pizzorno M, Cocito L. Using STN DBS and medication reduction as a strategy to treat pathological gambling in Parkinson's disease. Parkinsonism Relat Disord. 2007;13(6):369-71.

155. Broen M, Duits A, Visser-Vandewalle V, Temel Y, Winogrodzka A. Impulse control and related disorders in Parkinson's disease patients treated with bilateral subthalamic nucleus stimulation: a review. Parkinsonism Relat Disord. 2018;17(6):413-7.

156. Bermejo PE. Topiramate in managing impulse control disorders in Parkinson's disease. Parkinsonism Relat Disord. 2008;14(5):448-9.

157. Hicks CW, Pandya MM, Itin I, Fernandez HH. Valproate for the treatment of medication-induced impulse-control disorders in three patients with Parkinson's disease. Parkinsonism Relat Disord. 2011;17(5):379-81.

158. Bermejo PE, Ruiz-Huete C, Anciones B. Zonisamide in managing impulse control disorders in Parkinson's disease. J Neurol. 2010;257(10):1682-5.

159. Bosco D, Plastino M, Colica C, Bosco F, Arianna S, Vecchio A, et al. Opioid antagonist naltrexone for the treatment of pathological gambling in Parkinson disease. Clin Neuropharmacol. 2012;35(3):118-20.

160. Kurlan R. Disabling repetitive behaviors in Parkinson's disease. Mov Disord. 2004;19(4):433-7.

161. Sevincok L, Akoglu A, Akyol A. Quetiapine in a case with Parkinson disease and pathological gambling. J Clin Psychopharmacol. 2007;27(1):107-8.

162. Rotondo A, Bosco D, Plastino M, Consoli A, Bosco F. Clozapine for medication-related pathological gambling in Parkinson disease. Mov Disord. 2010;25(12):1994-5.

163. Pallanti S, Bernardi S, Raglione LM, Marini P, Ammannati F, Sorbi $\mathrm{S}$, et al. Complex repetitive behavior: Punding after bilateral subthalamic nucleus stimulation in Parkinson's disease. Parkinsonism Relat Disord. 2010;16(6):376-80.

164. Zahodne LB, Susatia F, Bowers D, Ong TL, Jacobson CE 4th, Okun MS, et al. Binge eating in Parkinson's disease: prevalence, correlates and the contribution of deep brain stimulation. J Neuropsychiatry Clin Neurosci. 2011;23(1):56-62.

165. Lipford MC, Silber MH. Long-term use of pramipexole in the management of restless legs syndrome. Sleep Med. 2012;13(10):1280-5.

166. Patel S, Garcia X, Mohammad ME, Yu XX, Vlastaris K, O'Donnell $\mathrm{K}$, et al. Dopamine agonist withdrawal syndrome (DAWS) in a tertiary Parkinson disease treatment center. J Neurol Sci. 2017;379(Aug):308-11.

167. Ávila A, Cardona X, Martín-Baranera M, Bello J, Sastre F. Impulsive and compulsive behaviors in Parkinson's disease: a one-year follow-up study. J Neurol Sci. 2011;310(1-2):197-201.

168. Biundo R, Formento-Dojot P, Facchini S, Vallelunga A, Ghezzo L, Foscolo L, et al. Brain volume changes in Parkinson's disease and their relationship with cognitive and behavioural abnormalities. J Neurol Sci. 2011;310(1-2):64-9.

169. Sharp ME, Viswanathan J, McKeown MJ, Appel-Cresswell S, Stoessl AJ, Barton JJS. Decisions under risk in Parkinson's disease: preserved evaluation of probability and magnitude. Neuropsychologia. 2013;51(13):2679-89.

170. Chang FCF, Kwan V, van der Poorten D, Mahant N, Wolfe N, $\mathrm{Ha} \mathrm{AD}$, et al. Intraduodenal levodopa-carbidopa intestinal gel infusion improves both motor performance and quality of life in advanced Parkinson's disease. J Clin Neurosci. 2016;25:41-5.

171. Wu K, Politis M, O'Sullivan SS, Lawrence AD, Warsi S, Lees A, et al. Problematic Internet use in Parkinson's disease. Parkinsonism Relat Disord. 2014;20(5):482-7. 